Linköping Studies in Science and Technology

Dissertation No. 1823

\title{
Making Sense of Adaptations
}

\author{
Resilience in High-Risk Work
}

by

\section{Amy Rankin}

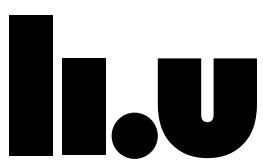

LINKÖPING UNIVERSITY

Department of Computer and Information Science

Linköping University

SE-581 83 Linköping Sweden

Linköping 2017 
(C) Amy Rankin 2017

ISBN: 978-91-7685-596-6

ISSN: 0345-7524

URL: http://urn.kb.se/resolve?urn=urn:nbn:se:liu:diva-133072 Printed by: LiU-Tryck, Linköping 2017

The cover photo is taken on Gotland, Sweden 


\section{Abstract}

To cope with variations, disturbances, and unexpected events in complex socio-technical systems people are required to continuously adapt to the changing environment, sometimes in novel and innovative ways. This thesis investigates adaptive performance in complex work settings across domains, with a focus on examining what enables and disables successful adaptations, and how contextual factors shape performance. Examples of adaptive performance studies include a crisis command team dealing with the loss of key personnel, a crew coping with unreliable system feedback in the cockpit, and a nursing team managing an overload of patients. The two main contributions of this thesis is the analysis of cases of people coping with variations and disturbances, and the development of conceptual models to report findings, structure cases, and make sense of sharp-end adaptations in complex work settings. The findings emphasise that adaptive performance outside procedures and textbook scenarios at the sharp end is a critical ability to cope with variation and unexpected events. However, the results also show that adaptations may come at the cost of new vulnerabilities and system brittleness. Analysing adaptive performance in everyday events informs safety management by making visible limitations and possibilities of system design, organisational structures, procedures, and training. 



\section{Populärvetenskaplig sammanfattning}

Komplexiteten i dagens säkerhetskritiska verksamheter, t.ex. flyg, sjukvård, kärnkraft och krisberedskap, gör det omöjligt att förutse och förbereda sig för alla potentiella händelser. För att hantera störningar och bibehålla kontroll vid oväntade händelser krävs att de operatörer som arbetar i systemet klarar av att anpassa sitt arbete i en komplex, föränderlig och dynamisk miljö. Det kan vara en krisorganisation som måste hantera att nyckelpersoner inte når fram till ett drabbat område, en pilot som ska fatta snabba beslut när flygsystemen ger otillförlitliga data eller en skeppsbesättning som manövrerar i en trång hamn just som dimman håller på att lägga sig.

Säkerhetsarbete bygger idag på att identifiera risker samt att utreda olyckor och incidenter, dvs. situationer där ett system inte lyckats anpassa sitt arbete fullt ut. Att lära av brister från tidigare händelser är viktigt, men det belyser inte nog det arbete människor gör varje dag för att på ett säkert sätt hantera störningar och oväntade händelser. I forskningsfältet Resilience Engineering betonas dessa goda exempel - att förstå det som "går rätt" - vilket kompletterar dagens säkerhetsarbete genom att den resilienta förmågan, att anpassa sig till förutsedda och oförutsedda förhållanden, stärks.

I denna avhandling studeras vardagssituationer och större händelser som kräver anpassning som ligger utanför vad som förväntas och således kräver ett visst mått av improvisation. I studierna ingår beskrivningar och analyser av verkliga situationer i flera olika domäner, exemplifierade ovan, där människor hanterar oförutsedda händelser och störningar. Resultaten visar att operatörens förmåga att anpassa sig till det som ligger utanför vad som beskrivs i organisationens rutiner och föreskrifter är viktig för den dagliga verksamheten. Resultaten visar också att anpassningarna skapar nya sårbarheter i systemet, både på kort och lång sikt. Som ett ytterligare resultat har flera modeller tagits fram för att vägleda forskare och praktiker $\mathrm{i}$ arbetet med att beskriva och analysera anpassningsförmåga och dess påverkan på systemet. Ökad förståelse för de processer som gör att anpassningar fungerar (eller inte) leder till kunskap om vad som möjliggör (eller hindrar) framgångsrik hantering av oväntade händelser, vilka delar av systemet som bör stödjas och stärkas för att öka säkerheten, samt ger en mer nyanserad bild av vilka sårbarheter som finns och hur framtida olyckor kan förebyggas. 



\section{Acknowledgments}

Throughout the journey of writing this thesis I have enjoyed the support of many wonderful people, and for this I am very grateful. There are a few I would like to thank in particular.

First of all, I want to thank my advisors. Henrik Eriksson, for guiding and supporting me through the ups and downs of the thesis-writing process, with encouragement and assurance. I greatly appreciate you always taking the time to discuss any concern, no matter how big or small. Jonas Lundberg, for your enthusiasm, for offering new perspectives when I got stuck, and for always emphasising my successes rather than failures ;-). Rogier Woltjer, for being a source of inspiration, for your never-ending support, and generous sharing of your time and knowledge, and last, but not least, for being a great friend.

The decision to become a graduate student was not something I had planned on when starting my undergraduate studies but the result of fun and interesting work while working on my master's degree. So, thank you Jiri Trnka, for encouraging me to continue my studies. Thank you also to my old flat mates Johan Blomkvist and Fabian Segelström who led the way!

Thank you to my co-authors for providing perspective and insight. Nils Dahlbäck, for support and patience as I was starting out. Joris Field, for all the hard work and fun times together. Dennis Andersson, for great discussions and travels. Erik Hollnagel and Calle Rollenhagen, for sharing your wisdom and knowledge. David Woods, for inspiration, insightful ideas, and for being a fantastic host during our visit to OSU. Members of the CRISIS-team and the Man4Gen-team, for a great learning experience. Thank you also to Björn Johansson, for valuable comments on an earlier version of the thesis introduction.

I am very grateful to the Graduate School Forum Securitatis, for organising interesting courses and providing me with the opportunity to travel and meet researchers all over the world. Thank you also to all the participants who took part in the studies, for your willingness and expertise.

Although I'm not always in my Linköping office it's good to know there are some great people to chat with whenever I am there. Thanks to, among others: Camilla Kirkegaard, 
Eva Blomqvist, Erik Prytz, Fabian Segelström, Jody Foo, Johan Blomkvist, Jonas Rybing, Lisa Malmberg, Mathias Nordvall, Mattias Forsblad, Robin Keskisärkkä, Tim Overkamp, Vanessa Rodrigues, Magnus Bång, and the rest of HCS. I would also like to thank Anne Moe and Lise-Lott Andersson for caring, and being so helpful with all things administrative.

And finally, I'm so happy for the long list of family and friends in my life, whose direct and indirect support cannot be overstated. In particular - Dad, because some of my favourite parts of me, I owe to you. I miss you. Mum and Claire, for always being there. Gordon, for being a fan. Lisa, for being my constant throughout the years. Marie and Cissi, for your friendship. The fantastic CogSci gang, for all the good times together. Erik and Liv, for everything, I love you so very much.

Visby, December 2016

Amy 


\section{Contents}

Abstract $\quad$ iii

Populärvetenskaplig sammanfattning v v

Acknowledgments vii

1 Introduction 1

1.1 Background

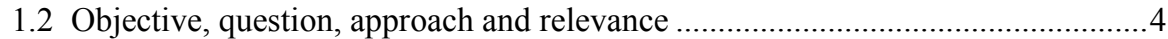

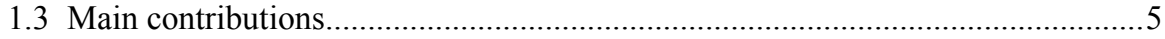

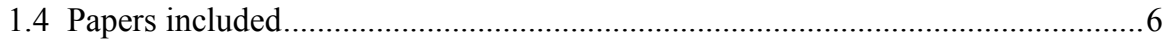

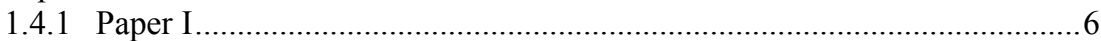

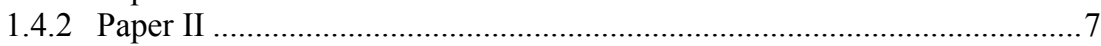

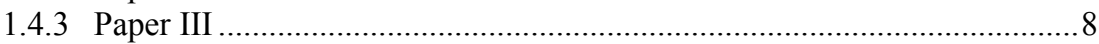

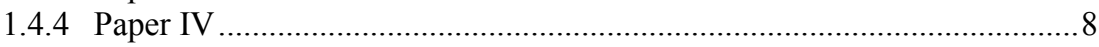

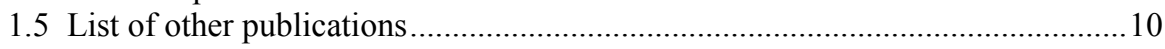

2 Frame of Reference $\quad 13$

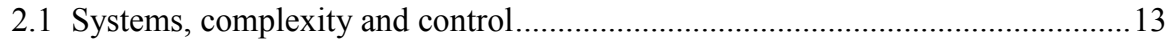

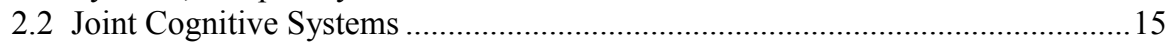

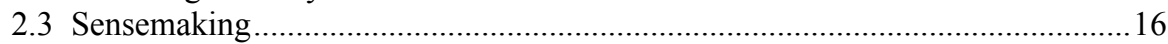

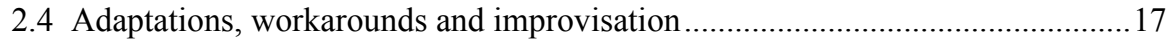

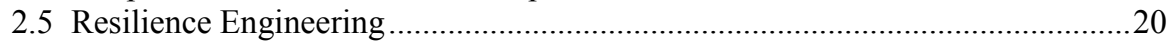

3 Methodology 23

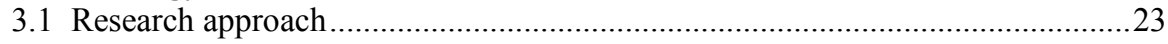

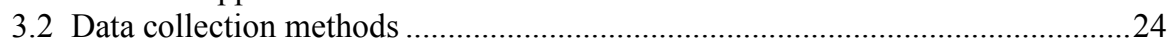

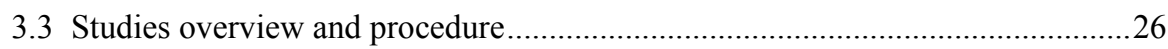

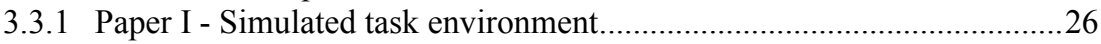

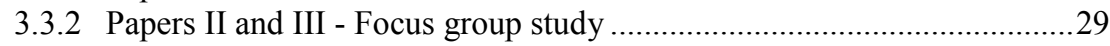

3.3.3 Paper IV - Interview study ................................................................ 31

4 Results $\quad 33$

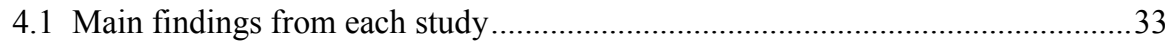

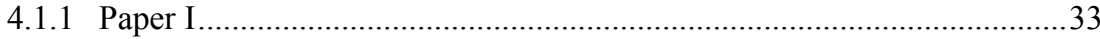

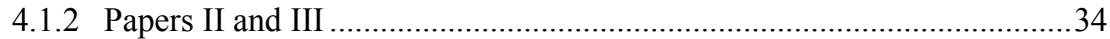

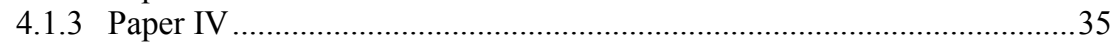

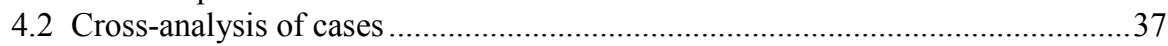

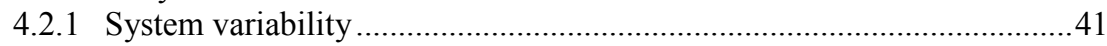

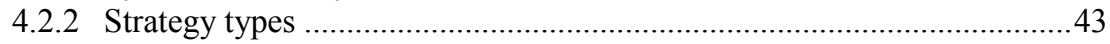

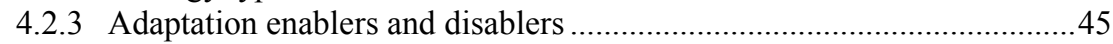

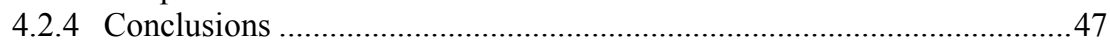

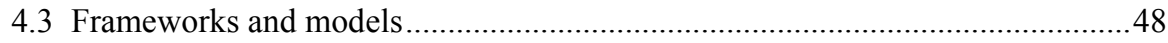

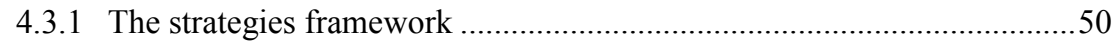

4.3.2 The crew-aircraft sensemaking model................................................52

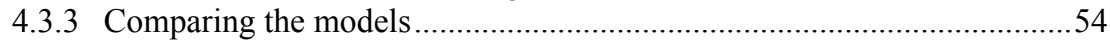

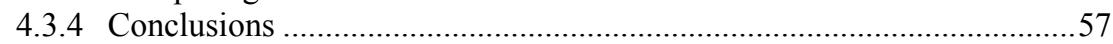

5 Discussion $\quad 59$

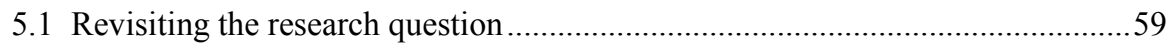




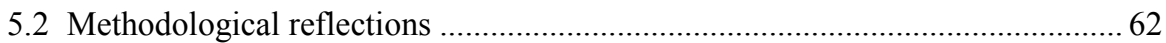

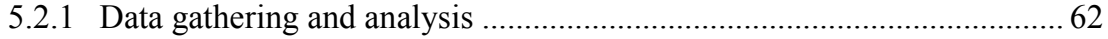

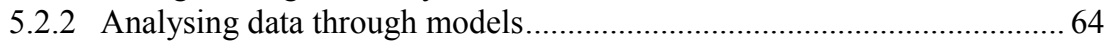

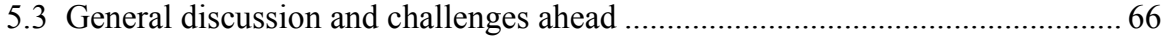

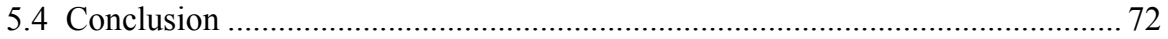

6 Bibliography

$\begin{array}{ll}\text { Appendix A } & \mathbf{8 5}\end{array}$

$\begin{array}{lr}\text { Appendix B } & 87\end{array}$ 


\section{Introduction}

The central theme of this thesis, how complex socio-technical systems cope with varying conditions and unexpected events, is of relevance to society as a whole, as the world we live in is growing increasingly complex and interdependent. Technology has transformed our way of life, creating an abundance of new opportunities in how we communicate, travel and work. However, such a transformation does not come without introducing new vulnerabilities. Increasingly interconnected and interdependent systems make consequences of expected and unexpected events difficult to anticipate and prepare for.

In socio-technical systems safety is commonly understood through the absence of things gone wrong (Hollnagel, 2014). Measurements of risks, incidents and accidents provide a baseline for improvements in safety management; the fewer occurrences, the safer the system. Efforts are focused on minimising risks, building barriers and ensuring that previous mishaps do not occur again. Less attention is paid to what actually creates safety, and what allows systems to stay functioning in situations that do not fit the preconceived plan and textbook scenarios. In the field of Resilience Engineering (RE) the aim is to identify how systems adapt to sustain safe operations despite performance variations, disturbances and unexpected events; that is, what factors create safety, and how these factors can be supported (Hollnagel, Nemeth, \& Dekker, 2008; Hollnagel, Woods, \& Leveson, 2006). RE assumes that below the surface of reported incidents and accidents there are numerous situations that look similar, but have a different, successful outcome. Typically, this entails dealing with surprises and avoiding negative consequences by altering or improvising plans. The studies in this thesis investigate how practitioners in complex socio-technical systems adapt to cope with expected and unexpected events. Focus is on what creates safety, and the need for new perspectives in safety management to manage the complexities of today's globalised, interdependent and dynamic world.

\subsection{Background}

The development of socio-technical systems has vastly grown in the past few decades. A socio-technical system (hereafter system) can be described as people and technology working together toward a common goal. Over the years, technology has become more 
sophisticated, increasingly efficient and has allowed a whole new set of system abilities. Computers have become an important part of our work and the advances in information technology have revolutionised the way we work and communicate. Due to these advancements, the number of variables, parameters and system components have increased, as have the interdependencies and coupling between them, making systems more complex than ever (Perrow, 1984). A result of this development is the challenge of predicting the consequences of disruptions and accidents, recent examples including the nuclear accident at Fukushima in 2011, the oil spill accident in the Gulf of Mexico in 2010 and the crash of Air France flight 447 into the Atlantic Ocean in 2009. The accidents stress the role of complexity and multiple factors, and the difficulties in foreseeing potential effects of expected and unexpected events.

To cope with complexity in a dynamic environment people continuously adapt their work, sometimes having to make challenging decisions and work around difficulties (e.g., Cook, Render, \& Woods, 2000; Koopman \& Hoffman, 2003; Woods \& Dekker, 2000). The complexity of systems makes our models necessarily underspecified, and thus does not allow a prediction of all possible future events and outcomes. Work is often performed in situations governed by ambiguity and uncertainty, requiring people to adapt to the changing environment, and the changing shape of risk. Consider, for example, a crisis response team who just found out that key personnel are delayed several hours due to weather conditions, a train conductor dealing with people trying to get on and off the train while it is in motion, or a crew aiming to squeeze a ship into a tight port during rush hour traffic, just as the fog is arriving. High-risk situations such as these, where systems must deviate from the intended plan, are not unusual; on the contrary, they happen all the time. For the most part, organisations have anticipated such situations, and prepared responses and strategies to successfully manage them, but for other cases they have not, which in rare instances lead to major accidents.

When the topic of safety comes up it is often in relation to the lack of safety; that is, we tend to hear about the less successful outcomes, especially when there are casualties, and large material damage is involved. Most people therefore associate the idea of safety with the absence of incidents and accidents (Hollnagel, 2014). In this traditional view, safety research and industrial safety management are largely focused on unwanted events and outcomes, through risk and incident/accident analysis, known as the Safety-I perspective (Hollnagel, 2014). This approach provides ways of describing and talking about system failures using in-depth analysis (e.g., Harms-Ringdahl, 2001; Rollenhagen, 2011; Sklet, 2004), usually uncovering deviation and violation of operational processes and prescribed rules (Dekker, Cilliers \& Hofmeyr, 2011). Although learning from 
accidents and incidents is a critical part of safety management, it is also important to be aware of the limitations.

First, the emphasis on studying situations where something has gone wrong only represents a small sample of outcomes in everyday operations (Hollnagel, 2014). Most nurses, pilots, control room operators and firefighters could attest to most work shifts not being impeccable, as all operations do not happen in an "ideal" manner; that is, the way they are described in procedures (Loukopoulos, Dismukes, \& Barshi, 2009), or "workas-imagined" (Hollnagel, 2012b). Disruptions and changes happen all the time, keeping people busy adapting to meet the demands of the situation. However, an understanding of these adaptations is available mainly as implicit knowledge within the organisation, described as "work-as-done" (Hollnagel, 2012b). Another main concern is that hindsight bias may distort the analysis (Dekker, 2002; Fischoff, 1975; Woods et al., 2010). Interpreting people's actions in the light of what "should have happened" and what they "could have done" to avoid an outcome allows a convenient explanation of the situation. However, it does not necessarily provide a deeper understanding of underlying factors contributing to the outcome, such as context, pressures from the organisation and conflicting goals (Dekker, 2004; Lundberg et al., 2009; Woods et al., 2010). A focus on failure gives the impression that human performance variability is a major hazard, and has led to remedies aimed at limiting human variability by, for instance, increasing automation and adding procedures. Less attention is paid to the other side of human variability where humans play a determining role in keeping systems safe and functioning in varying conditions (Dekker, 2004; Hollnagel, 2011a; Rasmussen, 1986; Reason, 2008; Woods et al., 2010).

The view of humans as a hazard to system safety is, however, gradually shifting, along with a growing understanding that all contingencies cannot be fully accounted for in operating procedures (Woods et al., 2010). In RE a more proactive approach to safety management is pursued. RE sees things that go right and things that go wrong, success and failure, as outcomes of the same underlying behaviour. Thus, to understand failure we must also understand success, also known as the Safety-II perspective (Hollnagel, 2009a; Hollnagel, Woods, \& Leveson, 2006). From this perspective, variability, fluctuation and surprises are natural parts of system operation and to be expected. A system's resilience is determined by its ability to adjust its functioning prior to, during, or following changes and disturbances, so that it can sustain required operation under both expected and unexpected conditions (Hollnagel et al., 2011; Hollnagel, 2014). Learning from what happens in everyday operation, and how systems adapt to cope with variations, is at the core of understanding what may be a threat to, and what creates, 
safety. Instead of eliminating negative outcomes, RE aims to understand the intricacies of why things work as well as they do.

To summarise, coping with complexity and uncertainty in socio-technical systems requires people to continuously adapt. Although informally recognised by many, the abilities to adapt are not well understood in organisations, leaving a gap of knowledge between "work-as-imagined" and "work-as-done" (Hollnagel, 2012b). Today's accident and incident investigations rarely address what enables and disables the ability to successfully adapt, providing a potentially skewed baseline for interpreting actions leading to unsuccessful outcomes. To advance safety there is a need for a new understanding of how systems continuously adapt to cope with an interdependent, complex and dynamic world.

\subsection{Objective, question, approach and relevance}

The objective of this thesis is to investigate how practitioners in high-risk work domains adapt to cope with variations and unexpected events in their work. The focus of the studied cases are events that do not fit the preconceived plan and that fall outside the system's designed-for-uncertainties. Guiding the research is the following central research question:

- How can adaptive performance at the sharp end be characterised and analysed, from the perspective of how systems cope with variations and unexpected events?

Adaptive performance refers to practitioners adapting in response to variations and unexpected events in their everyday work environment. Sharp end includes individuals and teams who operate and interact in the production processes of high-risk work domains (e.g., nurses, pilots). Variations refers to the variability of everyday performance in complex socio-technical systems (e.g., change of weather, technical disturbance). Unexpected events implies less predictability than system variations. In this thesis the use of the term is based on the subjective experience of the individual or team, and is thus closely related to expectations, timing, and context of the event. It does, however, not infer that the type of event is unanticipated, or rare, in the system.

The thesis applies a Resilience Engineering approach, gathering information from cases on how people adapt to cope with variations and unexpected events, and exploring how the cases can be characterised and analysed. The cases originate from safety-critical systems where practitioners are involved in high-risk work, meaning that the consequences of failures are unacceptable, as they could result in loss of life, significant material damage, or damage to the environment. The research uses a qualitative approach 
to study practitioners at work, and data is gathered through interviews, focus groups and observations.

Ultimately, efforts to improve safety are of relevance to society as a whole. This thesis is mainly directed toward relevant research problems for the scientific community and safety-critical organisations. Safety-critical organisations are becoming increasingly aware of the urgent need for new perspectives and methods to design, manage and assess safety. The cases described in this thesis are relevant in that they aim to investigate how systems adapt, focusing not only on why systems fail, but also on what creates safety. The framework and models developed are designed to complement current safety approaches, with the aim to increase the understanding of what allows systems to adapt to cope with varying conditions. However, the framework and models are still in an early stage of development, and have yet to be integrated into existing safety-management methods. It is beyond the scope of this research to identify actual solutions on how to assess and improve system resilience.

\subsection{Main contributions}

This thesis contributes toward the growing body of research addressing abilities of sociotechnical systems to successfully adapt to variability, disturbances and unexpected events. The conducted studies carefully explore cases of adaptive performance, and how the adaptive performance can be characterised and analysed. The results extend previous studies through a description of adaption-enabling factors, and the development of conceptual tools, supporting both retrospective and prospective research, and safety management activities. The main contributions are:

- The detailed description and analysis of cases of how people cope with events that fall outside of textbook scenarios ("work as done"). The cases aim to reveal insights into what creates safety that would be missed in traditional reporting methods (Papers I-IV).

- The development of novel conceptual tools to report findings, structure cases, and make sense of sharp-end adaptations in complex work settings (Papers II-IV).

These contributions can further be broken down into the following achievements:

- In-depth analysis of role-improvisation "as it happens", demonstrating how multiple data sources and parallel events can be structured and managed (Paper I).

- The development of a strategies framework for researchers and practitioners to report findings, structure cases, and make sense of sharp-end adaptations in complex work settings (Paper II). 
- The development of a variety space diagram and a control-loop model to support the strategies analysis and illustrate important case findings (Papers II \& III).

- Sensemaking analysis outlining challenges and possibilities for pilots to maintain control in surprise situations (Paper IV).

- The development of the crew-aircraft sensemaking model and supporting Data/Frame model illustrating the details of sensemaking and re-framing as a critical aspect of being able to successfully adapt in the context of cockpit operations (Paper IV)

- The identification of enablers and disablers of adaptive performance, underlining and contributing to previous literature by demonstrating that adaptive performance is a source of resilience, but also a cause of new vulnerabilities (Paper I-IV).

\subsection{Papers included}

\subsubsection{Paper I}

Rankin, A., Dahlbäck, N., \& Lundberg, J. (2013). A case study of factors influencing role improvisation in crisis response teams. Cognition, Technology \& Work, 15(1), 79-93.

In Paper I a crisis command team coping with the loss of key personnel is investigated. The command team quickly re-structures following the loss of staff members, leading to several members taking on multiple roles, including roles outside of their expertise. The study provides an in-depth analysis of the information and communication flow of persons acting in improvised roles, including contextual factors influencing the task at hand. Based on the observations from this case study, suggestions for how to improve a team's performance in similar situations are provided. The examined case builds on a role-playing exercise with the Swedish Response Team in a forest-fire scenario. The main contribution is an in-depth analysis of role-improvisation "as it happens", demonstrating how multiple data sources and parallel events can be structured and managed. The study allows insights into the processes affecting the situation and includes suggestions for future training.

\section{Background and author contributions}

The case study was based on a real-time role-playing exercise carried out by Svenska Stödstyrkan (the Swedish Response Team, SRT). A preceding interview and focus group study with the SRT command team members guided the scenario and study design (Lundberg \& Rankin, 2014; Trnka, Lundberg \& Jungert, 2016). Results from the preceding study showed that improvisation is viewed as an important part of the SRTs work, as is the switching of roles. The exercise and study design was thus aimed at creating a dynamic and non-routine situation in which the participants would be forced 
to take on roles outside their field of expertise (Trnka, Lundberg \& Jungert, 2016). Funding was provided by the Swedish Civil Contingency Agency.

The thesis author did not take part in the preceding interview and focus group study, but performed a subsequent analysis on parts of the data (Lundberg \& Rankin, 2014; Rankin, 2009). She was not responsible for the design and preparation of the exercise, but took part as an observer during the role-playing exercise. The data compilation and analysis was led by the thesis author, and supported by the other observers and exercise management personnel. She further led the preparation of the journal manuscript, supported by the co-authors.

\subsubsection{Paper II}

Rankin, A., Lundberg, J., Woltjer, R., Rollenhagen, C., \& Hollnagel, E. (2014). Resilience in Everyday Operations: A Framework for Analyzing Adaptations in High-Risk Work. Journal of Cognitive Engineering and Decision Making, 8(1), 7897.

Paper II deals with everyday adaptive performance in order to cope with variations in socio-technical systems. Examples include passengers trying to get on a train in motion, the organisation of medicine packets to avoid confusions at a hospital, and firefighters dealing with incorrect information regarding hazardous chemicals. The strategies framework is developed as a tool to describe and analyse adaptations. The categories in the framework target three main areas: (1) an interpretation of the situation in which the strategy takes place, (2) enablers for successful implementation of the strategy (3) the impact of the strategy on the overall system. Further, a variety space diagram has been developed to illustrate how system variability, disturbances, and constraints affect work performance. The examples that underlie the framework are derived from nine focus groups with representatives working with safety related issues in different work domains, including health care, nuclear power, transportation, and emergency services. The study demonstrates that people hold great capabilities to adapt to unfolding events in a complex and uncertain environment. The strategies framework guides practitioners and researchers to report findings, structure cases, and make sense of sharp-end adaptations in complex work settings.

\section{Background and author contributions}

This focus group study was a continuation of a research project investigating the underlying theoretical models used in accident investigations in high-risk organisations in Sweden (see Lundberg et al., 2009; Lundberg, Rollenhagen, Hollnagel, \& Rankin, 2012). In this preceding project, examples of how organisations managed variations kept 
emerging, prompting more directed studies on this topic. The current study was exploratory, with the objective of investigating commonalities between organisations using the concept of resilience as a starting point for discussions. The aim was to get practitioners involved in discussions on how new perspectives and learning from "what goes right" could be incorporated into their safety work. An early version of the results was also presented at the Resilience Engineering Association Symposia (REA) 2011, Sophia Antipolis, France (Rankin, Lundberg, \& Woltjer, 2011). Funding for the project was provided by the Swedish Civil Contingency Agency.

The author of this thesis took part in the preceding project on underlying theoretical models used in accident investigation as part of her undergraduate studies, through analysis of parts of the interview material (Rankin, 2008). In the current study she led the design of the focus groups and analysis of data. As focus groups were performed in parallel she was one of three moderators leading the focus group discussions. Further, she led and coordinated the journal manuscript preparation. All tasks were supported by the co-authors of Paper II.

\subsubsection{Paper III}

Rankin, A., Lundberg, J., \& Woltjer, R. (2014). A Framework for Learning from Adaptive Performance. In C. P. Nemeth \& E. Hollnagel (Eds.), Resilience Engineering in Practice, Volume 2 (pp. 79-95). Ashgate Publishing Limited.

In this book chapter, the strategies framework (see Paper II) is further explored through two cases: a crisis management team coping with the loss of key personnel (see Paper I) and a maternity ward coping with an overload of patients (see Paper II). The distinction between work-as-imagined and work-as-done is emphasised, as well as the importance of connections between the sharp and the blunt end. Main contributions include a controlloop model to illustrate the cyclic nature of adaptive systems. The chapter highlights the importance of sensemaking as an enabler for successful adaptations. Additionally, the chapter offers a discussion on the integration of the strategies framework with traditional accident and risk analysis methods.

\section{Background and author contributions}

The book chapter further explores ideas presented in Paper II. Funding was provided by the Swedish Civil Contingency Agency. The author of this thesis led the work of preparing the book chapter manuscript with support from the co-authors.

\subsubsection{Paper IV}

Rankin, A., Woltjer, R., \& Field, J. (2016). Sensemaking following surprise in the cockpit - a re-framing problem. Cognition, Technology \& Work, 18(4), 623-642. 
Paper IV investigates the re-framing process of pilots coping with unexpected events in the cockpit. Re-framing is the process by which a person "fills the gap" between what is expected and what has been observed; that is, to try and make sense of what is going on following a surprise. It is an active and adaptive process guided by expectations, which are based on knowledge and experience. In this paper, surprise situations in cockpit operations are examined by investigating the re-framing process. The results show difficulties that pilots have in re-framing following surprise, including the identification of subtle cues and managing uncertainties regarding automated systems, coping with multiple goals, tasks, narrow time frames, and identifying an appropriate action. A crewaircraft sensemaking model is presented, outlining core concepts of the re-framing processes and sensemaking activities. Based on the findings three critical areas are identified that deserve further attention to improve pilot abilities to cope with unexpected events: (1) identification of what enables and obstructs re-framing, (2) training to build frames and develop re-framing strategies, and (3) control strategies as part of the reframing process when aspects of the situation are not clearly specified.

\section{Background and author contributions}

The paper was written as part of the EU FP7 project Man4Gen ${ }^{1}$. The project objectives were to investigate the processes used by flight crews to respond to unexpected events. The interview study presented in Paper IV was conducted during the first out of three years of the project to obtain an operational perspective on themes highlighted in the preceding literature review, and to gain contextual knowledge to inform scenario development for the upcoming simulator experiments. An early version of the results was presented at the Resilience Engineering Association Symposium 2013, in Soesterberg, the Netherlands (Rankin, Woltjer, Field, and Woods, 2013), and other publications from the project include Field, Rankin and Woltjer (2014), Field, Woltjer, and Rankin (2015), Woltjer, Field, and Rankin (2015). Funding for this research was provided by the Man4Gen project.

The author of this thesis lead the preparation of the interview guidelines and took part as one of four interviewers (interviews were carried out in pairs). She was present in 15 of the 20 interviews. The transcriptions were carried out by the four interviewers, with the author of this thesis coordinating and carrying out a majority of the work. Data compilation and analysis was led by the thesis author, together with the co-authors of Paper IV, and with support from other researchers and domain experts within the project to interpret and understand the findings. Preparation of the journal manuscript was led by

\footnotetext{
${ }^{1}$ Manual Operations for $4^{\text {th }}$ Generation Airliners (2012-2015), website: http://man4gen.eu/
} 
the thesis author, and supported by the co-authors. Helpful advice and guidance was provided by Professor David Woods, Ohio State University.

\subsection{List of other publications}

Field, J., Woltjer, R., \& Rankin, A. (2015). Experimental investigation of flight crew strategies in handling unexpected events. In Proceedings of the 18th International Symposium on Aviation Psychology. Dayton, $\mathrm{OH}$.

Woltjer, R., Field, J., \& Rankin, A. (2015). Adapting to the unexpected in the cockpit. In Proceedings of the 6th Resilience Engineering Association Symposium. Lisbon, Portugal.

Field, J., Rankin, A., \& Woltjer, R. (2014). Modelling Flight Crew Strategies in Unexpected Events: A Cognitive Systems Engineering Perspective. In Proceedings of the 31st European Association for Aviation Psychology (EAAP) Conference. Valletta, Malta: EAAP.

Lundberg, J. \& Rankin, A. (2014). Resilience and vulnerability of small flexible crisis response teams: Implications for training and preparation. Cognition, Technology and Work, 16 (2), 143-155.

Rankin, A., Woltjer, R., Field, J., \& Woods, D. D. (2013). "Staying ahead of the aircraft" and managing surprise in modern airliners. In Proceedings of 5th Resilience Engineering Association Symposium. Soesterberg, the Netherlands.

Kovordanyi, R., Pelefrene, J., Rankin, A., Schreiner, R., Jenvald, J., Morin, M., \& Eriksson, H. (2012). Real-time support of exercise managers' situation assessment and decision making. In Proceedings of ISCRAM2012. Vancouver, Canada.

Andersson, D., \& Rankin. A. (2012). Sharing mission experience in tactical organisations. In Proceedings of ISCRAM2012. Vancouver, Canada.

Field, J., Rankin, A., \& Morin, M. (2012). Instructor tools for virtual training systems. In Proceedings of ISCRAM2012. Vancouver, Canada.

Lundberg, J., Rollenhagen, C., Hollnagel, E., \& Rankin, A. (2012). Strategies for dealing with resistance to recommendations from accident investigations. Accident Analysis and Prevention, 45, 455-467.

Rankin, A., Field, J., Kovordanyi, R., \& Eriksson, H. (2012). Instructor's tasks in crisis management training. In Proceedings of ISCRAM2012. Vancouver, Canada.

Field, J., Rankin, A., Van der Pal, J., Eriksson, H., Wong, W., (2011). Variable uncertainty: Scenario design for training adaptive and flexible skills. In Proceedings of European Conference on Cognitive Ergonomics. Rostock, Germany. 
Rankin, A., Field, J., Kovordanyi, R., Morin, M., Jenvald, J., \& Eriksson, H. (2011). Training systems design: Bridging the gap between user and developers using storyboards. In Proceedings of European Conference on Cognitive Ergonomics. Rostock, Germany.

Rankin, A., Lundberg, J., \& Woltjer, R. (2011). Resilience strategies for managing everyday risks. In Proceedings of the 4th Resilience Engineering Association Symposium. Sophia Antipolis, France.

Rankin, A., Field, J., Wong, W., Eriksson, H., \& Chris, J. L. (2011). Scenario design for training systems in crisis management: Training resilience capabilities. In Proceedings of the 4th Resilience Engineering Association Symposium. Sophia Antipolis, France.

Blomkvist, J., Rankin, A., \& Anundi, D. (2010). Barrier analysis as a design tool in complex safety critical systems. In Proceedings of Design Research Society International Conference. Montréal, Canada.

Kovordanyi, R., Rankin, A., \& Eriksson, H. (2010). Foresight training as part of virtualreality-based exercises for the emergency services. In Proceedings of NordiCHI conference. Reykjavik, Iceland.

Rankin, A., Kovordanyi, R., \& Eriksson, H. (2010). Episode analysis for evaluating response operations and identifying training needs. In Proceedings of NordiCHI conference. Reykjavik, Iceland. 



\section{Frame of Reference}

In this chapter the theoretical frame of reference that underlies the studies in this thesis is presented.

\subsection{Systems, complexity and control}

A general definition of a system is "a set of objects together with relationships between the objects and between their attributes" (Hall \& Fagen, 1968, p 18). Objects are the system components, and may be physical, such as a machine or a pen, or abstract, such as a process or guideline. It is the relationships between the objects and their properties (attributes) that make the notion of systems useful. The definition implies that a system has functions or purposes that are "distinct from its constituent objects, relationships and attributes" (Hall \& Fagen, 1968, p 18). This description of systems is in line with the view of complex systems in this thesis in the sense that the "whole that is both greater than and different from its parts" (Patton, 1990, p 20), implying that a system's behaviour is governed not only by predictable performance by individual components but also by emergent phenomena as a result of component relationships and complex interactions. More specifically this thesis is concerned with goal-seeking and purposeful systems (Ackoff, 1971). A goal-seeking system refers to a system that can respond, in one or a variety of ways, to produce a particular state (outcome). A purposeful system implies that the system can change its goals by selecting its ends and means, thus demonstrating will (such as humans). A system that includes multiple purposeful elements; that is, multiple goals in multiple states, can also be labelled organisation (Ackoff, 1971).

Systems can be described as open (interact with their environment) or closed (isolated from their environment (Bertalanffy, 1950; Flach, 2012). In open systems, which are in focus in this thesis, the boundary to the environment of the system is permeable, meaning that changes in the environment affect the behaviour of the system. Systems discussed in this thesis, are thus both open and goal-seeking, meaning that they are also adaptive. If a change in the environment or internal state of the system is reducing the systems 
efficiency to reach a goal it will thus adapt to achieve a state in agreement with the goal (Ackoff, 1971). The environment of a system consists of all variables (or objects) that can affect its state. However, a categorisation of what is part of the system, and what is part of the environment of the system can be done in many ways, depending on the interest of the researcher (Hall \& Fagen, 1968). Although systems are objective things, they are subjective insofar that a system, and its environment, is defined by the interest of the researcher for a particular context (Ackoff, 1971; Hall \& Fagen, 1968). This thesis is concerned with socio-technical systems, an approach emphasising the interrelations between people and technology in a workplace. The term was established in the 1950s in the context of labour studies, aiming to ensure technical effectivity and the workers wellbeing by focusing on the complexities of the work situation, rather than analysing separate aspects (Cooper \& Foster, 1971; Ropohl, 1999).

Definitions of complexity vary, from specific to more general. In the context of studying socio-technical systems and control specific definitions are often absent, and complexity commonly refers to a more general definition, such the number of possibilities in a problem space and (Hollnagel, 2012a), which goes back to how the notion of complexity was used in earlier work in cybernetics (Wiener, 1948) and communication (Shannon \& Weaver, 1969). For the studies in this thesis a general use of the term complexity is used, and understood in relation to the goal of the system; that is, to maintain control. As systems become increasingly complex, the number of possibilities in the problem space grow, making it impossible to foresee all potential failures, and thus control (Hollnagel, 2011). One way to describe system properties of complexity is through coupling and interactions (Perrow, 1984). Coupling refers to the time-dependency of a process and how vulnerable it is to cascading effects. In a system with many tight couplings a failure in one part of the system will soon spread to other parts, making the system more difficult to monitor and control. Interactions refer to the linearity of the system, and the visibility and tractability of the subsystems. Linear interactions suggest an expected sequence of events and predictable effects further down the line (Hollnagel, 2004). Complex interactions, on the other hand, are not as transparent; components are interconnected, tightly spaced and in close proximity, and thus outcomes become less predictable. Low predictability requires more time to decide on an appropriate action and thus having little time is more likely to lead to failures (Hollnagel \& Woods, 2005).

A broad definition of control is "the ability to affect the conduct of the recipient in the desired way and thereby achieve a desired effect" (Hollnagel \& Woods, 2005, p 135). In cybernetics, the study of control systems and communication, control (and complexity) has been described through the law of requisite variety, which states that "only variety can destroy variety" (Ashby, 1956). This assumption implies that the number of states of 
the controller (or the control mechanism) must be greater than or equal to the number of states in the system that is being controlled. It requires that a system can adapt to compensate for the difference between actual and intended states. However, sociotechnical systems are open systems and the problem space changes over time, which means that the numbers of possible states are effectively infinite (Flach, 2012). An infinite number of states implies that to stay in control a flexible control system must be used, requiring continuous adaptation to fit the current needs and match the variation of the processes being controlled (Hollnagel \& Woods, 2005). Control can thus be defined as steering in the face of changing disturbance (Wiener, 1965).

\subsection{Joint Cognitive Systems}

The field of Cognitive Systems Engineering (CSE) is devoted to the understanding of how complex socio-technical systems maintain control in dynamic environments (Hollnagel \& Woods, 2005). CSE first appeared in the early 1980s (Hollnagel \& Woods, 1983), a main driving force was the Three Mile Island nuclear accident in 1979, arousing discussions on "normal" accidents, how complex systems fail, and the cognitive work of operators (Perrow, 1984; Woods, 2016). Rather than aiming to create failure-safe systems focus in CSE is to understand how to "cope with complexity" (Hollnagel \& Woods, 2005; Woods \& Hollnagel, 2006a). CSE uses a systemic approach for analysing, evaluating and designing joint systems. More specifically, it focuses on (1) how people cope the complexity resulting from technological and socio-technological developments, (2) how people make use of artefacts in their work, and (3) how humans and artefacts can be described as joint cognitive systems (Hollnagel \& Woods, 2005).

A cognitive system is a system that "can modify its behavior on the basis of experience so as to achieve specific anti-entropic ends" (Hollnagel \& Woods, 2005, p 23), basically implying that the system has abilities to adapt its behavior to maintain control in the event of disturbance (i.e., being anti-entropic). A Joint Cognitive System (JCS) refers to a collective of cognitive systems and artefacts (social and physical) demonstrating goaldirected behaviour (Hollnagel \& Woods, 2005). The focus of the study is on people (controllers) and technology as a single unit of analysis, allowing an integrated view of how humans and machines work together in a context. The boundaries of the JCS are relative, and defined by their functions and the purpose of the analysis. Typically, in a JCS, one or more persons (controllers) and one or more technical support systems are involved in a goal-directed control process, working together in a complex environment.

Central to a CSE approach is a naturalistic perspective; that is, to study practitioners at work in a real-world setting. Traditionally, in cognitive psychology, studies of human 
perception are performed in a controlled laboratory setting (Hammond, 1993), implying that human cognitive functions take place in the brain, and can be studied in isolation of a real-world context. However, a naturalistic perspective argues the necessity of a realworld setting (naturalistic) to study how practitioners cope with complex, dynamic and evolving situations, address conflicts, manage trade-offs and make decision in situations governed by time-pressures and uncertainty. A pioneer of studying operators in their natural work environment is Rasmussen (Rasmussen, 1974; Rasmussen \& Lind, 1981), and since then a naturalistic perspective has further been discussed under labels such as Naturalistic Decision Making (NDM) (Zsambok \& Klein, 1997), Cognition in the Wild (Hutchins, 1995) and Macrocognition (Klein, Klein, Hoffman, \& Hollnagel, 2003).

A central view in CSE is that perception is goal-directed, active rather than passive, and guided by expectation. The control loop of the Contextual Control Model (COCOM) presented by Hollnagel and Woods (2005) demonstrates the cyclic nature of how control is retained in a perception-action cycle, emphasising that people use the past to make sense of the present, and that the context is an intricate part of people's assessments and how they act. The model, which builds on Neisser's perceptual cycle (1976), is the basis for analysing the dynamic process of joint systems control and for interpreting how people perform where the context determines the actions.

\subsection{Sensemaking}

A field related to CSE and the study of macrocognition (Hoffman \& Mcneese, 2009; Klein et al., 2003) is sensemaking. Sensemaking has been a topic of research in a variety of disciplines for decades (Dervin, 1983), and is the study of how people make sense of the world around them. The notion gained popularity in the context of organisational studies when introduced by socio-psychologist Weick (1995). Weick describes sensemaking as a continuous retrospective activity to understand on-going circumstances, and emphasises that explicit efforts of sensemaking occur when "the current state of the world is perceived to be different from the expected state of the world" (Weick, Sutcliffe, \& Obstfeld, 2005, p 409). Klein, Phillips, Rall, and Peluso (2007) presented the Data/Frame model, emphasising sensemaking as the combination of retrospective and prospective processes. The interplay between the two processes is necessary for people to make sense of the world around us; that is, the ability to detect a discrepancy after-thefact (retrospective), is highly reliant on the mental models we have and our expectations based on them (prospective). Central to the sensemaking process is thus the viewpoint that people actively seek data guided by their expectations (Christoffersen, Woods, \& Blike, 2007). 
To make sense of events presupposes a conceptual framework, a mental model, to infer meaning to observed data, referred to as frame (Klein et al., 2007; Klein, Wiggins, \& Dominguez, 2010). A frame, in this sense, is "a structure for accounting for the data and guiding the search for more data. It reflects a person's compiled experience" (Klein et al., 2007, p. 118). Constructing frames thus involves fitting observed data into a structure that links them to other elements. The focus of frame construction differs from, for example, the popular concept in human factors, of situation awareness (Endsley, 2006), which is commonly described as a state (of knowledge) attained by an individual based on data or inferences of data in the environment and is used to make predictions about the future. Studies of sensemaking, on the other hand, are about the processes used to achieve such states (Klein et al., 2007; Klein, Snowden, \& Pin, 2011; Malakis \& Kontogiannis, 2013).

\subsection{Adaptations, workarounds and improvisation}

One of the laws that govern cognitive work is the law of adaptation (Woods \& Hollnagel, 2006a, p 171). The law addresses the core of what makes a JCS resilient: its ability to adapt to variations and surprises. Concepts and theories central to adaptations discussed in this thesis are outlined below, including trade-offs, forces and boundaries, workarounds and improvisation.

Examples of adapting to "fill in the gaps" and find alternative solutions to complete tasks, or "workarounds", are found in literature of several related fields of research, including organisational science (Orton \& Weick, 1990), management science (Campbell, 2012), computer science (Norman, 1990) and human factors (Koopman \& Hoffman, 2003). A workaround is a goal-driven adaptation to overcome some obstacle or misalignment of goals, also described as occurring "when cumbersome processes seem too slow, when information required by idealised processes is not available, when technologies malfunction, when situational constraints or anomalies make it difficult to perform work activities, when personal goals conflict with organisational goals..." (Alter, 2014, p 1042). Workarounds may include small, localised and temporary adjustments, but as noted by Koopman \& Hoffman (2003), often end up being long lived. Types of workarounds may include, for example, changes in processes and activities, changes in assignment of participants, alternate use of information, changes in the environment and working around bugs in system technology or services (Alter, 2014). Views on workarounds diverge, from being essential to perform everyday tasks and a driving force to improve systems (Cook et al., 2000; Koopman \& Hoffman, 2003; Nemeth et al., 2007), to being undesirable and hazardous as procedures and responsibilities are violated, raising discussions on compliance vs. non-compliance (Ferneley \& Sobreperez, 2006; Pollock, 2005). Irrespective of perspective, as noted by Campbell (2012), workarounds are a useful 
source to analyse current rules and regulations, and can improve system preparation for future emergent and planned changes. Workarounds can be described as contextual, based on the local structure, and a combination of situational constraints, obstacles, anomalies, and participant goals (Alter, 2014).

Other studies of practitioners coping with complexity in high-risk environments describe adaptations as representing strategies (Furniss, Back, Blandford, Hildebrandt, \& Broberg, 2011; Kontogiannis, 1999; Mumaw, Roth, Vicente, \& Burns, 2000; Mumaw, Sarter, \& Wickens, 2001; Patterson, Roth, Woods, Chow, \& Gomes, 2004). Strategies include, for example, informal solutions to minimise loss of information during hand-offs and to compensate limitations in the existing human-machine interface (Mumaw et al., 2000; Patterson et al., 2004).

Hoffman and Woods (2011) described system adaptations being shaped by context, described in terms of trade-offs that place boundary conditions for the systems, such as efficiency-thoroughness, acute-chronic and optimality-fragility. While trying to balance several, and sometimes, conflicting goals, norms and values in expected and unexpected situations, adaptations of decisions and workflow are made by people at all levels of the organisation (Furniss et al., 2011; Mumaw et al., 2000; Rasmussen, 1986). Values and goals set by the blunt end concerning effectiveness, efficiency, economy and safety, will affect how the sharp end adapts their work. It is important to note that balancing these issues is not performed based on complete information and unlimited time for interpretation, but on currently available knowledge and resources (Simon, 1969; Woods et al., 2010). The terms "sharp end" and "blunt end" can be used to describe different functions of a system and how they relate to each other (Reason, 1997). The sharp end includes people who operate and interact in the production processes, for instance, doctors, nurses, pilots, air traffic controllers and control room operators. The blunt end includes people who manage the functions at the sharp end, such as managers, regulators, policy makers, and government. Decisions made at the management level of the organisation, "blunt end", affect the conditions at the "sharp end" of the organisation. However, sharp-end/blunt-end relations should be described and analysed in relative rather than absolute terms, every blunt "end" can be viewed as a sharp "end" in relation to its managerial superior function(s) (Reason, 1990; Hollnagel, 2004). At both the sharp and blunt end of an organisation trade-offs are made between factors such as economy, efficiency and safety. System adaptations based on such trade-offs create system variability at all levels simultaneously (Kontogiannis, 2009) and may, over time, change the work patterns of the system (Hollnagel, 2004). This variability is important as it allows systems to adapt to current demands and to evolve. The other side is that variability generates unpredictability. Over time, adaptations, and workarounds, will affect the 
overall system and change the organisation, sometimes in a direction that can lead to accidents (Cook \& Rasmussen, 2005; Kontogiannis, 2009). Rasmussen (1997) described this migrating effect in terms of forces such as effort and cost, which systematically push the systems toward the boundaries of what is acceptable to ensure safety. As described by Rasmussen's (1997), once the work performance has reached (been pushed to) the boundary of acceptable performance the system finds itself close to the margins of safety, where accidents are likely to occur. One of the big challenges is to identify how organisational processes affect potentially hidden processes and may push systems toward unsafe boundaries (Kontogiannis, 2009).

Also relevant to the understanding on adaptations is research on improvisation in organisation and management science (Weick, 1998) and emergency management (Mendonça \& Wallace, 2004; Wachtendorf, 2004). For reviews see Cunha (1999) and Hadida and Tarvainen (2015). Existing literature on organisational improvisation puts emphasis on using metaphors in arts, such as jazz, Indian music and theatrical improvisation (Kamoche, 2003; Vera \& Crossan, 2004). Hadida (2015) argued that the use of metaphors is a means to form meaning from complex local circumstances that would otherwise be difficult to compare. For example, jazz improvisation starts from a structure, framing but not caging the process, or as described by Crossan (1998), there are rules for how to innovate and "break the rules". Definitions of improvisation vary, but converge on two common traits; temporal convergence; that is, structuring and planning of an action takes place as it is being executed (Chelariu, 2002; Moorman \& Miner, 1998) and a deviation from existing practices or knowledge (Trotter et al., 2016). Improvisation differs from bricolage in that it occurs in the time frame of seconds-to minutes, while bricolage is about making do with what is available, over long or short time (Hadida \& Tarvainen, 2015). Improvisation includes a range of varying behaviours, from small deviations in intended course of action to spontaneous action based mainly on intuition (Crossan, 1998). Mendonça, Beroggi, and Wallace (2001) suggest that improvisation consists of reworking knowledge "in a novel way in time to fit the requirements of the current situation" (p 32). This definition emphasises the importance of previous training and experience, which all come together during improvisation. Although improvisation may appear as an ad-hoc activity, it is affected by experience, training, team-work, sensemaking and real-time information (Cunha, 1999; Grote, Weichbrodt, Günter, Zala-Mezö, \& Künzle, 2008; Mendonça \& Fiedrich, 2006; Trotter et al., 2016; Vera \& Crossan, 2005). 


\subsection{Resilience Engineering}

Resilience Engineering (RE) is an approach to safety stemming from perspectives and traditions in CSE. A key assumption in RE is that failures and successes are seen as coming from the same underlying processes and therefore safety cannot be understood by eliminating risks (Hollnagel et al., 2008). RE aims to better understand what makes systems able to adapt under varying conditions on "how to help people cope with complexity under pressure to achieve success" (Woods \& Hollnagel, 2006b, p 1). Resilience Engineering is a young field of research, first defined at a symposium in Sweden 2004. Since then several books have been published outlining the main concepts (Hollnagel et al., 2008; Hollnagel, Pariès, Woods, \& Wrethall, 2011; Hollnagel et al., 2006; Nemeth \& Hollnagel, 2014; Nemeth, Hollnagel, \& Dekker, 2009), six Resilience Engineering Association Symposia ${ }^{2}$ have been held and in 2015 a special issue in Reliability Engineering and System Safety on the topic has been published (Nemeth \& Herrera, 2015).

The concept of resilience was first introduced into systems theory through the work of Holling (1973) in the field of ecology. While resilience in ecosystems had previously been understood as the time it takes to return to a stable state following a disturbance, Holling expanded this view by describing an ecosystem's ability to absorb changes of state, and remain cohesive despite extreme pressures (Walker \& Cooper, 2011). In the last three decades, the popularity of the concept has steadily grown and is applied in many fields, including psychology, engineering, management sciences, ecology, safety and more. Views on what the concepts means and how it is applied varies. For example, in psychology resilience refers to an individual's or groups ability to successfully cope with traumatic events (Masten, 2001), in engineering to the degree to which a structure like a building can return to baseline following a disturbance (McDaniels, Chang, Cole, Mikawoz, \& Longstaff, 2008), in management sciences it can be about abilities to withstand difficult economic conditions (Simmie \& Martin, 2010), or cope with emergency response; that is, the ability and speed to which critical systems can sustain operation and be restored following a disturbance (Manyena, 2006) and in ecology, it signifies the system's ability to avoid irreversible degrading (Zolli \& Healy, 2012).

This thesis focuses on system abilities to adapt its performance to "handle disruption and variations that fall outside of the base mechanism/model for being adaptive as defined by that system" (Woods, 2006, p 21). Resilience is a shift in perspective, from traditional approaches of relying on predictions (based on analysis in hindsight) to an acceptance that unexpected events are to be expected in complex systems. It is about being proactive,

\footnotetext{
${ }^{2}$ Papers can be viewed at http://www.rea-symposium.org/
} 
with the aim to prepare systems to cope with variation and stay alert to system variations and the changing shape of risk. Resilience is concerned with how systems "stretch" to cope with disturbances and variations as a system is being pushed toward and beyond its boundaries (Cook \& Rasmussen, 2005; Woods \& Branlat, 2011), also described as graceful extensibility (Woods, 2015). The central part of this perspective is the system's ability to adapt, which differs from perspectives of resilience as being robust, that is, its ability to absorb change, and resilience as the ability to rebound, that is, to return to its original state (see e.g., Woods, 2015). A system's resilience is, in this view, determined by its abilities to cope with events that are unexpected or that do not fit the preconceived plan. In this thesis, "outside textbook performance" is commonly referred to, and describes what falls outside the system's designed-for-uncertainties. (Hollnagel, 2012b; Woods, 2006). On the contrary to what is perhaps the most common way to talk about resilience, as something you "have", resilience here is viewed as something a system does (Wears, 2011). This view suggests that a system does not acquire or hold on to resilience, but an emergent phenomenon, something that transpires in a particular situation. Resilience is reflected in how well a system copes with current demands and variations over time. Assessing how resilient a system thus concerns assessing the potential for resilience, focusing on identifying factors that enable resilience (Hollnagel, 2011; Mendonça, 2008). Hollnagel (2009) describes four central abilities to characterise and assess resilient systems; anticipate what may happen (what to expect), monitor what is going on (what to look for), respond effectively when something happens (what to do) and learn from past experiences (knowing what has happened). 



\section{Methodology}

In this chapter the methodologies used in this thesis are presented, including general characteristics of studies in CSE, the data gathering methodologies used in this thesis, and the methods and analysis processes applied in the individual studies. For a discussion on the methodology, see Section 5.2.

\subsection{Research approach}

In the field of CSE, people and technology are studied in the context in which they work. Areas of investigation include joint system efforts, interactions and relations between system parts, and phenomena that emerge through system interactions (Woods \& Hollnagel, 2006a). The methodological principles of RE are similar to CSE, with a focus on adaptive abilities and what happens as a system is being pushed toward and beyond its boundaries, or how a system stretches (Woods \& Hollnagel, 2006a), and on the importance of understanding both successes and failures (Hollnagel, 2012b).

Woods and Hollnagel (2006a) identify classes of methods to study joint systems: naturalistic observation, simulated task environment and lab experiment. Naturalistic observation (Flach, 2000) include a variety of ethnographical approaches to collect observations made in situ; that is, in a field setting. Studies in the field are characterised by a natural setting and the manner (subjective interpretation) in which they are conducted (Frankfort-Nashmias \& Nashmias, 1996). A main aim of naturalistic observation is to unravel the complexities of the work environment and activities (e.g., Koopman \& Hoffman, 2003; Patterson, Woods, Cook, \& Render, 2006). Simulated task environments, or experiments-in-the-field, involve simulating a staged or scaled environment to capture features that are believed to be the critical in the situation. A challenging but critical issue for conducting such experiments is to design the problems faced in the scenarios, as they represent what is expected to be important to the studied phenomena. A deep understanding of the mapping between the target situation and the test situations is required to allow items of interest to be made tangible, hence, observable (Woods \& Hollnagel, 2006a). Highly realistic simulations include many of 
the constraints occurring in natural environments, enabling people's expertise in the environment to apply to the simulation or exercise. Simulated task environments enable measurement of performance at many levels, consequence-free evaluation of naturally high-risk activities, and higher control of constraints in the environment than natural environments, although lower than in a laboratory setting (Flach, 2000). Lab experiments refer to methods used to pick out variables and test in experimenter-created situations.

Interpreting and analysing data of joint systems can be done by "tracing the process" for how the JCS responds to challenges (Woods \& Hollnagel, 2006a). A process tracing analysis can, for instance, be done as a description of performance on different levels of abstraction, from raw data, to context specific analysis, to a formal and subsequently a more conceptual level of description (Hollnagel, Pedersen, \& Rasmussen, 1981; Woods, 1993). Performance descriptions can be contrasted to cases across scenarios, domains and artefacts, aiding the analyst to abstract patterns of performance (Woods \& Hollnagel, 2006a). To identify patterns requires the ability of the researcher to immerse into the "messy details" of technical work, and at the same time not get lost in the details of the setting (Nemeth, Cook, \& Woods, 2004). However, patterns are not necessarily "right", or a "truth" that everyone can agree on, but an observation that can be revised as new discoveries are made and new situations arise (Woods \& Hollnagel, 2006a).

As outlined above, research in CSE and RE is largely informed by field studies; observing and describing work in natural settings. A joint systems approach can thus be said to rely largely on interpretivist studies, as it is assumed that knowledge is gained through "social construction, consciousness, shared meanings, documents, tools, and other artefacts" (Klein \& Myers, 1999). Interpretivist studies thus seek insights into how people, in a context, make sense and ascribe meaning to surrounding phenomena (Orlikowski \& Baroudi, 1991). The focus of the studies in this thesis has been to examine cases on how people cope with variations and unexpected events. The studies employ a qualitative and interpretivist research approach, and methods of data gathering include interviews, focus groups and observations. These methods are detailed below.

\subsection{Data collection methods}

Observing practitioners in a natural or staged environment is a central technique in a joint systems approach. The main goals of observations are to describe the setting, actions taking place, and the meaning behind the actions (Frankfort-Nashmias \& Nashmias, 1996). There are different types of observation methods which can be applied, for example, open-ended naturalistic observation (does not build on a hypothesis) and various degrees of active/passive participant observation (Patton, 1990). A main advantage of 
observations is directness (Frankfort-Nashmias \& Nashmias, 1996), allowing the observer to study behaviour as it occurs.

Interviews are an important tool to gain details of cognitive work, and are conducted with different approaches depending on the purpose of the study. Gathering data through interview techniques, eliciting narratives, or "stories", have the advantage of offering insights into how work is perceived by the individual telling the story. Interviews allow discoveries to be made through the investigation of the thought processes and interpretations made by the interviewee. Interview data can go beyond describing performed work, through identification of perceived relationships to, for example, supporting technology and different goals (e.g., Cook \& Rasmussen, 2005; Koopman \& Hoffman, 2003; Miller, Patterson, \& Woods, 2006; Woods \& Hollnagel, 2006a). Such techniques are useful when studying, for example, decision making (Crandall, Klein, \& Hoffman, 2006; Klein, Calderwood, \& MacGregor, 1989), sensemaking (Klein et al., 2007; Klein, Pliske, Crandall, \& Woods, 2004) and to illustrate multiple perspectives of a work setting (Cook, 1998).

In this thesis, semi-structured interviews and focus group discussions have been used. In semi-structured interviews the interviewer prepares questions and guides the respondent to ensure important topics are covered, also allowing the respondent to elaborate on the topics discussed (Patton, 1990). General guidelines for planning interviews include doing a background check of interpersonal factors and previous experiences, relationships between the participants (if group interviews are involved) and the environment in which the discussions are to take place (Wibeck, 2000). Interview techniques developed to study cognition in a real-world context include, for example, the Critical Incident Technique (CIT) (Flanagan, 1954), the adapted Critical Decision Method (CDM) (Klein, Calderwood, \& MacGregor, 1989), and various forms of cognitive task analysis (Crandall, Klein, \& Hoffman, 2006). CDM is applied in one of the thesis studies. The method, like other cognitive task analysis methods, is intended to reveal information on human expert knowledge and thinking processes, particularly in settings governed by complexity, time pressure and a dynamic environment. For a review of studies applying CDM see Hoffman, Crandall and Shadbolt (1998).

Group interviews can vary in structure; from open discussions based on a theme to more structured questions (Patton, 1990). A popular approach in group interviews is focus groups. In focus groups "people are brought together to participate in a discussion of an area of interest" (Boddy, 2005, p. 251). Focus group methods have largely been developed for, and widely used, in market research (Morgan, 1997). Today, however, the method is increasingly used in an academic setting (Boddy, 2005; Wibeck, 2000). The 
method has been found suitable to explore new research areas and examine well-known research questions from a new perspective (Morgan, 1997). Focus group topics are prepared to gain insights into one or several topic(s), and can also aim to examine the interactions and different points of view of the participants (Morgan, 1997). Focus groups generally tend to be less controlled by the moderator than most group discussion techniques, allowing broad and in-depth discussions (Boddy, 2005). In focus groups, interactions between the participants are viewed as an essential part and participants are commonly chosen based on this criterion (Wibeck, 2000).

\subsection{Studies overview and procedure}

Table 1 offers an overview of the studies, including the papers, study focus, datacollection and analysis technique. The details of study design and analysis are further outlined belo. See the introduction section (Section 1.5) for details on the author's contributions in the studies.

Table 1. Overview of studies

\begin{tabular}{|l|l|l|l|l|}
\hline Paper & Study focus & Method & Data collection & $\begin{array}{l}\text { Analysis } \\
\text { process }\end{array}$ \\
\hline $\begin{array}{l}\text { Study 1 } \\
\text { (Paper I) }\end{array}$ & $\begin{array}{l}\text { Crisis management } \\
\text { exercise, team } \\
\text { coping with loss of } \\
\text { key personnel }\end{array}$ & $\begin{array}{l}\text { Simulated task } \\
\text { environment }\end{array}$ & $\begin{array}{l}\text { After-action } \\
\text { review (group } \\
\text { interview) } \\
\text { Video recordings } \\
\text { Voice recordings } \\
\text { Communication logs } \\
\text { Photographs } \\
\text { Notes from participants }\end{array}$ & Episode analysis \\
\hline $\begin{array}{l}\text { Study 2 } \\
\text { (Papers II } \\
\text { \& III) }\end{array}$ & $\begin{array}{l}\text { Learning from what } \\
\text { goes right in high- } \\
\text { risk work }\end{array}$ & $\begin{array}{l}\text { Focus group } \\
\text { discussions }\end{array}$ & $\begin{array}{l}\text { Interview notes } \\
\text { Voice recordings } \\
\text { Notes from participants }\end{array}$ & $\begin{array}{l}\text { Transcript coding } \\
\text { using iterative } \\
\text { bottom-up and top- } \\
\text { down approaches }\end{array}$ \\
\hline $\begin{array}{l}\text { Study 3 } \\
\text { (Paper IV) }\end{array}$ & $\begin{array}{l}\text { Sensemaking } \\
\text { following surprise } \\
\text { in cockpit } \\
\text { operations }\end{array}$ & $\begin{array}{l}\text { Semi-structured } \\
\text { interviews }\end{array}$ & $\begin{array}{l}\text { Interview notes } \\
\text { Voice recordings }\end{array}$ & $\begin{array}{l}\text { Transcript coding } \\
\text { using iterative } \\
\text { bottom-up and top- } \\
\text { down approaches }\end{array}$ \\
\hline
\end{tabular}

\subsubsection{Paper I - Simulated task environment}

\section{Background and study set-up}

The study in Paper I was based on a real-time role-playing exercise carried out by the Swedish Response Team (SRT). The SRT is a taskforce with flexible composition, assembled based on the needs of the crisis, whose primary task is to assist Swedish citizens living or visiting an area affected by a crisis, such as a natural disaster or terrorist attack. Typically, an initial assessment team consisting of eight persons leave Sweden, followed by a base unit, consisting of a group of commanders (six persons), a command 
staff (eighteen persons) and three field support teams (eleven persons in each team) (Kulling, Sigurdsson, \& Hamberger, 2008; Larsson, 2008). The role-playing exercise design targeted the command staff of eighteen persons. All other parties (SRT support teams, authorities, affected citizens) were played by the exercise organisers.

A preceding interview and focus group study with SRT command team members guided the scenario and study design (Lundberg \& Rankin, 2014; Trnka et al., 2016). The interview and focus group discussions focused on the participants' experiences in operations following the Tsunami in 2004 and the Lebanon crisis in 2006. Results showed that improvisation is an important part of the SRTs work, and that role-switching happens in real-time operations. The participants mention that role flexibility has many positive qualities, including: completing tasks despite a lack of resources, positive team-building effect and increased endurance of the team (Lundberg \& Rankin, 2014; Trnka et al., 2016). Problems with role flexibility include: decreased efficiency and increased workload due to unclear organisational structure and inefficient planning, increased burden for all team members as people in new roles require more guidance, and that people may get stuck in temporary roles. Further, participants mentioned that more varied training scenarios with different structures and settings would be useful. The exercise and study design was thus aimed at creating a dynamic and non-routine situation in which the participants would be forced to take on roles outside their field of expertise.

The scenario of the role-playing exercise was based on a real event: the 2007 California Wildfires $^{3}$. According to the scenario, around 20,000 Swedish citizens were in the affected area, and a large number of citizens were requesting assistance from the Swedish embassy. The SRTs mission included an assessment of needs, and support for the Swedish authorities and citizens in the affected area. The main tasks of the exercise participants were to: (a) establish a command post, (b) establish a functional command staff, and (c) initiate activities in line with the mission objectives. The exercise lasted for four hours, and was followed by a one-hour after-action review. During the after-action review the participants were asked to reflect on their own and on their team's performance. For more information on how the simulated role-playing exercise was designed and carried out, see Trnka et al. (2016). The author of this thesis joined the research team after the focus group studies and the design of the exercise were carried out. However, the author did perform an analysis on the topic of flexible roles, based on the material gathered in the interviews and focus groups (Lundberg \& Rankin, 2014; Rankin, 2009; Rankin, Dahlbäck, \& Lundberg, 2013).

\footnotetext{
${ }^{3}$ For overview see: http://www.fire.ca.gov/fire_protection/downloads/siege/2007/Overview_CompleteFinal.pdf
} 


\section{Participants}

Participants in the role-playing exercise were operational personnel, acting in their professional functions. Under normal circumstances, the command staff includes eighteen members in total, but in the scenario this number was intentionally reduced to eleven to create a situation that was "stressed"; that is, a situation where available resources did not meet actual needs. For an overview of role assignments and roleswitching, see Trnka et al. (2016). Expertise missing in the command team were medical, fire engineering, safety, ICT/communications, and crisis support expertise. This arrangement created a situation where participants had to take on multiple roles, sometimes outside their field of expertise, to accomplish the SRTs tasks in the exercise. Two hours into the exercise, a logistician carried out an improvised role as the 'safety and health protection' function, and the analysis/planning and media staffed the communications function. These two functions are in focus in Paper I.

\section{Data collection and analysis}

The analysis of the role-playing exercise involved a triangulation of data, including: observation notes from five observers, video recordings, communication logs (phone conversations, e-mails, and log-books), photos, and notes written by the participants. From the after-action review, voice recordings and participants' notes were gathered.

The analysis presented in Paper I focuses on the main task where the command team lacked expertise: dealing with an air quality issue. This focus was chosen as a lack of expertise on the subject forced the participants to manage a task that was normally performed by other roles in the command staff. Sub-tasks included were, for example, to increase awareness about hazardous smoke and to gather information on protective facemasks.

To structure the data, episode analysis was used (Korolija, 1998; Korolija \& Lundberg, 2010). Episode analysis is a bottom-up, data-driven qualitative method to study communication where multiple participants and subject areas are involved. The method originates from conversation analysis and includes breaking communication down into sub-units, called "episodes" (Korolija \& Linell, 1996). Each unit contains an unbroken chain of actions internally bound together by a topical trajectory and/or a common activity. For example, an episode may start as the issues of air quality are introduced to the command team (e.g., a concerned citizen requests information). The episode "air quality" would include a mapping of all data gathered that concerns air quality issues throughout the exercise. The method has been adapted from the original episode analysis methodology to fit the objectives of this study, which includes less focus in detail on how individual utterances are structured, and more on the information flow. This adapted style 
of episode analysis has previously been applied to studies of joint emergency response operations (Aminoff, Johansson \& Trnka, 2007; Korolija \& Lundberg, 2010; Rankin, Kovordanyi \& Eriksson, 2010; Trnka \& Johansson, 2009).

An episode may be broken down into several sub-episodes if an episode has multiple parallel exchanges or serves multiple goals. A context-dependent approach (Korolija \& Linell, 1996) was applied in the exercise analysis, meaning that a new sub-episode was defined if an event altered the course of actions taking place. For example, a new subepisode was created under "air quality" when concerned field personnel called the command team and asked if they should wear facemasks. A second sub-episode was initiated when a staff member retrieved information from the Environmental Protection Agency, altering the team's course of action. The same data can thus be a part of several sub-episodes and new sub-episodes can spring from previous ones. For the episode "air quality", the focus of Paper I, a total of eleven sub-episodes were identified. Data tied to these episodes were transcribed and further visualised on a temporal scale to provide a view of available information at a given time (see Paper I for visualisation and further details of the analysis).

\subsubsection{Papers II and III - Focus group study}

\section{Background and study set-up}

The focus group study is a continuation of a research project investigating the underlying theoretical models used in accident investigations in high-risk organisations in Sweden (Lundberg et al., 2009, 2012). In this preceding project, examples of how organisations managed variations kept emerging, prompting more directed studies on this topic. Focus groups in the current project were used to bring people from different organisations and work environments together to discuss situations related to resilience and safety culture. The aim was to get practitioners involved in cross-domain discussions on learning from "what goes right" and how this could be incorporated into their safety work. The study was exploratory with the objective of investigating commonalities between organisations using the concept of resilience as a starting point for discussions. The main topic of discussion was on work near the margins of safety where people must adapt their performance, often outside prescribed textbook scenarios.

Nine focus groups were carried out on two separate days and each occasion was a fullday event, starting at 9 a.m. and ending at 5 p.m. The morning session included an introduction of central concepts in resilience engineering and safety culture, to make sure all participants were familiar with the concepts to be discussed in the focus groups. On the first occasion, there were a total of four groups (14 participants) and on the second occasion five groups (18 participants). The focus groups were performed in parallel 3- 
hour sessions, with three or four participants in each group and one focus group leader. The first 45 minutes of the focus group session included a round of introductions and reflections on the presentations in the morning session. The participants were given a few minutes to write down their thoughts on a piece of paper and then shared their experience with the other participants in a round-robin fashion. This step was followed by discussions based on pre-prepared questions. The group leaders' task was not to interfere too much in the discussions, but aimed to ensure that all participants had a chance to discuss their point of view, and that all the main topics were addressed. Following the focus group session each group summarised the results of their discussion and presented it to one of the other groups (15 min presentation). The other group was encouraged to ask questions and reflect on the results from the presenting group. Two or more different organisations were represented in each group. The day ended with a half-hour summation of key issues that had been raised during the day, for all participants. Results from the first four focus groups provided many examples of everyday work situations that require local adaptations to cope with hazardous situations. The topic of the five remaining focus groups was consequently narrowed down to "working near the safety margin", focusing on everyday situations where adaptations were made to cope with fluctuating demands. Details of the study set-up and the discussed topics can be found in Appendix A.

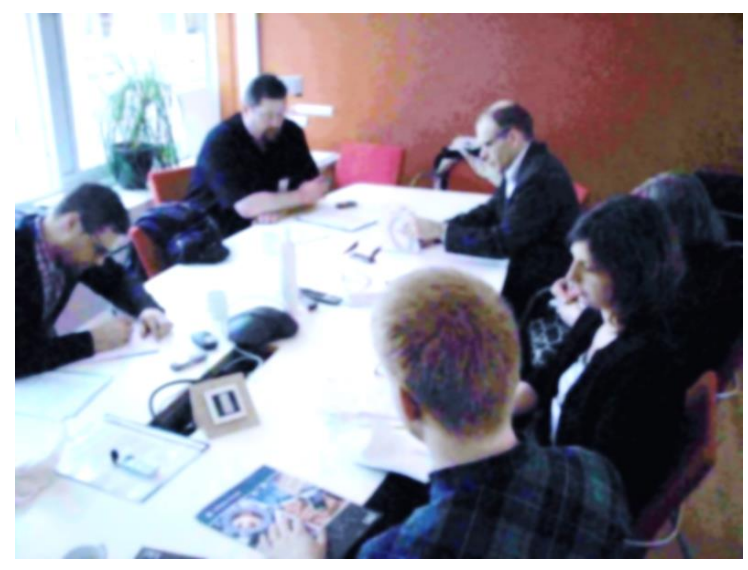

Figure 1. Focus group session (Paper II).

\section{Participants}

Nine focus groups were conducted with a total of 32 participants. The participants all worked with safety-related issues as well as incident and accident investigation in safetycritical domains. The following domains were represented (with number of participants): Patient Safety (13), Nuclear Safety (8), Occupational Safety (3), Air Traffic Control 
Safety (2), Maritime Safety (2), Emergency Services Safety (2), Railway Safety (1) and Road Safety (1).

\section{Data collection and analysis}

All focus group sessions were recorded and the audio files transcribed. The transcriptions were coded using iterative bottom-up and top-down approaches. The transcript data was first split into categories based on the main topics of the focus group discussions. A bottom-up analysis was then performed, allowing new categories and sub-categories to emerge from the data (Miles \& Huberman, 1994). A total of 73 examples of situations where people work near the margins of safety were identified. In 17 of the examples, sharp-end strategies to cope with the situations were identified, and these were used as a basis for further analysis and development of the strategies framework.

Three theoretical frameworks were applied to the 17 cases and the analysis was reviewed by two other analysts. Two of the frameworks have previously been used to guide analysis of system resilience abilities (Furniss et al., 2011; Hollnagel, 2009). The framework developed by Furniss and colleagues aims to identify common features of resilience manifestations across domains. Hollnagel's "four cornerstones" framework describes the four main system capabilities critical for resilience. The third framework (Hollnagel et al., 1981) structures data on different levels of abstraction, from raw data to a formal and subsequently a more conceptual level of description. The result of the analyses was the development of the strategies framework and the variety space diagram.

\subsubsection{Paper IV - Interview study}

\section{Background and study set-up}

This study was carried out as part of the EU FP7 "Man4Gen" research project". The project aim was to identify factors that affect the ability of flight crews and aircraft to handle unexpected events. This study was carried out during the first year of the project to frame core concepts, and to gather contextual details of surprise situations in cockpit operations for use in subsequent simulator experiments.

The interview guide consisted of two main parts. The first part focused on specific events, and the pilots were asked to describe a recent situation where they felt surprised. The development of the questions was guided by the Critical Decision Method (Klein, Calderwood, \& MacGregor, 1989). Following the pilot's initial description of the event, follow-up questions were used to encourage the respondents to reflect on their experiences regarding why the situation was surprising, what information was considered,

\footnotetext{
${ }^{4}$ Manual Operations for $4^{\text {th }}$ Generation Airliners (2012-2015), http://man4gen.eu/ .
} 
and how the crew decided on a course of action. The surprise situations described by the pilots varied in type, and thus the thoroughness of questioning also varied to fit each case described. Further, the length and depth of the descriptions were fitted to the time restrictions of the interview. The second part of the interview included questions designed for more general reflection on surprise in cockpit operations, and in relation to the areas central to the overall project: confusion and problem solving, automation and system knowledge, manual control, training, procedure applicability and team work/communication. The full interview protocol can be found in Appendix B. The protocol was used as a guide to ensure all key areas were covered and not every question was utilised for each interview.

\section{Participants}

Semi-structured interviews were carried out with 20 pilots. Each interview lasted between 50 and 90 minutes, depending on the length of the responses given, and time availability. The experience and qualifications of the pilots ranged from first officers to captains, flight instructors, and training and safety managers from several different western-European airlines. The overall experience level of the pilots was high, with 14 out of 20 participants being instructors and examiners. The average number of flight hours of the participants was 10,892 and the average age 49 .

\section{Data collection and analysis}

The analysis was carried out in three steps: (1) transcription, (2) data tagging and, (3) identifying sensemaking patterns following surprise. The interviews were transcribed in full. A total of 48 surprise situations were extracted from the transcribed interview data. The cases were tagged according to the sensemaking activities, and key areas for investigation (mentioned in the study set-up above). A bottom-up approach was also applied allowing new categories and sub-categories (tags) to emerge from the extracted data, based on relevant data that did not fit the pre-defined categories (Miles \& Huberman, 1994). The final step of the analysis included an iterative cross-case analysis to identify patterns of what enabled and disabled the re-framing process following surprise. The cross-case analysis involved comparisons of the similarities and differences of the cases. Nine categories of challenges relating to the re-framing process were identified in the analysis: (1) absence of salient cues, (2) passive and insidious disturbances, (3) conflicting data, (4) getting stuck in narrow interpretations, (5) sudden changes and rapid transitions, (6) coping with insufficient system knowledge, (7) multiple goals and trade-offs, (8) uncertainty management, and (9) roles and communication. See Paper IV for details of the analysis and an illustrative example for each category. 


\section{Results}

This chapter presents the main findings in Paper I - IV, including a brief overview of the main results from each study, a cross-analysis of the 16 cases presented in the Papers, and an overview of the framework and models developed.

\subsection{Main findings from each study}

Table 2 offers an overview of the four papers, including the work domains represented, a brief description of the topic and the number of cases presented in each paper. For the details of each study, see the individual papers.

Table 2. Overview of attached Papers and number of cases presented in each Paper.

\begin{tabular}{|l|l|l|l|}
\hline Paper I & Work domain(s) & Description & $\begin{array}{l}\text { Number of cases } \\
\text { (Table 3) }\end{array}$ \\
\hline Prisis management & $\begin{array}{l}\text { Case study of a command team } \\
\text { adapting to the loss of key personnel }\end{array}$ & $\begin{array}{l}1 \\
\text { (case 1) }\end{array}$ \\
\hline Paper III & $\begin{array}{l}\text { Maritime, Health care, } \\
\text { Nuclear, Rail, Road, Air } \\
\text { Traffic Control, } \\
\text { Emergency services, } \\
\text { Occupational safety }\end{array}$ & $\begin{array}{l}\text { Everyday situations in safety-critical } \\
\text { domains where people adapt to cope } \\
\text { with variations and disturbances }\end{array}$ & $\begin{array}{l}6 \\
\text { (cases 2-7) }\end{array}$ \\
\hline Health care & $\begin{array}{l}\text { Same as Paper II. Focus on coping } \\
\text { with major disturbances, and the } \\
\text { importance of sharp-end/blunt-end } \\
\text { interactions }\end{array}$ & $\begin{array}{l}\text { 2 } \\
\text { (cases 1 and 7) }\end{array}$ \\
\hline Paper IV & Aviation & $\begin{array}{l}\text { Sensemaking in cockpit operations } \\
\text { following surprise }\end{array}$ & $\begin{array}{l}\text { 9 } \\
\text { (cases 8-16) }\end{array}$ \\
\hline
\end{tabular}

\subsubsection{Paper I}

The aim of the study presented in Paper I was to deepen the understanding of the processes taking place during improvised work "as it happens". Crisis situations are often characterised by ambiguous and unplanned-for events and the need for improvised roles can therefore be of great importance to cope with the dynamic events during a crisis. 


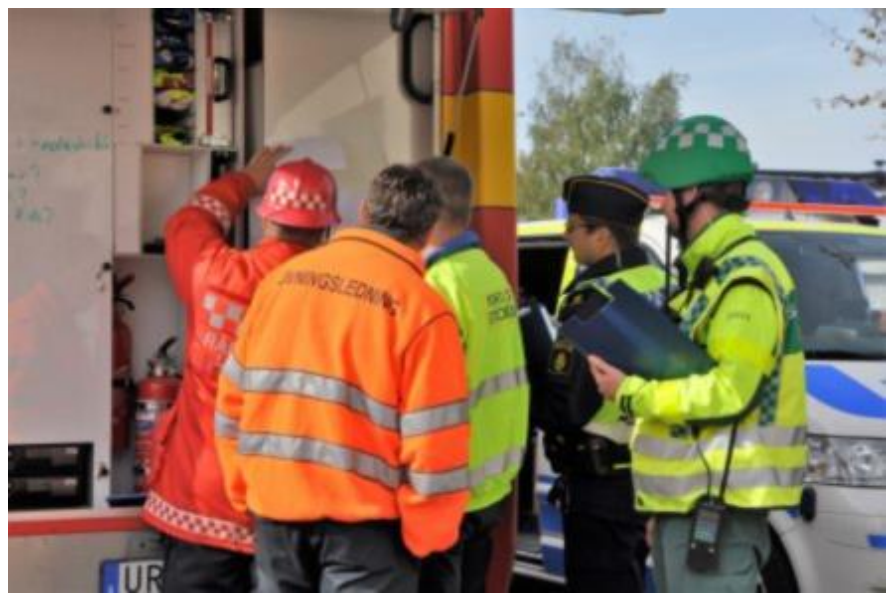

Figure 2. Command team meeting.

The in-depth analysis of communication and information sharing of the command team offers a closer look at factors contributing to successful adaptation and system vulnerabilities. Following the loss of one third of the staff members the command team quickly restructured the team. The team was successful in swiftly assigning new roles, prioritising tasks and setting up a plan of action. However, the analysis reveals several vulnerabilities stemming from the new command structure. For example, critical information was misinterpreted, including information about the necessary face-mask protection, which may have had severe consequences if gone unnoticed. Another example was a mix-up of emergency phone numbers, which may have caused problems further down the line. The team's difficulties in managing the disturbance stems from multiple sources, including, language and communication, domain knowledge and organisational structure. Based on the analysis three suggestions for improving the team's ability to support flexible roles are: (1) train to take on the responsibility for tasks and roles outside one's professional area of specialisation, (2) develop more formal routines for hand-overs of roles and tasks and (3) improve routines for information sharing.

\subsubsection{Papers II and III}

The study examines situations where people adapt their performance to deal with the demands of their everyday work environment. The examples, gathered through focus group discussions, demonstrate how: (1) current procedures and system barriers do not sufficiently cover the risks created in the situations described and (2) local adaptations of the work environment are developed at the sharp end to minimise these risks. In some situations, adaptations work well locally, but create new risks as circumstances in other parts of the system change. External forces, system design and multiple (sometimes 
conflicting) goals are some of the factors that affect the outcome of the situations. The results underline the need to study "work-as-done", to understand why things go right, and why they sometimes go wrong. The analysis focuses on how adaptive performance in complex socio-technical systems can be characterised and analysed. Based on 17 cases (6 examples are presented in Paper II) a strategies framework for analysing adaptive performance was developed. The framework is presented in more detail in Papers II and III and in Section 4.8.1.

In Paper III the strategies framework is further explored through two cases: a crisis management team coping with the loss of key personnel (see Paper I) and a maternity ward coping with an overload of patients (see Paper II). The distinction between workas-imagined and work-as-done is emphasised, as well as the importance of connections between the sharp end and the blunt end. Main results include a control-loop model to illustrate the cyclic nature of adaptive systems and highlight the importance of sensemaking as an enabler for successful adaptations. Additionally, the Paper offers a discussion on the integration of the strategies framework with traditional accident and risk analysis methods.

\subsubsection{Paper IV}

In Paper IV unexpected events in cockpit operations are examined. Through cases derived from interviews with pilots, the re-framing process following surprise is investigated. The study reveals several important issues regarding challenges and possibilities for pilots to maintain control in surprise situations. Nine categories of challenges with the re-framing process are identified, including: (1) absences of salient cues, (2) passive and insidious disturbances (3) conflicting data, (4) "getting stuck" in narrow interpretations, (5) sudden changes and rapid transitions, (6) coping with insufficient system knowledge, (7) multiple goals and trade-offs, (8) uncertainty management and (9) roles and communication. An example case of each category is presented in Paper IV.

Strategies to cope with unexpected events include anticipatory strategies to "stay ahead of the aircraft", and are used to keep the frame updated and avoid surprise. Expectations guide where attention is focused, making anticipatory strategies key to increase pilot's ability to question their current frame (i.e., their understanding or mental model), to switch frames rapidly, and to counteract getting stuck in frames or even being surprised in the first place. The findings imply that it may not be sufficient to rely on simple strategies to cope with unexpected events, it requires more elaborate frames that are built through experience. Sensemaking activities to cope with the unexpected event are identified, including activities found in previous studies (Klein et al., 2007), and two new sensemaking activities: rapid frame-switching and abandoning the search for a frame. 
Rapid frame-switching requires an action within a very short time frame as a response to an external event, and represents the critical ability of a pilot to quickly switch frames. Abandoning the search for a frame is the decision to stop an active search for a coherent frame, a strategy to cope with uncertainty. By turning the automation off the pilots simplify the system configuration and enable the use of a known frame.

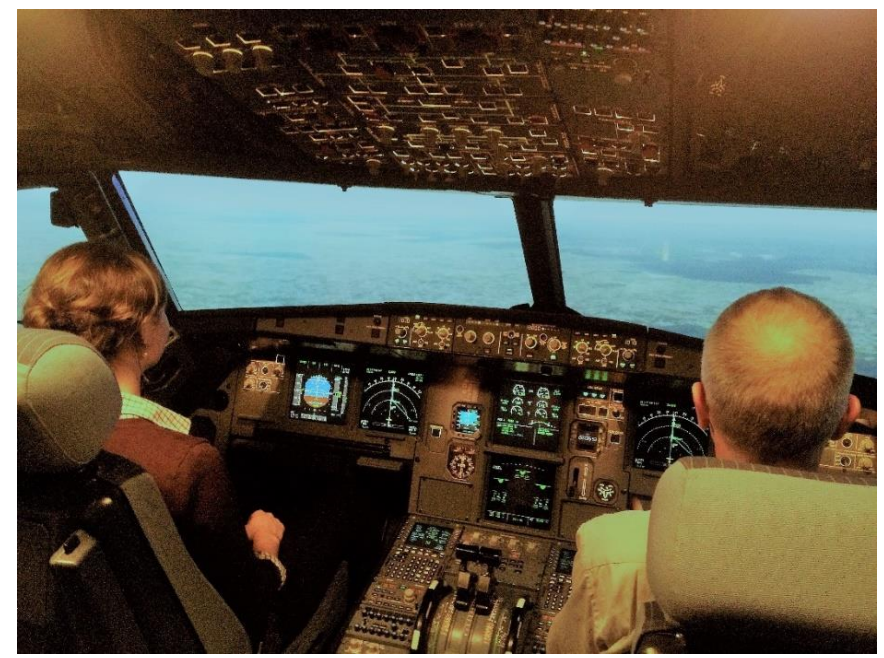

Figure 3. Cockpit simulator A320.

The findings raise important issues regarding pilot training-programs. Training programs today mainly focus on aiding pilots to tackle specific known problems through procedures. Findings in the study suggest that training programs should support pilot abilities to detect and identify problems, and decide on a course of action. This may include abilities to identify the connection between system parts, and identify critical cues. Based on the results three critical areas are identified that deserve further attention to improve pilot abilities to cope with unexpected events: (1) further investigation into what enables and obstructs the re-framing process, (2) exposure to surprise situations in training to develop re-framing strategies (3) identification of control strategies as part of the re-framing process when aspects of the situation are not clearly specified. A crewaircraft sensemaking model is developed based on the COCOM (Hollnagel \& Woods, 2005), highlighting the core concepts of the sensemaking process. Further, the original Data/Frame (D/F) model (Klein et al., 2007) has been adapted to include the sensemaking activities found in the studies. The two models are described in more detail in Paper IV and in Section 4.3.2. 


\subsection{Cross-analysis of cases}

The aim of this section is to bring together the findings from the different studies, allowing a reflection of similarities and differences across cases. The analysis should be viewed as an attempt to explore the process of cross-analysing cases to generalise results. It is recognised that the cases are divers, varying in type and depth, and thus the ability to draw general conclusions about adaptive performance is limited. It should be noted that the presentation in this section builds on the 16 cases presented in the papers and not on the complete material underlying the studies in each paper.

Table 3 offers an overview of the analysis of the 16 cases presented in the four papers. The categories displayed in Table 3 were chosen based on availability of comparable data. Column 2 presents the work domain and case name. In column 3 the context describes the general setting, or situation in which the adaptation takes place. In column 4 the adaptation activity describes the strategy (as described in Paper II and III) or the sensemaking activities (as described in Paper IV). Column 5 presents the adaptations, which have been clustered into four categories, or four strategy types: restructure roles and functions, increase margins, increase monitoring, extend/compare knowledge. Each type is described in more detail in Section 4.2.2. Column 6 presents the enabling/disabling factors related to the strategy based on six main categories identified: resources, sensemaking, problem detection, team work, system flexibility and domain knowledge. In column 7 it is noted if the situation is a regular or an irregular situation. Regular situations include cases that describe daily situations, commonly the result of everyday system performance variability, such as a nurse organising medicine packages or a crew forgetting an item on the checklist. Note that everyday examples do not necessarily imply that the situation falls within the systems designed-foruncertainties. The irregular situations include cases that are less frequent and fall outside of the category of what is expected from everyday variations, such as a command team not able to reach the site of the crisis or multiple system failures in the cockpit during a commercial flight. Cases 9 and 12 from Paper IV are noted as regular/irregular, as the type of case (pressing a wrong button and not noticing passive failures) were seen as "regular" occurrence in cockpit operations, although the particular problems described in each case are "irregular" occurrence. In Figures 4 and 5 they are noted as "regular". 


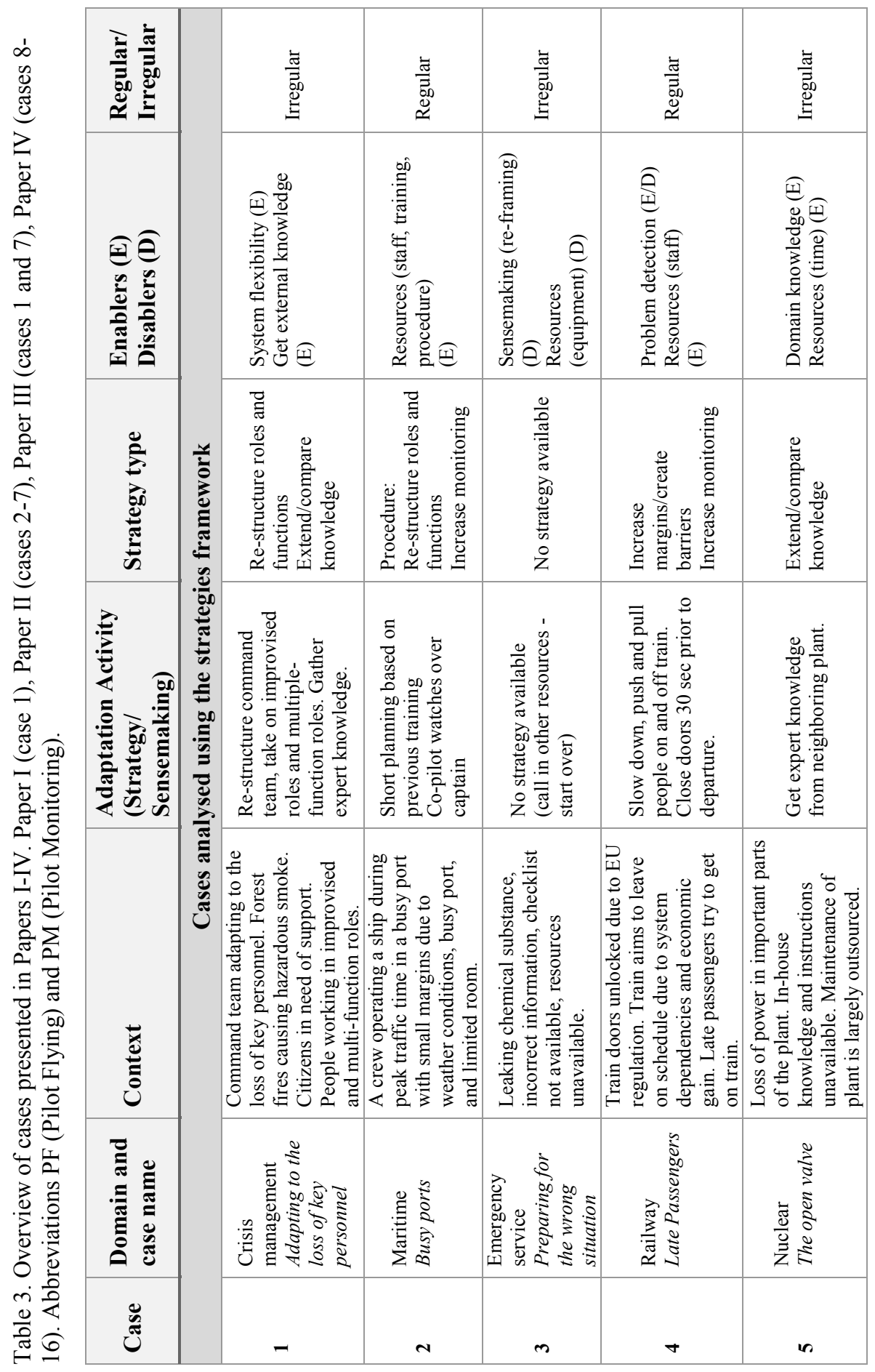




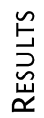

\begin{tabular}{|c|c|c|c|c|c|c|}
\hline 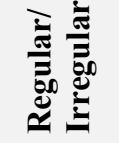 & 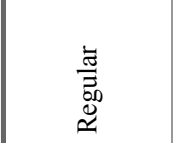 & 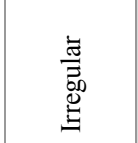 & & 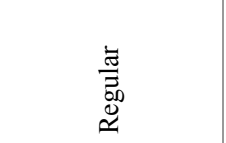 & 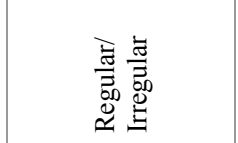 & 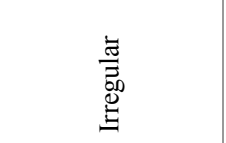 \\
\hline 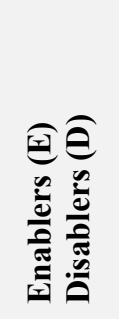 & 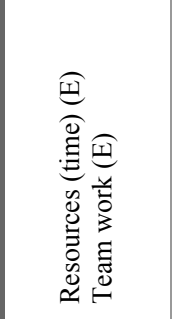 & 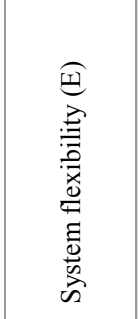 & & 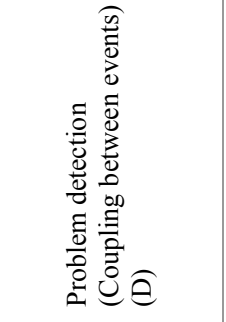 & 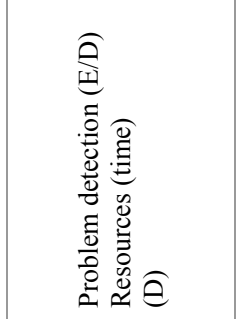 & 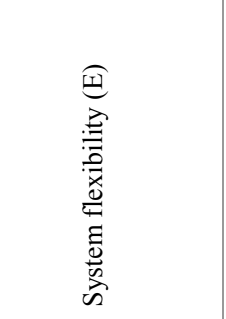 \\
\hline 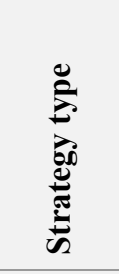 & 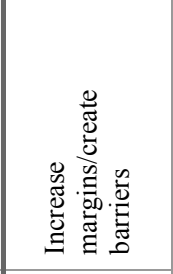 & 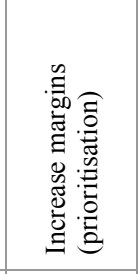 & 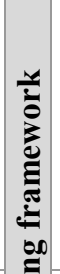 & 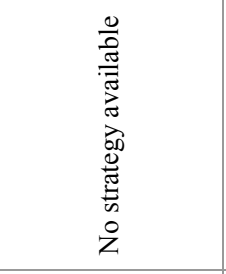 & 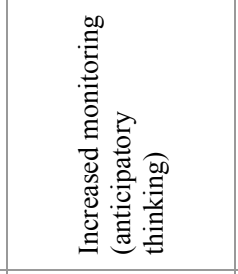 & 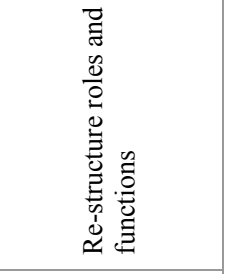 \\
\hline 造 & 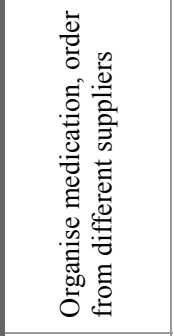 & 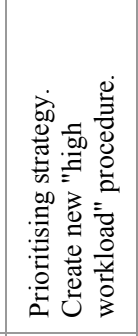 & 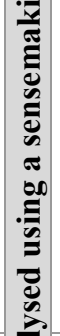 & 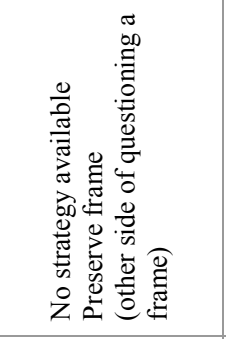 & 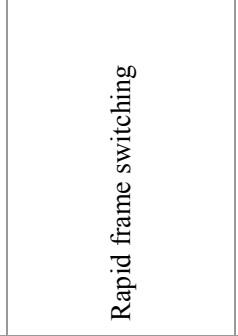 & 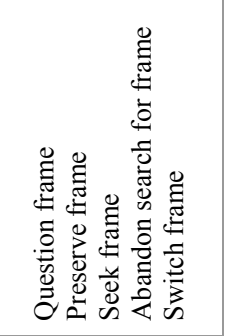 \\
\hline ن롤 & 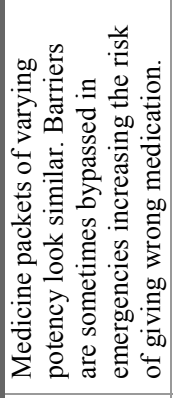 & 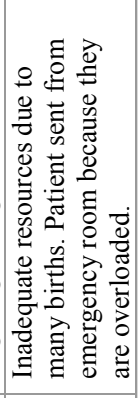 & 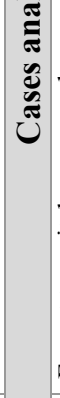 & 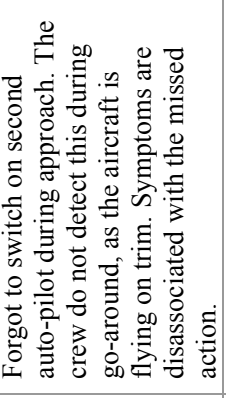 & 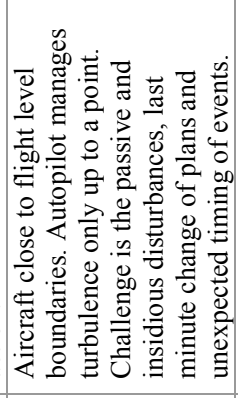 & 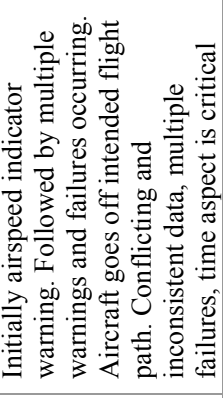 \\
\hline 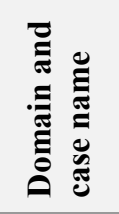 & 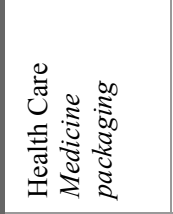 & 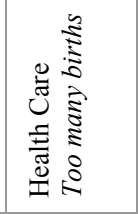 & & 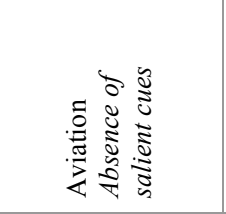 & 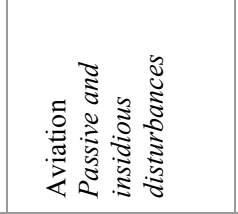 & 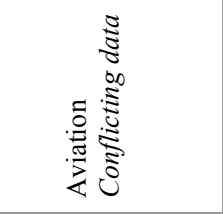 \\
\hline 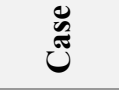 & 6 & $r$ & & $\infty$ & $a$ & $\Theta$ \\
\hline
\end{tabular}




\begin{tabular}{|c|c|c|c|c|c|c|}
\hline 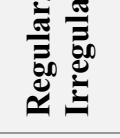 & 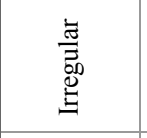 & 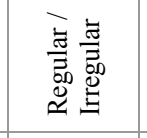 & 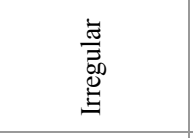 & 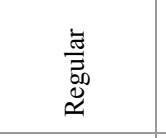 & 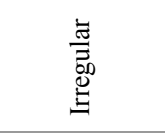 & 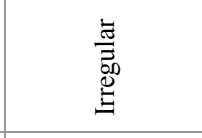 \\
\hline 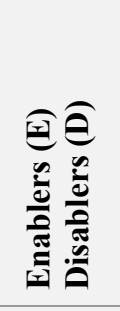 & 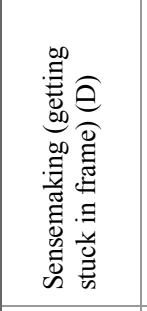 & 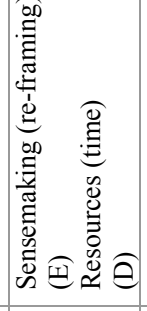 & 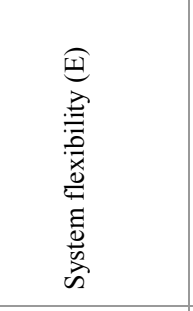 & 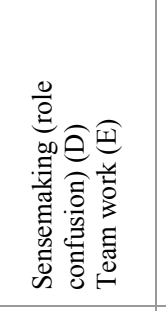 & 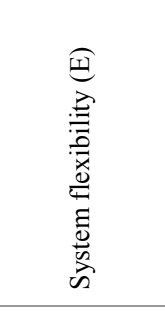 & 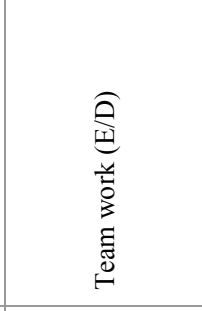 \\
\hline 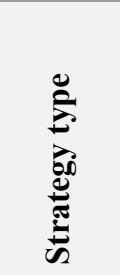 & 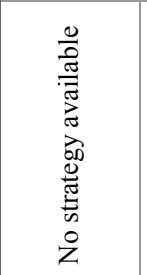 & 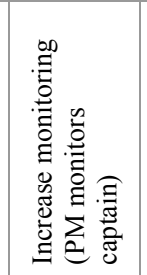 & 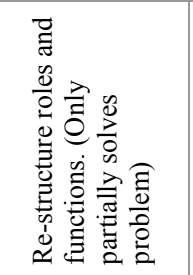 & 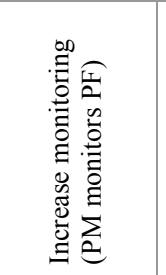 & 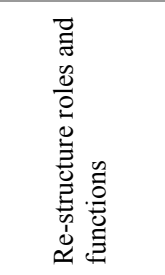 & 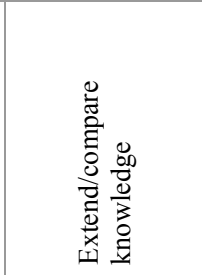 \\
\hline 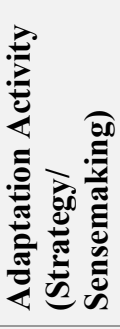 & 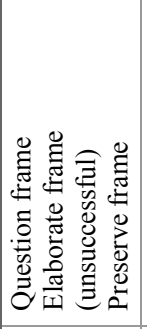 & 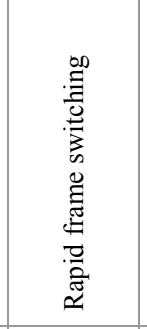 & 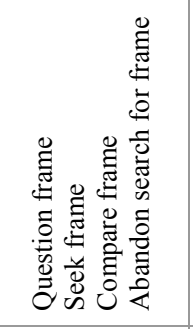 & 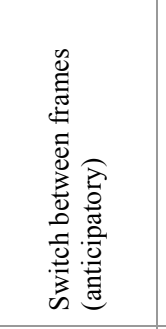 & 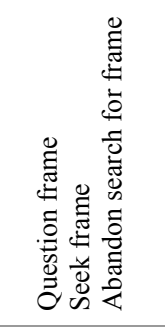 & 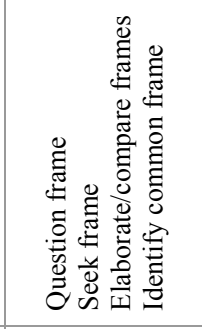 \\
\hline 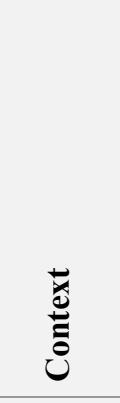 & 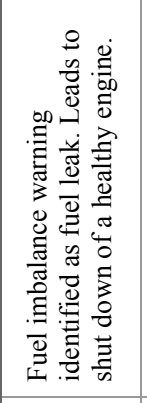 & 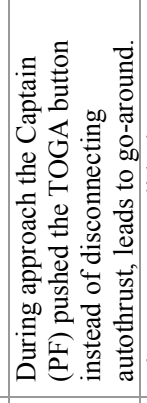 & 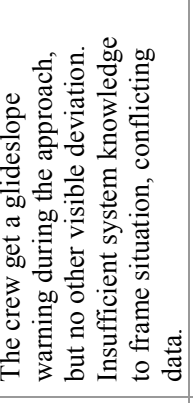 & 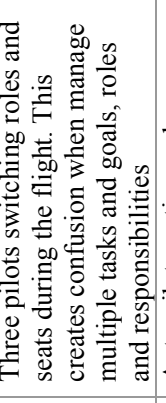 & 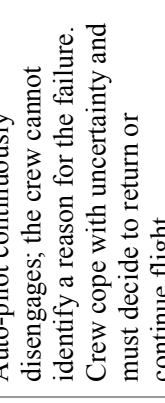 & 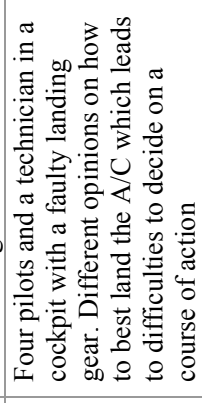 \\
\hline 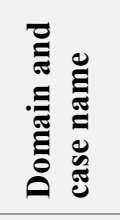 & 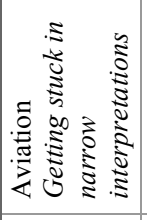 & 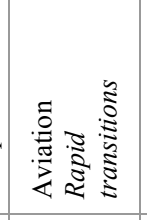 & 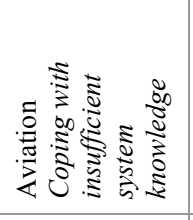 & 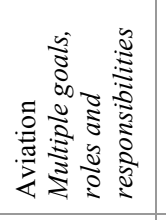 & 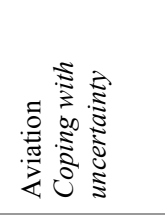 & 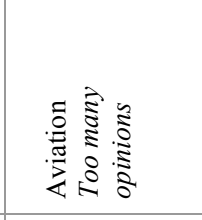 \\
\hline $\begin{array}{l}\text { Uू. } \\
\tilde{z}\end{array}$ & $=$ & $\simeq$ & 9 & \pm & 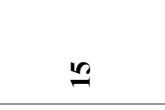 & $\simeq$ \\
\hline
\end{tabular}




\subsubsection{System variability}

As demonstrated in the cases, work processes in complex systems are associated with variations and unexpected events, and require people to adapt their performance. The cases exemplify that different system parts are a source of variability, including, people, technology and the environment. In this section, a few prominent factors found in the cases exemplify system variations. However, it should be noted that it is not the individual variations that create the need to adapt, the need to adapt arises in the interaction with other system parts.

Environmental factors that cannot be controlled by the system can be described as external factors. These include, for example, weather (cases 1, 2, 9, 14), receiving incorrect information (case 3), late passengers (case 4) and number of patients at a hospital (case 7). Factors that are governed by the organisation can be described as internal factors, which contribute to the contextual constraints at the sharp end, and include, for example, production pressures, work facilities and rules and regulations (e.g., cases 4,6 , and 14).

Human performance variability is exemplified in several cases. In case 6 the nurses reorganise medicine packages to decrease the risk of taking the wrong medication, and in case 12 the captain accidentally presses the TOGA button (causing the aircraft to go into a go-around), instead of disarming the automatic thrust, as the airplane comes in for landing. In case 8 the crew forget to turn on the second auto-pilot and in case 16 a fourperson crew and a technician run into difficulties as they cannot reach consensus on how to perform the landing.

Technological failures are a factor in several of the cases: 5, 10, 13 and 15. Three out of the four cases demonstrate difficulties in crew-automation coordination in the cockpit. The complex automated systems logic and non-transparent system feedback creates uncertainty and misunderstandings (cases 5, 8, 9, 10, 11, 13, 15). Crew-automation coordination is not only a challenge following system failures, but may also become a factor in combination with the need to go-around (case 8), and sudden and unexpected changes in weather (case 11). Similarly, in a nuclear setting the source of a malfunction of the system is hard to identify, as the operators inherently simplified models of the system are not sufficient to locate the source of the problem (case 5).

\section{Adaptation reverberations and sharp-end/blunt-end interactions}

Just as all system parts may be a source of variability creating the need for adaptive performance, an adaptation that allows the system to cope with a disturbance creates new vulnerabilities (and opportunities); that is, adaptation reverberations. 
Some adaptation reverberations are easy to detect. For example, adapting a system to current conditions may require a shift in resources by moving them from one part of the system to another (cases 1, 6, 10, 14 and 15). A re-organisation may be very effective as it allows an increase in resources where it is necessary, such as in case 1 where the command team had lost important function. However, as shown in several cases a reorganisation also contributes to an increased pressure on existing resources (e.g., cases 3 , 10 and 15). In case 3 the sharp-end adaptation of pushing and pulling people off the train absorbs resources designed for other areas of operation. In cases 10 and 15 the pilots are not only coping with uncertainty and unknown system failures, but are also required to focus their attention on flying the aircraft manually.

As unplanned adaptations are necessary in complex systems, it is in many cases acceptable that new vulnerabilities emerge, such as in the cases of manual flying (case 10,13 and 15) or role improvisation (case 1). However, reverberations can be hard to detect and their identification may be particularly troublesome in situations where the connections are loosely coupled. For example, in case 6 the local adaptation of ordering medication packages from specific pharmaceutical companies to get colour variation failed when the order was automatically placed at a different company due to medication being out of stock. The nurses where not informed of the switch contributing to an increased vulnerability in the system. Potential harmful side-effects such as this demonstrates the importance of local adaptations being communicated and acknowledged upward (blunt end) and downward (sharp end) in an organisation.

Well-functioning sharp-end/blunt-end interactions are a central part of adaptation reverberation. Case 7 exemplifies a strategy that can start out as local adaptations (sharp end copes with many patients) but over time be implemented as a procedure (blunt end enforces new "high workload procedure"), signifying not only that the system can respond by adapting to a harmful situation, but also learn from it. This organisational learning can be compared to case 5 where a mobilisation of resources resolved the immediate problem (sharp end get expert help from neighbouring plant) but no effort is made at the blunt end to acknowledge the exposed system brittleness and learn from the incident. Further demonstrated in the examples is the power of complementary strategies; that is, strategies from several levels of the organisation working toward the same goal (case 4). As the blunt-end-induced strategy in case 4 (closing the door 30 seconds prior to departure) reduces the disturbance this rule enables the sharp end staff to free more resources and better manage the unsafe situations. 


\subsubsection{Strategy types}

By analysing and comparing the 16 cases presented in Table 3 four generalised strategy types are identified. The four types are: (1) re-structure roles and functions, (2) increase margins (create barriers, prioritise), (3) increase monitoring (anticipatory) and (4) extend/compare knowledge. Figure 4 shows how each case maps to one or several of the identified strategy types.

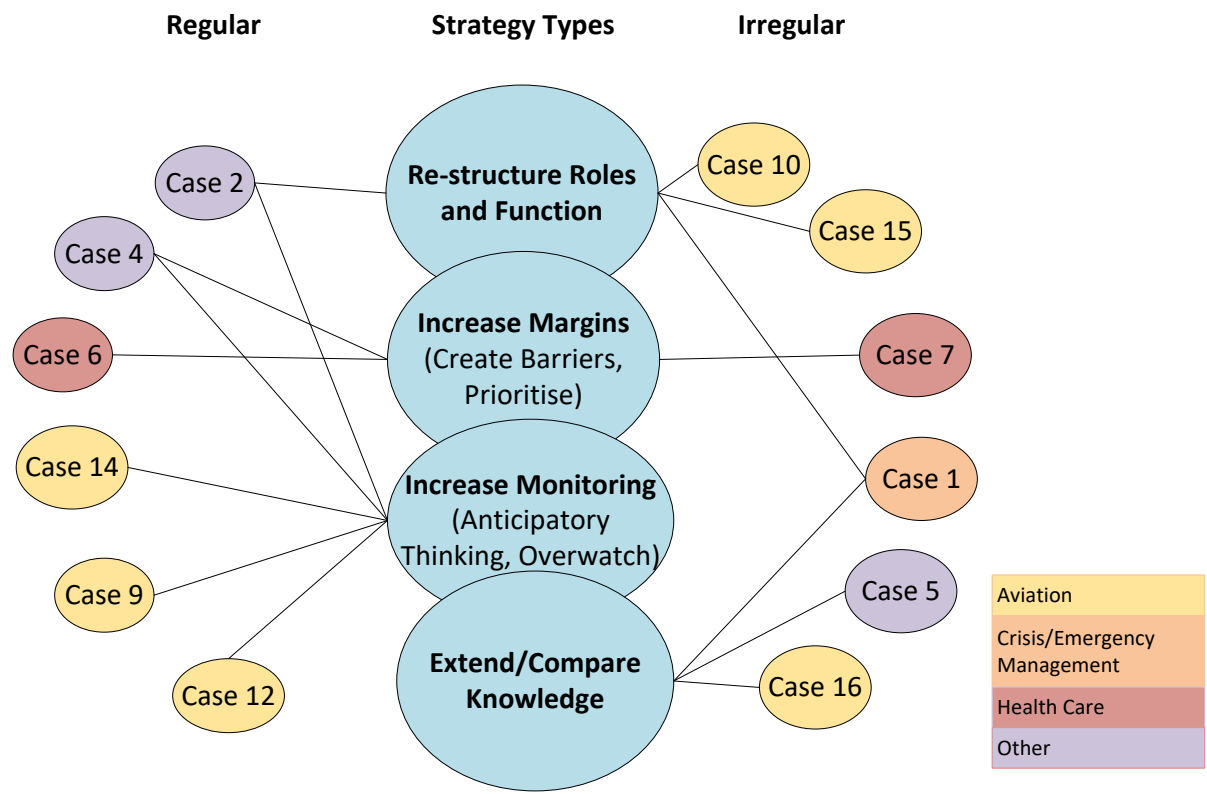

Figure 4. Strategy types used in the cases presented in Table 3. Cases 3, 8, 11 and 13 are not included as no strategy was available. The left side presents regular situations and the right side irregular situations.

\section{Re-structure roles and functions}

By changing its structure, a system can adapt to cope with new situation demands. A restructuring pattern is exemplified in cases 1, 2, 10, 13 and 15 (see Figure 4). In case 1 the command team re-structure the roles and set-up of the team to compensate for the loss of key personnel. A lack of domain knowledge and people in multiple roles create new system vulnerabilities. However, it allowed the team to sustain operation and assist afflicted citizens. In case 2 a re-structuring of the crew is part of the systems procedure to cope with challenging outside conditions (e.g., bad weather, busy ports). By assigning monitoring functions and carrying out swift actions the crew manage to cope with small margins. In cases 10, 13 and 15 the pilots cannot trust the flight systems, and decide to 
disconnect them and fly the aircraft manually. In other words, the crew re-distribute the functions and roles of the joint system to take control of the situation. As mentioned also in case 1, although the coping strategy is necessary, it makes the crew-aircraft system more vulnerable and susceptible to performance breakdowns, as the prioritised activities are time-consuming.

\section{Increase margins (create barriers, prioritise)}

Increased margins are found in cases 4, 6 and 7. In cases 4 and 6 local barriers are created, and may also be described as strategies to "buy time". In case 4 a new rule is introduced that train doors lock 30 seconds prior to departure, giving the train staff increased time margins when passengers try to get on the train as it is about to leave the platform. Similarly, in case 6 nurses organise the medicine packages to avoid confusion when medicine is required promptly. In case 7 , the medical team extend their capacity to cope with the increasing number of patients by introducing a new priority list.

\section{Increase monitoring (anticipatory thinking and overwatch)}

Several cases show increased monitoring as a strategy to adapt to the on-going situation (cases 2, 4, 12 and 14). In cases 2 and 4 the ship and train crews use the anticipatory strategy of increased monitoring to identify potential difficulties in busy ports (case 2), and recognising when a passenger may be in danger (case 4). In case 9, increased monitoring of outside conditions and automated systems could enable a detection of the problem, and thus eliminated the surprise factor. However, in this case the crew were flying in cruise, which is seen as the least likely time to encounter any disturbance, making minor changes difficult to detect due to non-transparent system feedback (which may also be included as a disabler). In case 12 the Pilot Monitoring reports careful monitoring of the captain to ensure appropriate actions are performed in a timely manner. A similar "overwatch" strategy is presented in case 2 where the Pilot Monitoring on the ship searchers for potential dangerous situations as the ship navigates with small margins. In case 14 a contributing factor to the surprise is a re-structuring of roles to optimise the fly-and-rest schedule. However, as the Pilot Flying gets confused, the Pilot Monitoring pays careful attention, and performs tasks not normally assigned to his role.

\section{Extend/compare knowledge}

In cases 1, 5 and 16 the coping strategy is to acquire the expert knowledge necessary to solve the problem. In case 1 the command team contact authorities to fill the knowledge gap created when key personnel are lost. In case 5 an expert is called in to help identify why power is lost at the nuclear plant. Having too many expert opinions can also be a challenge as demonstrated in case 16 where four pilots and one technician try to agree on a course of action to safely land an aircraft with a faulty landing gear. 


\section{Regular vs irregular situations}

The cases in Figure 4 have been placed on the left side if they are categorised as regular events and on the right side if they are categorised as irregular event. The division of these two categories allows the identification of potential differences in adaptive performance between more and less expected types of situations. Although the sample size is small a few trends are worth noting. For instance, Figure 4 shows that increased monitoring is a strategy used for many of the regular situations, while a re-structuring of roles and functions, and gaining external knowledge, is a strategy that is more common for the irregular situations. This finding suggest that monitoring skills are developed to identify and cope with routine variations.

For the regular events, in cases 2 and 4 the operators learn to look for specific external factors, such as other ships at busy port or late passengers getting on a train. In cases 2 , 9, 12 and 14 the monitoring skills are used to support and watch over automated systems and co-workers. In cases 4 and 6 the train conductors and nurses respectively develop routines to increase their margins and "buy time" to safely cope with known potential variations such as late passengers or patients that require immediate attention. Similarly, in case 7 (irregular occurrence) the medical staff increase the margins to cope with an ongoing irregular situation, which later turns into a new procedure for "high-workload" situation at the maternity ward.

Not surprisingly the irregular events require more information gathering from external parties, as the situations go outside of what can be understood by the operators (cases 1 , 5 and 16). Re-structuring roles and functions is also recurring for irregular events, in large because restructuring human-automation functions is a strategy used by pilots to cope with uncertainty (cases 10, 13 and 15).

\subsubsection{Adaptation enablers and disablers}

The enabler/disabler categories presented in Figure 5 are some of most prominent factors identified across the cases. As previously mentioned, the cases have been analysed with different focus, and using different frameworks, which is also reflected in the results. For example, the cases in Paper IV are selected and analysed from a sensemaking perspective, explaining why many of the cases have "sensemaking" and "problem detection" as a central enabler/disabler category. The results in Figure 5 should thus only be viewed as a representation of the focus in the analysed cases, and not an exhaustive account of enabling/disabling factors. Any generalisation should be done with caution.

In some sense, enablers/disablers are a dichotomy, as the lack of an enabling factor may be described as a disabling factor. In Table 3 it is noted whether the identified factor took 
the role of enabler or disabler for each case. Only a few prominent enabling/disabling factors are highlighted below.

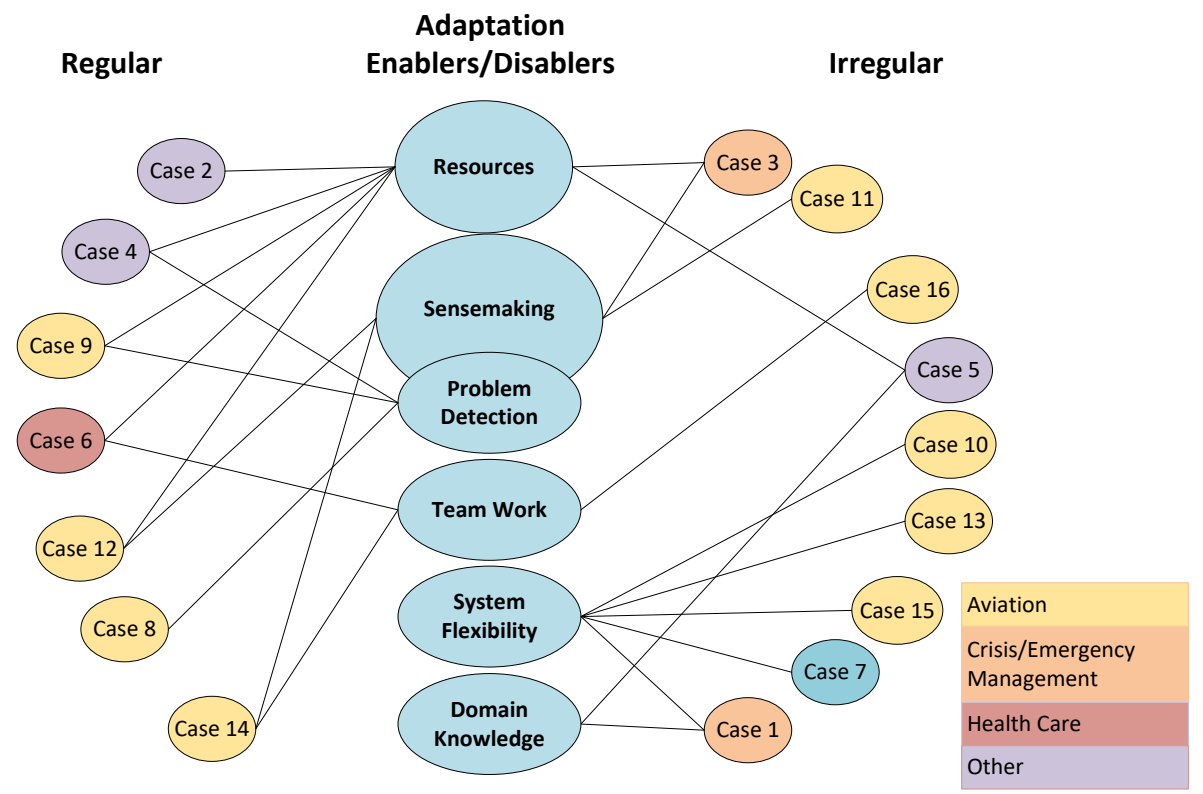

Figure 5. Adaptation enablers and disablers. The left side presents regular situations and the right side irregular situations.

Resources (including time, staff and equipment) are a key factor in the "regular" occurrences. In cases 6, 9 and 12 time is the enabling/disabling factor to manage the situation, including taking swift action following surprise in cockpit and time to organise medicine packages. Resources also come in the form of available equipment (case 3), and staff at the right place and the right time (cases 2 and 4).

The category of sensemaking (and problem solving) demonstrates the importance of reframing to enable a response to a hazardous situation (cases 3, 11 and 12). Time is commonly an enabler is such situations, allowing an elaboration and comparing of frames. In other situations, the challenge is to detect that there is a problem in the first place (cases 4, 8 and 9), or avoid getting stuck in narrow interpretation of a situation (case 11). Competing tasks and complex technical systems contribute to the challenges of detecting that something is going wrong. Five out of the seven situations referring to sensemaking (and problem solving) as a main adaptation enabler/disabler concern cockpit operations, reflecting the focus of analysis in cases 8-16. 
Although team work in most situations is a pre-requisite for system operations (e.g., case 6 ), it may also be a source of variable performance contributing to difficulties to adapt, as demonstrated in cases 14 and 16.

A main category in the irregular cases is system flexibility, in several situations referring to problems in the cockpit systems (cases 10, 13 and 15). In all three cases the confusion and uncertainty regarding the automated system lead to the strategy of turning the automated systems off and flying manually. When and if automation should be turned off in difficult situations is a highly relevant topic in aviation today, as systems advance and a younger generation of pilots are increasingly dependent on the functioning of automated systems. In cases 1 and 7, system flexibility allows a new team structure to cope with the loss of team members (case 1) and a large number of patients (case 2).

In cases 1 and 5 operators were in situations where their domain knowledge did not fit the situations for which they were responsible, and gaining external knowledge was thus key to resolve the situation.

\subsubsection{Conclusions}

As is shown in the three studies there is a great deal to learn from systematic gathering and analysis of sharp-end responses to disturbances and unforeseen events. The main conclusions of the analysis can be summarised as follows:

- Analysis of context, the forces and conditions, offer information on (1) what underlie the need to adapt and, (2) constrain the ability to adapt.

- Successful adaptation is not an ad-hoc activity. Adaptations are not always successful and (locally) successful adaptations may create brittleness in other parts of the system. To increase the potential for successful adaptations requires awareness and support through system design and training.

- To enhance resilience at the sharp end requires support from the blunt end. Processes associated with a system's sharp-end/blunt-end interactions can reveal how sharp-end adaptations may be strengthened, and how they may change the system over time.

- Adaptive strategies and adaption-enabling/disabling factors can be abstracted to identify patterns on how systems respond to different types of variations (e.g., regular and irregular). 


\subsection{Frameworks and models}

A result of the studies in this thesis is the development of conceptual framework and models (hereafter referred to as the models). The models are based on the data gathered in the studies, and build on previous theories and models of joint systems. Adapting and developing models offers a lens from which to view and structure data. In this sense, a combination of bottom-up data driven explorative approach and top-down application of previous models and theories has been used. The model development has worked toward several objectives, including (1) visually representing the findings, (2) contrasting and analysing cases, (3) relating findings to theories and models the field, and (4) developing tools to guide researchers and practitioners in analysing adaptive performance.

Table 4 presents an overview of the models developed. The strategies framework to analyse sharp-end adaptations is central in Papers II and III. To support this analysis a variety space diagram and control-loop model have further been developed. In Paper IV a crew-aircraft sensemaking model is developed to illustrate important parts of sensemaking. To support the sensemaking analysis an adapted Data/Frame model further visualises the sensemaking activities.

In this section the models are presented and discussed. First, a summary of the models is provided (for detailed and illustrative cases, see Papers II-IV). Second, an illustrative case is used to discuss and compare the models (case 1) and, third, conclusions are presented. 


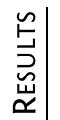

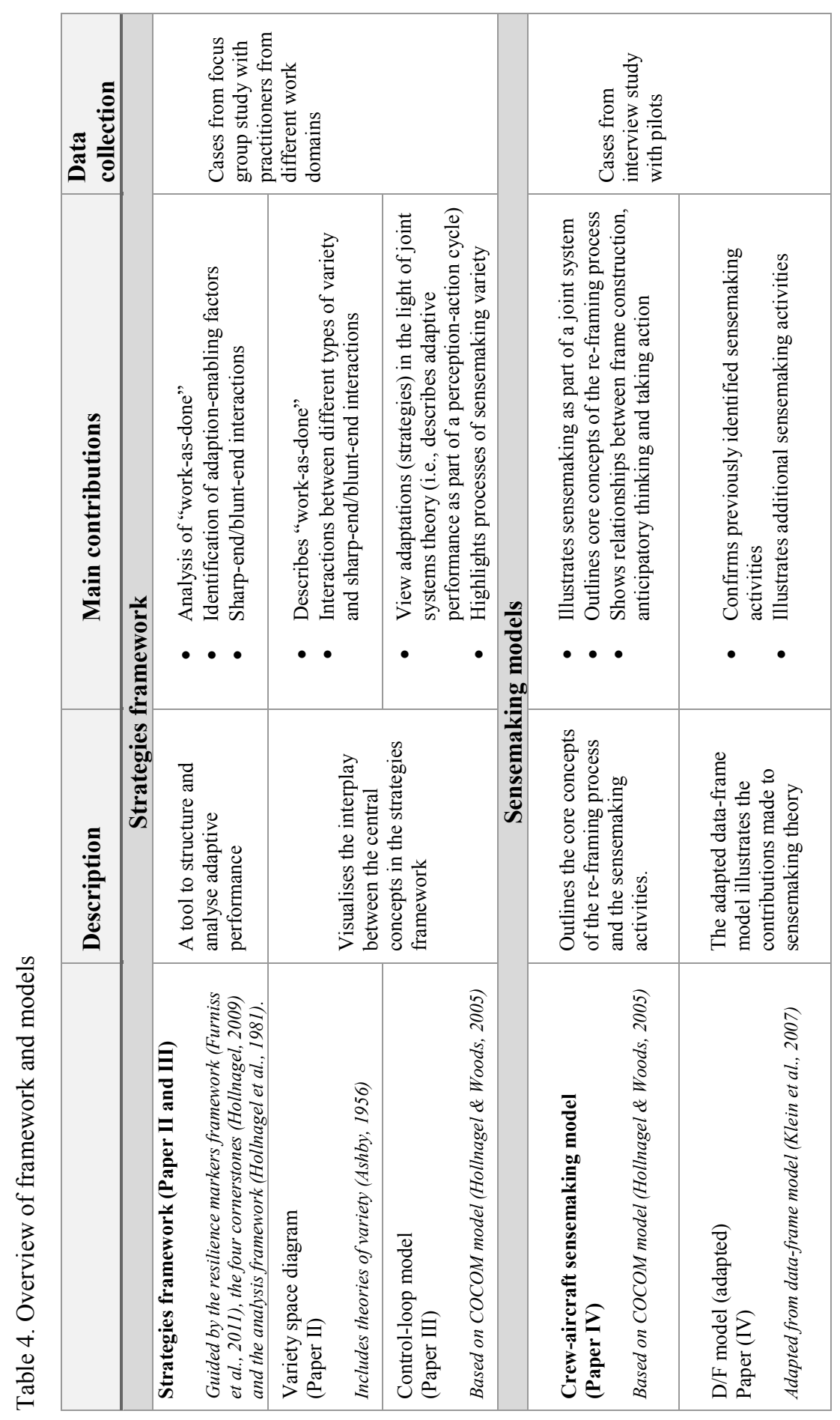




\subsubsection{The strategies framework}

The strategies framework presented in Table 5 has been developed as a tool to describe and analyse adaptations (here described as strategies). Models and methods for capturing abilities associated with resilience are still rare, and this framework is a starting point for systematic gathering and analysis of adaptation-enabling factors and their relation to organisational pressures shaping the working environment. Increasing awareness of "work-as-done" and its effects on other parts of the system can help improve safety through foresight, preventative measures and mitigation of risks.

Table 5. The strategies framework

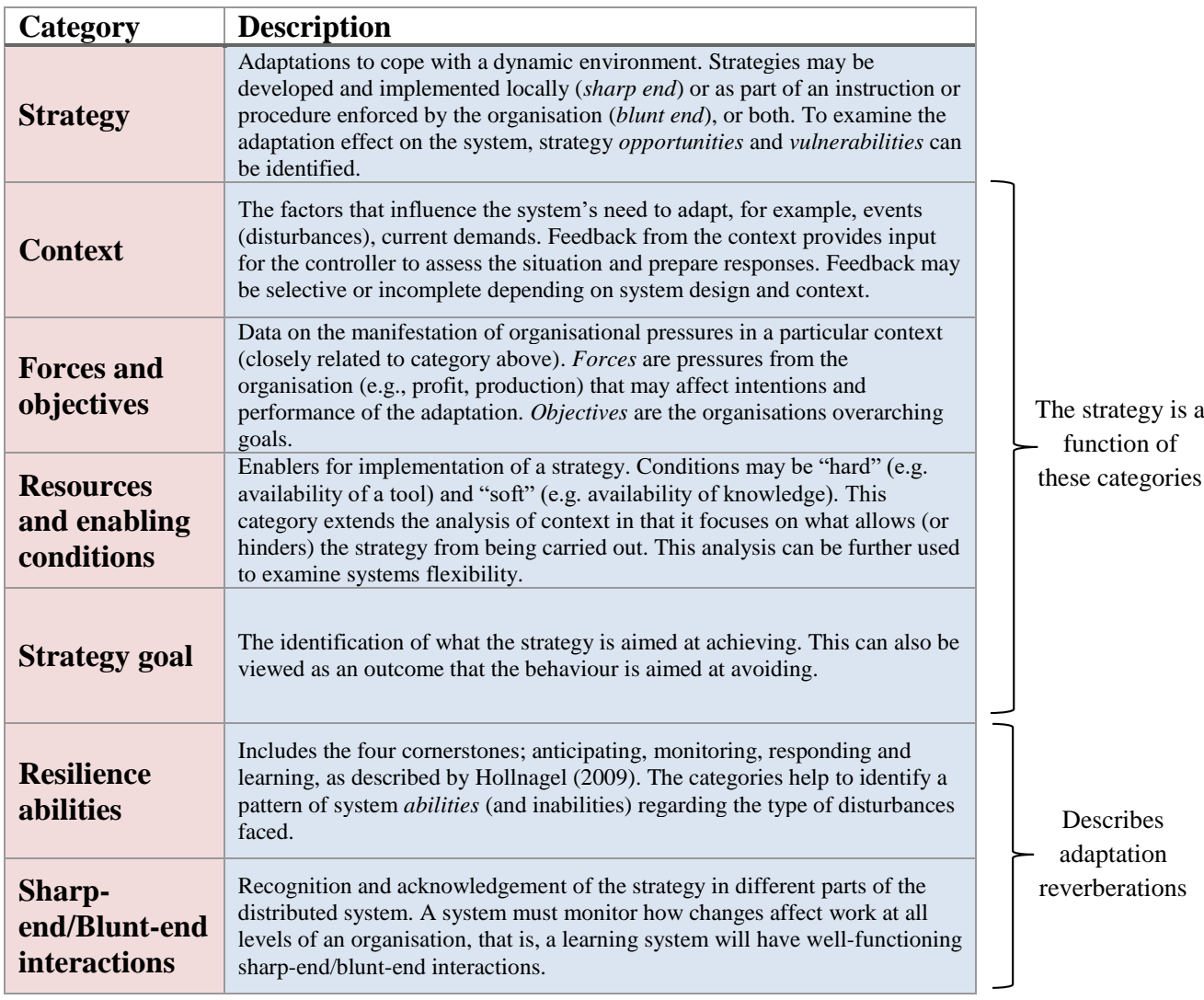

The framework has been developed bottom-up based on examples of everyday work situations where people adapt their performance to deal with the demands of their everyday work environment. The examples were gathered in a focus group study (Papers II and III) and 17 cases underlie the development of the framework (including cases 2-7 
in Table 3). The strategies framework is presented in Table 5, and the categories in the framework target three main areas: (1) an interpretation of the situation in which the strategy takes place, (2) enablers for successful implementation of the strategies (3) how the strategies affect the overall system.

\section{The variety space diagram}

The variety space diagram illustrated in Figure 6 aims to support the strategies framework analysis by visualising relationships of central concepts. In the model the connections between different types of a system variety are presented (Control Variety (CV), Sensemaking Variety (SV) and Disturbance Variety (DV)), and the sharp-end/blunt-end interactions. Visualising the connections allows a characterisation of different types of adaptations, and how well they are supported by management. For a detailed description and examples of applying the variety space diagram, see Paper II.

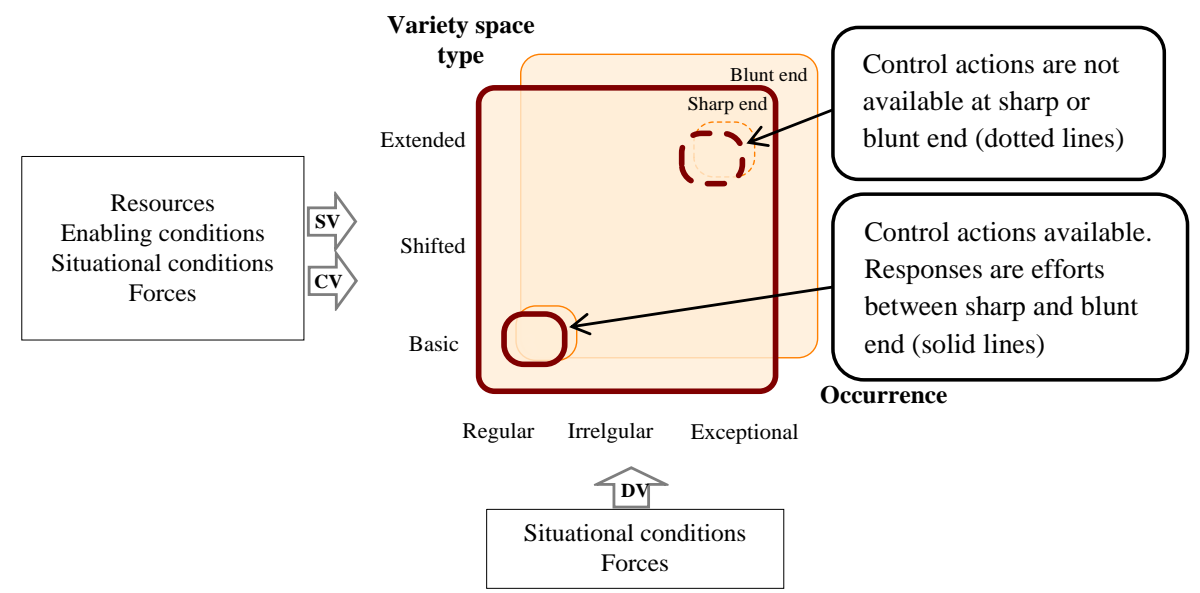

Figure 6. The Strategies framework categories illustrated in the variety space diagram

\section{Control-loop model}

Similar to the variety space diagram the objective of the control-loop model illustrated in Figure 7 is to support the strategies framework analysis by visualising the interplay between central concepts. Building on the principle of a basic control loop, the model serves to recognise the dynamics of a socio-technical environment, by depicting the processes taking place as a situation unfolds. The model constitutes two loops; an outer loop illustrating the environment, which is affected by external events and changes made through adaptations, and an inner loop illustrating the process that constitutes the sensemaking variety, including anticipatory abilities, organisational pressures (forces and goals), and available resources. For a detailed description and examples of applying the control-loop model, see Paper III. 


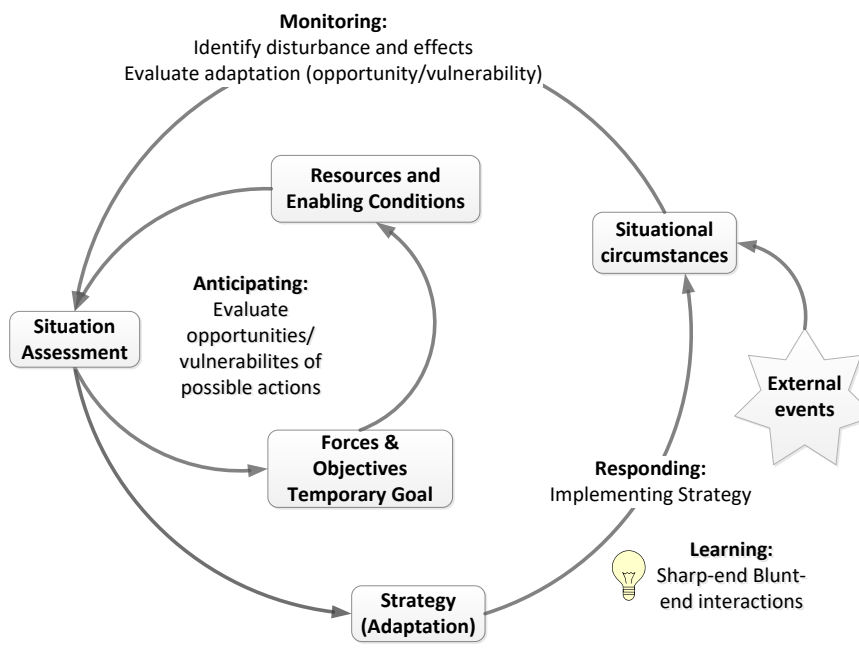

Figure 7. The strategies framework categories illustrated in the control-loop model.

\subsubsection{The crew-aircraft sensemaking model}

The crew-aircraft sensemaking model in Figure 8 outlines the core concepts of the reframing process and the sensemaking activities by combining two models: the Contextual Control Model (COCOM) from Hollnagel and Woods (2005) and (2) the Data/Frame (D/F) model (Klein et al., 2007). The model contributes to the understanding of sensemaking as part of a joint system, including the interactions between the two pilots and the aircraft systems. Further, the model illustrates the relationships between frame construction, expectations (anticipatory thinking) and taking action. 


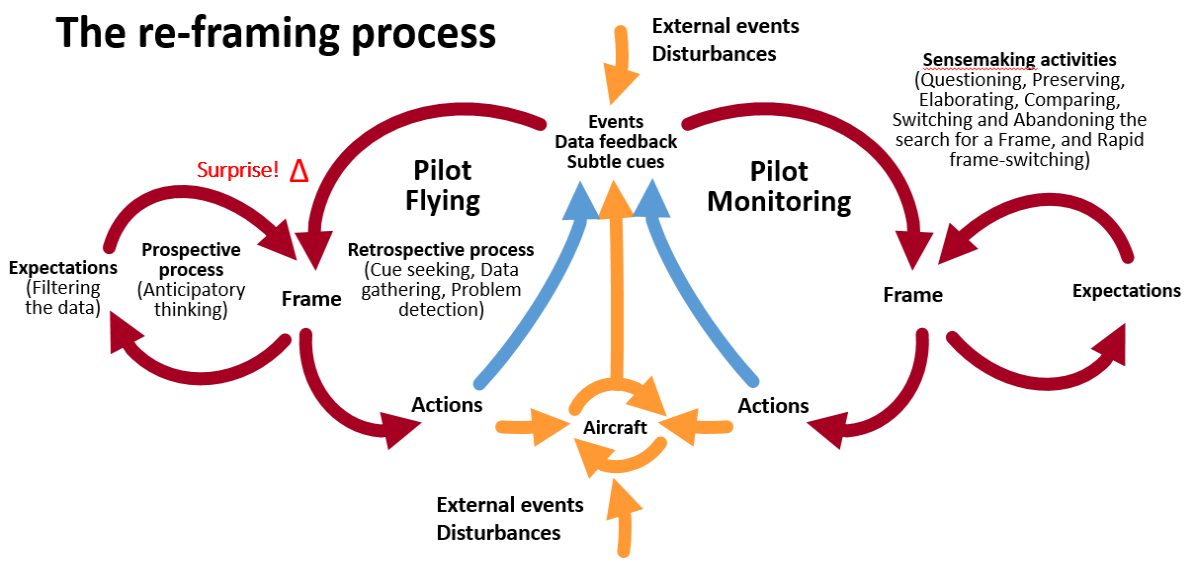

Figure 8. The crew-aircraft contextual control loop demonstrates the re-framing process. Core concepts include the retrospective and prospective processes used to construct a frame and take action (illustrated on the left side). Sensemaking activities in the reframing process identified in Paper IV are questioning, preserving, elaborating, comparing, switching and abandoning the search for a Frame, and rapid frameswitching (illustrated on the right side).

Using a cyclical model shows the core of the sensemaking view that feedback from the environment modifies the current frame (situation assessment), which in turn guides the search for more information (and actions taken). The interconnected loops in the model represent the dynamics between the two crew members (Pilot Flying (PF) and Pilot Monitoring (PM)) and the aircraft. Two main loops for each crew member describe the retrospective (feedback from environment) and prospective processes (anticipatory thinking) of the re-framing process which together serve the purpose of ascribing both meaning and action (Weick et al., 2005). Red arrows represent functions and processes (as described by Klein et al., 2003), yellow arrows describe aircraft processes and external events and disturbances, and blue arrows represent coordination and communication in the cockpit. Sensemaking activities are included on the right side of the figure: question, preserve, elaborate, compare, switch, abandon the search for a frame, and rapid frameswitching.

\section{The data-frame model}

Figure 9 , adapted from Data/Frame model (Klein et al., 2007), shows the relations between the sensemaking activities identified in Paper IV (cases 8-16 and Fig 8). A surprise (unexpected data) may in some situation lead to discarding the data and preserve the frame (situation assessment), if the data is not seen as relevant. However, in most cases it will lead to a questioning of the current frame, which may be followed by several activities. Activities identified in the pilot interview study include: elaboration of a frame 
to include the new data, rapid frame-switching to re-gain control of the situation, and the iterative process of seeking a new frame through comparing frames. If a plausible frame is identified there is a switch to this frame, and if a frame cannot be identified in a timely manner the search for a plausible frame may be abandoned all together, which also involves switching to a known frame. In other words, to give up the search for an explanation of what is going on, and adopt a different strategy based on what is known.

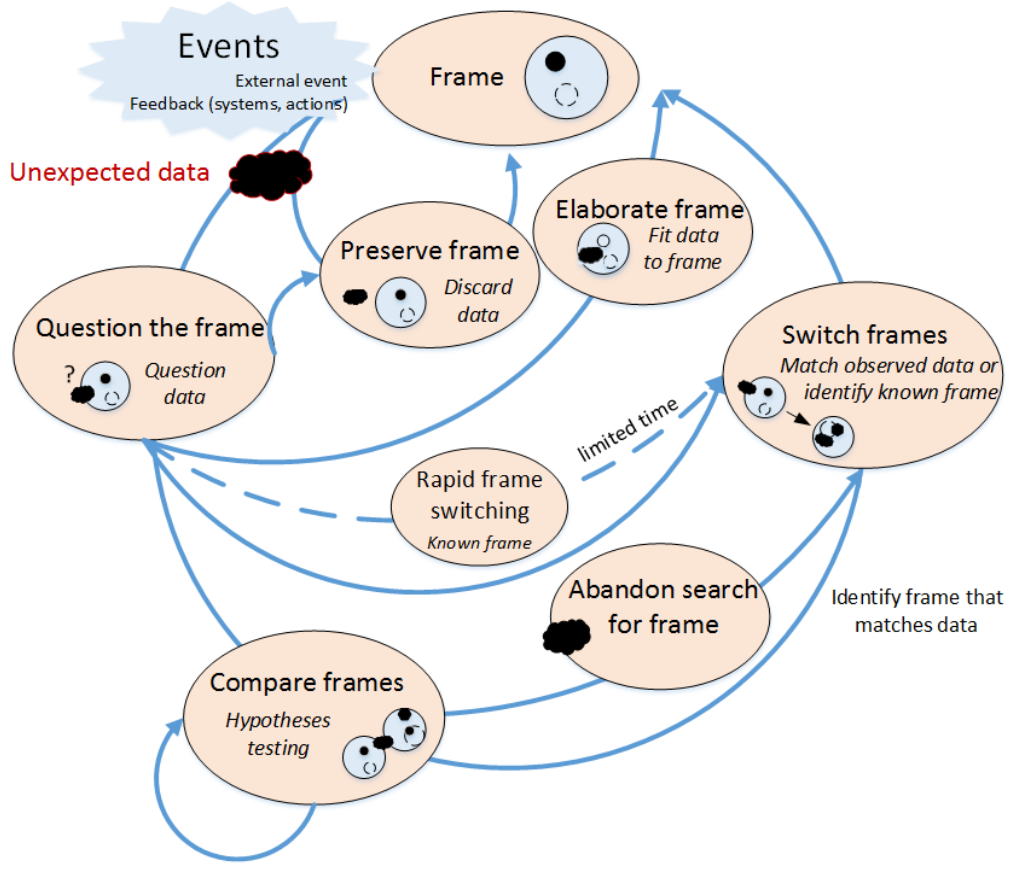

Figure 9. The Data-Frame (D/F) model shows the sensemaking activities in the reframing process identified in Paper IV. Two sensemaking activities have been added that are not part of the original D/F model (Klein et al., 2007); Rapid frame-switching and Abandon search for frame.

\subsubsection{Comparing the models}

In this section case 1 (Table 3), presented in Paper I, is used to discuss and contrast the framework and models developed as part of this thesis. First, a brief re-cap of the case is provided.

Case 1. Adapting to the loss of key personnel. Following a weather disturbance, a crisis management command team was unexpectedly reduced from 18 to 11 members, and the team was forced to adapt to the loss of important functions. The team responded rapidly by re-structuring the functions and roles, several people took on multiple roles as well as 
roles outside their field of expertise. Adapting to the new situation was enabled by the team's flexibility in taking on roles outside their field of expertise, which was supported by the role descriptions found in the organisations procedures. However, the team was functioning in a fundamentally different way, creating new system vulnerabilities through a less efficient structure with somewhat unclear responsibilities. The vulnerabilities were not fully detected by the team, or at least not explicitly acknowledged, and critical information was lost. Some of the misinformation was detected as briefings were held and incoming information was questioned. However, strategies aimed at ensuring the tasks were carried out adequately were not sufficient to compensate for, and unravel, the misinterpretations. Several critical aspects were overlooked and conflicting information within the team went undetected.

Applying the strategies framework to case 1 offers a way to structure and describe the data, using the adaptation (re-structuring of the command team) as a starting-point. A large amount of information is gathered from different data sources for this case, which allows an in-depth description of the framework categories, including the adaptive strategy, the context in which it takes place, forces and conditions, what enables/disables the ability to adapt, sharp-end/blunt-end interactions, and how the resilience abilities come into play. Strategies to cope with the situation made by individuals and groups throughout the exercise can further be identified and analysed using the framework categories. A cross-analysis (see Section 4.2) of all identified strategies could offer valuable insights to the team's ability to adapt to meet goals (and sub-goals), and what factors enable or hinder their ability to do so.

A limitation of the framework is that it is static, describing only individual adaptations, and thus lacks the ability to illustrate the processes taking place throughout the exercise. Another limitation of the framework, compared to the empirically-driven episode analysis performed in case 1 , is its ability to depict complex interactions and identify links between multiple on-going events. To gather necessary data and apply the high-level categories of the framework without an elaborate pre-analysis such as the episode analysis, may be challenging, as multiple events are simultaneously going on in different parts of the team. Further, it requires extensive understanding of the roles, tasks and environment in the exercise. In a naturalistic setting, where key events are not known before-hand, it is expected that this understanding would be even more challenging. Other areas of application for the strategies framework (in case 1), would be as a discussion guide during the after-action review. Both observers and exercise participants could share their views regarding the team's ability to adapt, offering valuable learning opportunities. 
The variety space diagram was developed to support the strategies-framework analysis by visualising relationships between central concepts. Building on Ashby's theory of variety (Ashby, 1956), the concept of variety space is used to demonstrate shifts and extensions of the available actions. In case 1 the disturbance of losing key personnel causes a shift in variety as the team re-structures the command team's responsibilities and priorities. The findings of the episode analysis presented in Paper I show that the command team create enough control variety (available actions given environmental constraints) to cope with the situation, but lack the necessary sensemaking variety (ability to revise understanding of the situation as events unfold), to take appropriate actions. In this sense, the variety space diagram allows the analyst to reflect on adaptive abilities in relation to available variety and the role of sharp-end/blunt-end interactions. However, for a single case the variety space diagram appears to offer limited insight, beyond what has been found using the strategies framework. It is expected that the variety space diagram would be more useful to discuss, reflect and compare multiple strategies. The model could guide a discussion on, for example, how many of the strategies used during the exercise apply regular and shifted variety (within procedure) vs extended variety (outside textbook performance), and how well blunt end support (procedures, real-time back-up) cover the needs in different types of scenarios.

The limitations of the strategies framework being static, as mentioned above, becomes particularly evident in a multi-faceted and evolving case such as the command team exercise. Using the structure of the control-loop model for analysis of the framework categories can offer some reflection of this process. For example, when following the control-loop "steps", the context is re-examined following each adaptation, allowing a reflection on the effects of potential adaptation reverberations. The control-loop model further complements the strategies framework by emphasising and visualising the importance of the sensemaking process for successful adaptation (the inner loop). For example, it is not only the objective "forces and conditions" of the situation that play into the decisions made, but also how they are perceived by the decision maker(s).

The crew-aircraft sensemaking model combines two theoretical models to describe the sensemaking process in a two-pilot cockpit. The model emphasises the role of expectations for understanding an on-going process and deciding on a course of action. Applied to case 1 the model could be used to discuss how the commanders in roles outside their field of expertise construct frames based on context and available data. Results from the episode analysis in Paper I suggest that the lack of expertise plays an important role for the ability to adapt, an analysis that could be supported by a sensemaking model, such as the Data/Frame model. Identification of sensemaking strategies may well fuse a discussion on how to improve and identify vulnerabilities with sensemaking abilities in 
similar situations. The model could guide discussions on, for example, what abilities the team have to elaborate/compare frames and what strategies can be used to avoid preserving a frame.

\subsubsection{Conclusions}

As described above the framework and models can be used to analyse and describe cases, complementing each other by highlighting different aspects of adaptive abilities. The main points are:

- The models are developed to describe and highlight processes and relationships between central parts of complex and dynamic joint cognitive systems. Illustrated in the models are the findings from each respective study, with the intention to depict concepts that are common to the cases. The models can be used to guide the investigation and visualisation of adaptive performance in other cases than the ones described.

- The models complement each other as they emphasise different focus and have been developed with different goals in mind. The strategies framework is developed as a tool to analyse "work-as-done", and the sensemaking models are developed to visualise theoretical concepts involved in the sensemaking process. However, the models all have in common that they are based on theories in CSE/RE and they include many similar concepts. As such, the models offer little comparison and contradiction of underlying theories, but rather complement each other.

- The strategies framework consists of a set of categories that have been identified as important for understanding adaptive performance, or "work-as-done". The variety space diagram is developed to support the strategies framework, and shows how different types of variety come into play, the sharp-end/blunt-end interactions, and how adaptations over time may become part of regular functioning. The control-loop model complements the strategies framework by illustrating the framework categories as a process. Further, the control-loop model emphasises the importance of the sensemaking process as a central part of the adaptations process.

- The crew-aircraft sensemaking model is based on the cyclic COCOM model, and is fitted to the crew-aircraft context. However, the sensemaking processes can be applied to other joint systems. Illustrated in the model is the interplay between the retrospective process of receiving feedback from the environment and the prospective process of anticipatory thinking, and how these form the decision process and actions taken. The main application for the crew-aircraft sensemaking model and the complementary data-frame model, is research on sensemaking in dynamic events. It is further suggested that the concepts can be used to guide discussions for researchers and practitioners on sensemaking 
strategies and abilities. For example, during an after-action review of an exercise different strategies can be highlighted and discussed.

- As tools for analysis the models can be used to guide what to look for. As with all interpretative field work, knowledge for the context and processes being studied is an important factor to increase the validity of the analysis. The core constituents of the developed models are high-level, abstract concepts, and the completeness and accuracy of the analysis is thus bounded by the knowledge and understanding of the observer/analyst, and the depth and quality of data gathered. It is likely that applying these models can generate different types of analyses with different outcomes depending on the perspective of the analyst. The framework and models should thus be used with these limitations in mind.

- A suggested area of application for the strategies framework is as a discussion guide during for practitioners, for example, during an after-action review. Both observers and exercise participants can share their views regarding the abilities of the team to adapt, offering valuable learning opportunities. Further, such training sessions can strengthen abilities to reflect on vulnerabilities and opportunities of adaptive strategies when in real-life situations. 


\section{Discussion}

This chapter discusses the main contributions of the studies and the methods used. In addition, it explores possibilities and challenges for resilience engineering ahead.

\subsection{Revisiting the research question}

In this section the research question presented in the introduction is used to guide the discussion of the results.

- How can adaptive performance at the sharp end be characterised and analysed, from the perspective of how systems cope with variations and unexpected events?

The research question guiding the studies in this thesis is broad and open, and an exhaustive or conclusive answer cannot (or will ever) be provided. Ways to characterise and analyse work performance in complex systems will continuously evolve through development of new and more nuanced methods. A variety of methods can enrich perspectives and increase chances of fitting different settings, contexts, study objectives, focus of analysis and availability of data. The studies offer several examples of how adaptations can be described and analysed in different settings. The conceptual models developed can guide researchers and practitioners in what to look for, and in offering perspectives on how to view the results. The following discusses the results and conclusions of each study in more detail.

The study in Paper 1 shows the details of an in-depth analysis, episode analysis, offering a demonstration and guidance on how to structure and manage multiple data sources and parallel events for analysis of adaptive performance "as it is happening". Further, the study is unique in its detailed account of role-improvisation in crisis management (Lundberg \& Rankin, 2014; Rankin et al., 2013). The analysis uncovers several enabling and disabling factors contributing to the abilities of the command team to adapt to the unexpected loss of command team staff, including among other things: expertise, joint briefings, hand-overs and language skills. An important result is the illustration of how multiple factors in the context and organisation affect the situation. The case study offers 
an example of the fine balance between situations with successful and less successful outcome, and how minor details may greatly affect the overall result. This result exemplifies and underlines the argument that successes and failures are closely related (Hollnagel, 2014), and problems that may occur when situations are analysed in hindsight, where the aim is to identify causes of a known outcome (Fischoff, 1975; Woods et al., 2010). Findings suggest that studying and contrasting situations with successful and less successful outcome to identify enablers and disablers (rather than just causes) can offer new insights into a system's adaptive abilities. Further, factors enabling successful adaptation (in this case role-improvisation), are linked to organisational structure (joint briefings, hand-overs, joint log) suggesting that successful improvisation requires a certain amount of structure. This result is in congruence with previous literature on organisational improvisation that improvisation is a highly structured activity (Cunha, 1999; Grøtan, Størseth, Rø, \& Skjerve, 2008; Mendonça \& Wallace, 2015; Vera \& Crossan, 2005). To improve a system's ability to adapt successfully in similar situations would thus require training of team efforts and a strong organisation of responsibilities and task.

A major contribution of the study presented in Papers II and III is the examples of people adapting to cope with disturbances in their everyday work environment. The work extends previous studies on adaptive performance with the focus on adaption-enabling factors and the development of a framework to analyse adaptive performance, offering guidance to researchers and practitioners. The framework supports retroactive analysis of situations, and pro-active safety management by capturing and analysing everyday situations. Also developed, are the variety space diagram and control-loop model to support the framework analysis by highlighting important aspects and relations that affect adaptive performance. The cases presented in the papers offer examples of framework application. The study suggests, in concurrence with many previous studies, that people hold great capabilities to adapt to unfolding events in a complex environment. The analyses demonstrate how multiple factors converge in time, enabling or hindering successful adaptive performance (strategies), including external forces, contextual factors, resources, expertise and support from management. The need to deviate from a plan, and in some cases outside procedure, sheds light on latent vulnerabilities in the system. However, the analyses also show that adaptive performance may create new vulnerabilities in the system. As previously discussed in literature, over time, many minor changes will change the system, sometimes in a direction that can lead to accidents (Cook \& Rasmussen, 2005; Kontogiannis, 2009). Learning from adaptive performance is thus more than identifying enabling factors; it is about understanding how different parts of the system (horizontally and vertically) affect each other and how systems change over time. The intent of the developed framework is to enhance current methods for safety 
management by offering different perspectives, with focus on the investigation of how forces and contextual factors enable success through adaptation, and the importance of monitoring and learning from adaptations in both the short and long term.

A key contribution of the study presented in Paper IV is the application of a sensemaking perspective to cockpit operations following unexpected events, demonstrating re-framing as a critical enabler for successful adaptation. The cases in the study provide several examples of the importance of pilot abilities to take action, with short time frames, in situations governed by uncertainty and ambiguity. A key finding from the study is demonstrating the significance of expectations and actions as part of the pilot's decision process to anticipate problems, test hypotheses and make sense of the current state. The developed crew-aircraft sensemaking model offers a description of the Data/Frame theory (Klein et al., 2007) as part of a joint system, and aims to illustrate the relationships between expectations (anticipatory thinking), actions, and how frames are constructed. The data-frame model captures the re-framing strategies found in the analysed cases, including two new sensemaking activities not previously mentioned in literature, "rapidframe switching" and "abandoning the search for a frame". The findings of the study further raise important issues regarding pilot training programs, which today focus on specific known problems, and less on processes critical to cope with unexpected events. Results from the study suggest three areas that deserve further attention, including further research questions about re-framing activities, improvement of training programs and identification of control strategies to cope with unexpected events.

In agreement with literature in CSE and RE the studies show that situations that go outside the textbook scenarios are a regular occurrence in complex socio-technical systems. Many of the gathered cases are narratives, told by practitioners, which may not be reported through the organisations' traditional reporting mechanisms, in many cases because the personnel deal with the situations successfully. The findings support previous studies of "work-as-done" (see e.g., Section 2.4), and together they make a strong case that adaptive performance at the sharp end plays a critical role in complex socio-technical systems' ability to cope with everyday variations and unexpected events, across domains and settings. Analysing everyday situations where people adapt can inform safety management by making visible limitations and opportunities of system design, organisational structures, procedures and training. Further, it can increase the understanding of what enables a system to adapt, allowing the systems to secure and improve its adaptive capacity.

In addition to the findings from the individual studies, the results section (Chapter 4) offers a cross-case analysis. The analysis demonstrates how next steps of a strategy 
framework analyses could be performed to obtain more generalisable results. Also, the cross-analysis shows that the categories used in the framework and models provide data that are indeed suitable for cross-analysis. It is expected that for a more homogenous set of examples (e.g., setting, domain, and contextual constraints), a cross-analysis would provide a useful assessment by visualising how a system deals with variations and disturbances at the boundaries of system performance. For example, identification of different types of adaptive strategies can make visible strengths and weaknesses in a system ability to cope with stresses and changes. Four adaptive strategy types identified in the analysis in Section 4.2.2 are: (1) re-structure roles and functions, (2) increase margins, (3) increase monitoring and (4) extend/compare knowledge. This type of analysis shows, for example, that a main adaptive strategy in relation to everyday stresses is increased monitoring of particular aspects to anticipate problems ahead. This observation raises questions on how to support monitoring skills, and how the increased workload of monitoring affects the overall safety. The analysis also shows that strategies for irregular occurrences mainly include extending/comparing knowledge and restructuring/prioritising the work. This observation raises important questions on, for example, how to target training to improve sensemaking and prioritising skills. The increased understanding that comes from learning about how a system adapts can thus be used for multiple purposes, such as (1) making changes to the system where vulnerabilities are found and (2) ensure abilities to cope with variations and disturbances are enabled through system design and training.

\subsection{Methodological reflections}

This section offers a discussion on the methodologies used in this thesis.

\subsubsection{Data gathering and analysis}

A large part of the data material in this thesis builds on narratives told by practitioners through interviews and focus groups (in Paper I observations were also carried out). Methodologies to gather narratives offer great possibilities to explore people's experiences and thought processes in relation to an event. However, it also imposes limitations on the validity of the data, and the generalisations that can be made from it.

As elaborated on in Section 3.2 the strength of interview and focus-group material is that it allows a capturing of the interviewees' experiences and point of view, including data on what was perceived as troublesome, challenging or confusing. Interviews may be the best means to gain in-depth insights into the thought process and individual experiences, which have been a focus in all studies, and of particular importance in Paper IV. Further, interview methodology is time-effective in the sense that it is possible to gather a lot of information regarding a case in a short time. 
The applied methodologies have several limitations, however. First, the interaction between the researcher and the participants will affect the data gathered. Data is a social construct between the two parties, affected by our expectations and personalities (Klein \& Myers, 1999). The studies in this thesis further include multiple parties present for each data collection session, including, multiple-participant (and researcher) role-exercise, focus groups, and interview studies with at least two interviewers per session. In other words, there are multiple sources influencing the elicited data, including focus of discussion, and how the researcher organises and understands the data. The interactions, personalities, and expertise of the researchers and participants thus affect the reliability of the studies, and it is conceivable (even likely) that other details or aspects of each case would be brought out in a different setting with other people involved. Second, in an interview/focus group setting participants have to recall previous events, which is associated with risks of subjectivity and the possibility of inaccuracies and incompleteness (Ericsson \& Simon, 1994). This fallacy may be particularly true for narratives that involve critical and emotional events that occurred years earlier, as are some of the narratives in this thesis. Third, eliciting expert knowledge in complex dynamic systems is challenging given the complexity of the tasks and work context. Respondents may vary in their ability to articulate this tacit knowledge. A narrative from an individual perspective about a complex setting is inherently incomplete, and obtaining valuable data relies on the interviewer's ability to uncover the intricacies of the specific situation, know when to ask further questions and feel confident that significant aspects are covered (Miller et al., 2006). Similarly, to observe work in complex environments requires sensitivity to the context and the ability to connect important details in a coherent fashion (Klein \& Myers, 1999; Woods \& Hollnagel, 2006a). From an observer's perspective, this task requires a balance between focusing on gaining detailed understanding of the work process and environment, and at the same time "zoom out" to search for patterns and identify "regular irregularities". The role and expertise of the researcher thus brings opportunities and limitation to studies. Limiting, in the sense of not understanding all the details of the context, and opportunities due to the advantage of identifying patterns across settings and cases (Woods \& Hollnagel, 2006a).

The consequences of the above-mentioned limitations for validity and reliability of the results should be viewed in relation to the individual study objectives, and how the data is used to make inferences about adaptive performance. Paper I uses a triangulation of different methods to capture the details of the exercise, thus increasing the internal validity of the data and results. Closely tied to the external validity of the results is the realism of the exercise, and how immersed the participants felt in the activity. Results from the after-action review and follow-up questionnaire suggest that the participants found the exercise realistic and an important learning experience (Trnka et al., 2016). In 
Papers II and III an exploratory approach was applied, and the objective was not clearly defined at the outset. An important part of the study was to let safety managers from different domains interact, to learn from each other and allow similarities and differences in their organisations to be discussed. The data gathered during the focus-group sessions are not necessarily complete or precise accounts of the incidents, but a source to investigate challenges and form hypotheses. Further, the analysis does not attempt to draw objective or quantifiable inferences as examples vary in type and depth. Instead, the focus has been to identify the constraints and cognitive demands in each context described. Similarly, in Paper IV, although objectives and discussions where more controlled than in Paper II, answers vary in type and depth, and the data is used to explore the individual experience rather than offer complete accounts of events.

Additionally, measures to counteract some of the limitations mentioned above included involving several analysts in reviewing and interpreting the data. Where several analysts were involved in coding the data, measures were taken to ensure inter-rater reliability, as in Paper IV. Also, when possible, practitioners were involved in validating the interpretations made of the data. This method of validation was widely applied in Paper IV, drawing on a network of experienced pilots and engineers to help interpret the data within an aviation context. There were, however, no opportunities to ask the interviewees themselves if they thought that the interpretations were correct. For the other two studies field experts were not an integrated part of the analysis process, but results were presented and discussed with experts in the field at project meetings and conferences. Throughout the work reported in this thesis opportunities to make observations have been limited (mainly performed in Paper I), although this method would be a valuable complement in future studies to validate the models developed and presented in Papers II, III and IV.

It might be argued that the number and diversity of the cases presented do not lend themselves to being generalised. This is true, insofar that the results are not sufficient to offer any normative conclusions about adaptive performance in the systems under study. What can be offered are accounts of situations that happen in today's complex system; descriptive results offering examples of how joint system adapt to variations and disturbances. The body of research already existing within, or related to, the fields of CSE and RE further strengthen the results. By linking the findings to theories and models in the field, as is done in the development of models, the validity of the findings increases, as does the general knowledge of the field.

\subsubsection{Analysing data through models}

The modeling approach taken here follows Hall and Fagen's (1968) notion of systems that it is the relationships between system objects and their properties (attributes) that 
make the notion of systems useful. In this view, the relations between system parts are in focus, allowing a way to investigate systems independently from their specific domain, through patterns of relations (Wears, 2011). The conceptual models developed in this research aim to illustrate such relationships. Adapting and developing models has offered a lens from which to view and structure the data. This approach further allows a connection to previous research and to future studies, building a repository of cases. In this sense, a combination of bottom-up data-driven explorative approach and top-down application of previous models and theories is applied. The model development has thus served multiple functions, including; (1) relating findings to previous theories and models, (2) visually representing the findings, (3) contrasting and analysing cases, and (4) developing tools to guide researchers and practitioners in analysing adaptive performance.

The validity and use of the models are important questions. One concern is the reliability of the data gathered, which is discussed in Section 5.2.1 (content validity). Another concern is how well the models are able to represent what is actually going on in the systems (external validity). Models of complex systems necessarily focus on certain aspects, and oversimplify others. Taking a complexity approach (in contrast to a reductionist view), and describing every detail of a system (if this task was even possible) will still not allow descriptions of emerging phenomena in on-going complex systems, and thus fails to predict future states with any certainty. This limitation does not mean, however, that using models does not serve an important purpose to simplify complex systems so that we can make sense and learn about them. However, as discussed by Human (2015), simplifications impose several considerations to keep in mind, for example, that system descriptions decompose the system to match the view of the researcher, and that the knowledge gained through a description is always relative to the perspective from which the description was made. This reflection does not mean that descriptions are invalid; it only states that a limited number of characteristics of the system can be considered by any specific description. In the case of the models developed in this research there are no attempts to make comprehensive models covering all processes, they necessarily focus on particular aspects, and attempt to uncover and depict relationships found in the data, using theory to guide observations. The application of the data across cases (Papers II, III and VI) and work domains (Papers II \& III) suggests that the categories of the models are relevant to analyse different settings. Further validation of the models could be done by, for example, (1) gaining consensus from researchers and practitioners with different background that important aspects of the work is captured and, (2) broaden the analysis to multiple settings and cases, to see if the similar adaptive phenomena is uncovered in other cases. The strategies framework presented in Papers II and III has been applied in two other studies (Höglund, 2013; Nilsson, 2012), validating 
the method as a useful tool to gather information on "work-as-done", and revealing new insights into the use of the framework. To realise its potential as a tool for practitioners, it should be tested and applied by practitioners, and adapted to fit as an integrated part of existing safety management methods (for a more elaborate discussion on this topic see Paper III).

To conclude, the models in this research are aimed at identifying and unravelling some of the underlying structures that govern adaptive systems. They can serve as a way to identify links between system inputs and outputs, provide a language to articulate, and guide the formation of new hypotheses on patterns that govern adaptive systems. It is likely that the adaptations could be visualised in other ways, bringing other aspects forward. However, the application across settings suggests that the aspects investigated are interesting to examine in other cases. Using a conceptual model such as the strategies framework allows each analyst to examine the local context and adapt the models as needed. In this sense, the limitations and challenges of developing conceptual models also enable individual flexibility.

\subsection{General discussion and challenges ahead}

The studies presented in this thesis are part of a body of research in Resilience Engineering (RE) that in the past decade has developed theories, methods and models, and identified indicators and patterns of how systems adapt to cope with dynamic complex systems. The combined work has verified the existence and importance of resilience, offering good motivation for the continued work to better understand adaptive performance to improve safety in complex systems. However, critical questions on how to measure, assess and improve adaptive performance are still unanswered. Below a few main points are discussed, and questions for further studies are suggested.

\section{Develop and validate theories, methods and tools}

Studying resilience in safety-critical organisations involves tackling some fundamental methodological challenges, such as not knowing exactly what to look for or when to look for it. The concept of resilience is broad, manifestations of resilience are varied, and it is an emergent phenomenon, which can only be fully understood in relation to the context in which it occurs. The development of indicators is thus an important step to validate and generalise results, and guide practitioners and researchers to know what to look for. To uncover the complexities of work in complex systems, case-based and contextdependent studies are a common approach in RE research, as have been used in this thesis. Although there are important strengths to a case-based methodology, it poses challenges to validate and generalise results. To cope with the methodological challenges thus requires iterative work of testing and re-testing theories and methods by researchers 
across settings to identify and validate key indicators and assessment tools. Although the specifics of each case may not translate between settings, the testing of theories and identification of underlying patterns offers the possibility of formulating general guidelines that are applicable in different settings. However, a recent literature review (Righi, Saurin, \& Wachs, 2015) highlighted that frameworks, guidelines and methods to identify and categorise resilience are often not further developed and validated. Further, the extent to which context-dependent adaptations can be generalised remains an open issue (Mendonça \& Wallace, 2015). The study presented in Papers II and III exemplifies how previous frameworks can be revised through analysis of more cases. The strategies framework has further been applied in two other studies (Höglund, 2013; Nilsson, 2012). Also, the cross-analysis in Chapter 4 demonstrates how to combine different cases under one framework. A more focused research agenda allowing cases of success and failure to be compared, and guidelines and assessment tools iteratively developed and validated could benefit research in RE.

Questions for further studies:

- What are key performance indicators?

- How can indicators be validated?

- To what extent can performance indicators be generalised to different settings and different layers of a system?

The development of indicators is useful to validate and generalise results and guide practitioners and researchers to know what to look for. However, the challenge will be to find sufficiently general indicators applicable to different settings, and yet specific enough to allow useful guidance. It may be found that only on an abstract, conceptual level can indicators be identified, leaving much of the assessment up to the analyst. The development of indicators requires consideration of factors such as local vs. global adaptations, and changes over time. Learning about local abilities to adapt is important, but for systems to be resilient over time requires an understanding for the global effect of local adaptations. For example; how are adaptations assessed on different layers? How can individual adaptations be assessed in the context of a larger system? What are the links between sharp-end adaptive capacity and an organisation's overall ability to adapt? With some exceptions (e.g., Mendonça \& Wallace, 2004) studies of RE have largely focused on sharp-end analysis, which poses important questions on the importance of the role of individuals compared to the overall organisation (Bergström, Van Winsen, \& Henriqson, 2015). The importance of adaptive performance on different layers of the system, and how they affect each other, is still fairly unexplored. 
Another important issue to consider is how to manage continuously evolving systems. For example, how are assessments and re-assessments made to detect and address changes over time? To what extent is it possible to anticipate system needs to adapt in the future? If the source of variation changes, how does this situation affect the system's ability to adapt? Interlinked with these queries is the topic of methodologies to capture indicators:

- What methods can be used to capture relevant measurements to assess adaptive performance (e.g., adaptive strategies, system boundaries, adaptation enablers)?

- What are strengths and weaknesses of different methods?

- How can different representations of a system add to the understanding of systems' adaptive abilities?

Through cross-evaluation of different methodologies to capture data related to adaptive performance, at different layers of the system, it is possible to improve validation and generalisation of assessments. Further, an evaluation could serve as a toolbox for practitioners and researchers to use and adapt to needs and goals of the current analysis. This approach includes the evaluation of conceptual tools to guide analysis with RE viewpoints and assumptions, and the use of specific methodologies, indicators, and measurements to assess performance. Example of methodologies may include, observations, interviews, group discussion guides, self-reporting tools, case and incident analyses methods, various quantifiable measurements (e.g., risk assessments) and computer-based modelling methods. Also, an evaluation should include a critical discussion to what extent it is possible to generalise indicators and measurements of adaptive performance.

\section{Applied resilience - linking resilience efforts to today's practice}

Observation and assessment methodologies commonly applied in RE today, such as the in-depth case-based analysis, are in many regards incompatible with the needs of, for example, safety managers, who require more applied and less time-consuming tools (Le Coze \& Herchin, 2014; Righi et al., 2015). There have been several advances in recent years (including the work in this thesis) to develop more practical tools and general guidelines for capturing "work-as-done", see for example, (Hollnagel, 2011; Huber, Van Wijgerden, Witt, \& Dekker, 2009; Rankin et al., 2014; Woltjer, Pinska-Chauvin, Laursen, \& Josefsson, 2015). However, good examples and accessible techniques to guide practitioners in RE approaches are few and far apart. Further, more efforts should be made to understand what is already captured using traditional safety reporting mechanisms in industry today, and how RE techniques can complement these. RE aims to guide the process of re-framing views and assumptions about systems, not discard the developed methods already in place (Hollnagel, 2011). What is already used in organisations today 
should be the starting-point, and complemented by new methods where required. For example, incident reports and analyses offer insights on where the boundaries of adaptive performance have been exceeded (Woods \& Cook, 2006). Questions should be steered toward understanding the information required to complement current analyses, and make visible system adaptive abilities. The strategies framework is an example of a complementary tool to incident and risk analysis, focusing attention on capturing stories of success, and thus describing what is within the performance boundaries. However, as with all developed guidelines and tools, users must adjust the implementation to target each system's current methods and goals. For example, in crisis management the strategies framework could serve as a valuable tool during and after exercises to discuss strategies and their effect on the performance of the team. In aviation and health care, however, the strategies framework could function as an online-reporting mechanism to capture everyday adaptations.

Questions for further studies:

- To what extent are manifestations of resilience already captured in today's reporting mechanisms, such as, risk assessments and incident analysis?

- How well do the methods capture strength and vulnerabilities of the systems' ability to adapt?

Depending on the specifics of the study, new methods may not always be required for assessment of systems adaptive abilities, it may be sufficient to include new ways to analyse and interpret already reported data.

- How can previous methods be expanded/adjusted to increase understanding for system adaptive abilities?

- What resources are required to integrate new methodologies?

The introduction of complementary methods includes understanding what requirements are essential for integrating new methodologies in today's safety work, such as time, resources, and necessary background knowledge. Tools designed for industry should further consider cost-benefit analyses as part of the evaluation of strengths and weaknesses.

\section{Resilience Engineering to evaluate and improve system safety}

Similar to the studies presented in this thesis a majority of the research in RE focuses on describing resilient performance rather than assessing and improve it (Nemeth \& Herrera, 2015; Righi et al., 2015). For example, tools such as the strategies framework supports identification and awareness of resilience at the sharp end (an important first step), but does not offer much support on how to assess resilience at a larger scale, and offers little 
guidance on how to improve system resilience. Similarly, more renowned guiding tools, such as the Resilience Analysis Grid (Hollnagel, 2011), offer support on what questions to ask and how to structure an analysis, but no aid in how to interpret results and improve their systems based on it.

In the next phase RE should demonstrate what is possible to achieve, and how a resilience perspective contributes to the safety of complex systems. Although previously emphasised that resilience is about shifting perspectives, and that assessments and enhancements should be managed by the systems current approaches (Hollnagel, 2011), there is a need to go beyond suggested guidelines and indicators to demonstrate and validate valuable improvements made by applying a resilience perspective (Nemeth \& Herrera, 2015). For example, findings in this thesis suggests training as a key to improve abilities of sharp end personnel for successful adaptation in the face of unexpected events. Next steps would be to integrate these findings into training programs, and evaluate the effects in the short and long term. Evaluation methods may include the development of guidelines, milestones and indicators to assess when each milestone is reached. An example of such an initiative is the development of the resilience maturity model for city resilience (website: smr-project.eu). The maturity model includes five stages, and concrete actions on how to progress from one stage to the next. A set of indicators are developed to help evaluate progress. The development of similar strategic support tools as part of an RE toolbox could be an important tool to attract practitioners.

While the necessity and benefits of adaptive capacity has been keenly argued, vulnerabilities that are created by enabling adaptive capacity and adaptation reverberations should not be forgotten. In line with previous studies (Koopman \& Hoffman, 2003; Woods \& Dekker, 2000), the studies in this thesis include examples demonstrating that system changes introduce new vulnerabilities. Changing system structures to enable more flexible and adaptive abilities to cope with disturbances and unexpected events will create new challenges, which practitioners must monitor carefully.

\section{Questions for further studies:}

- What does it mean to design for resilience?

- What does it mean to operationalise resilience on a larger scale?

- How can the effects be evaluated?

Making visible "work-as-done" and mapping out the adaptive performance landscape of a system has been the focus of RE research so far. Next steps include using this information to improve system resilience, on large and small scales, for immediate use and over time. 
- In what areas of system design evolution does RE play a role?

- Can generic and objective models be used to inform system design and training principles?

With the view of RE as an approach to re-frame the viewpoints and assumptions made about the system, its contributions can be found in all stages of the design evolution. To this end, it may be possible to develop guides and tools to ask critical questions during different phases. The support may include guidance for needs and requirements assessment, the development and introduction of new technology and changes in procedures and organisational structure. It remains open to explore what such guidelines could look like and who they are best suited for (e.g., engineers, safety managers, and operators). More specific assessments of adaptive performance may, however, target particular phases. Either way, RE is an approach to complement, not replace, current work and should thus function as part of a team effort with engineering or safety management teams to improve system safety.

- Are there parts of "resilience" that may also be counter-productive?

- How can system changes be evaluated over time?

There is no one solution to fit all systems, and there are no simple or complete solutions. Changes made to improve resilience will introduce new opportunities as well as challenges. Finding the right balance between robust and flexible system structures to be efficient and cope with known variations, and at the same time be prepared to cope with variability and surprise will be a challenging task. Further, the design for resilience has to take into consideration system "trade-offs" such as pressures for systems to be "faster, better, cheaper" (Woods \& Branlat, 2011) as part of the equation. Increasing resilience involves understanding what is required to sustain adaptive capacity over time, to see trends, to capture brittle points and to continuously evaluate the adaptive strategies available. 


\subsection{Conclusion}

The main aim of this research is to examine how adaptive performance in response to variations and unexpected events at the sharp end can be analysed. Paper I offers a demonstration on how it is possible to perform an in-depth analysis of a complex situation involving multiple data sources and parallel events. Papers II and III provide a collection of cases where people adapt to cope with disturbances in their everyday work environment, which has guided the development of a strategies framework for analysing adaptive performance. Paper IV establishes how an analyst can use sensemaking theory to analyse how people re-frame following unexpected events. In addition to the findings from the studies, the introductory section of this thesis presents a cross-case analysis. The analysis demonstrates how next steps of a strategy framework analysis could be performed, including multiple cases to allow more generalisable results.

The cases analysed in the studies tell a different story than the textbook situations of what people do at work. Together with a growing body of literature examining "work-as-done" the cases demonstrate that adapting outside textbook scenarios it is a regular occurrence in complex socio-technical systems. Results suggest that adaptive performance at the sharp end plays a critical role to cope with system variations and unexpected events across domains and settings.

The cases described in this thesis are, for the most part, practitioner narratives, which may not surface through the organisations' traditional reporting mechanisms because people deal with the situations successfully. A significant finding from the analysed examples is the importance of understanding adaptation enablers/disablers and how adaptation affect other parts of the system. Adaptations that have a positive effect in one part may have unanticipated and unintended side-effects in other system parts. This important point emphasises the need to monitor and analyse when things "go right" as the effects of adaptations are difficult to identify and anticipate if they are not recognised. Through careful monitoring and learning from adaptations it is possible to identify combinations of circumstances, forces and goals that create system brittleness as the system is pushed toward its boundaries of safe operation.

Characterising and analysing adaptive performance in high-risk work, where consequences of failures may have substantial effect on life and property, can inform safety management by making visible limitations of system design, organisational structures, procedures and training. This approach provides information on a safetycritical system's ability to adapt to disturbances, and what enables and hinders such abilities. Analysing sharp-end adaptations offers new perspectives on how to improve safety and the ability to deal with unexpected and unforeseen events. 


\section{Bibliography}

Ackoff, R. L. (1971). Towards a system of systems concepts. Management Science, 17(11), 661-671.

Alter, S. (2014). Theory of workarounds. Communications of the Association for Information Systems, 34(55), 1041-1066.

Aminoff, H., Johansson, B., \& Trnka, J. (2007). Understanding coordination in emergency responses. In Proceedings of the EAM European Annual Conference on Hum Decision Making and Manual Control. Lyngby, DK.

Ashby, R. (1956). An Introduction to Cybernetics. London: Chapman \& Hall Ltd.

Bergström, J., Van Winsen, R. Van, \& Henriqson, E. (2015). On the rationale of resilience in the domain of safety: A literature review. Reliability Engineering and System Safety, 141, 131-141.

Bertalanffy, L. Von. (1950). The theory of open systems in physics and biology. Science, 111(2872), 23-29.

Boddy, C. (2005). A rose by any other name may smell as sweet but "group discussion" is not another name for a "focus group" nor should it be. Qualitative Market Research: An International Journal, 8(3), 248-255.

Campbell, D. (2012). Public managers in integrated services collaboratives: What works is workarounds. Administration Review, 72, 721-730.

Chelariu, C. (2002). Learning to improvise, improvising to learn: A process of responding to complex environments. Journal of Business Research, 55(2), 141-147.

Christoffersen, K., Woods, D. D., \& Blike, G. T. (2007). Discovering the events expert practitioners extract from dynamic data streams: The modified unit marking technique. Cognition, Technology and Work, 9(2), 81-98.

Cook, R. I. (1998). Being bumpable. In Presentation at Fourth Conference on Naturalistic Decision Making. Warrenton, VA, May 29-31, 1998.

Cook, R. I., \& Rasmussen, J. (2005). "Going solid": A model of system dynamics and consequences for patient safety. Quality \& Safety in Health Care, 14(2), 130-134. 
Cook, R. I., Render, M., \& Woods, D. D. (2000). Gaps in the continuity of care and progress on patient safety. BMJ (Clinical Research Ed.), 320(7237), 791-794.

Cooper, R., \& Foster, M. (1971). Sociotechnical systems. American Psychologist, 26, $467-474$.

Crandall, B., Klein, G. A., \& Hoffman, R. R. (2006). Working minds: A practitioner's guide to cognitive task analysis. Cambridge, MA: MIT Press.

Crossan, M. M. (1998). Improvisation in action. Operations Research, (5), 593-600.

Cunha, P. (1999). Organizational improvisation. What, When, How and Why, 1(3), 299341.

Dekker, S. (2002). Reconstructing human contributions to accidents: The new view on error and performance. Journal of Safety Research, 33, 371-385.

Dekker, S., Cilliers, P., \& Hofmeyr, J. (2011). The complexity of failure: Implications of complexity theory for safety investigations. Safety Science, 49(6), 939-945.

Dekker, S. (2004). Ten questions about human error: A new view of human factors and system safety. Mahwah, NJ: Lawrence Erlbaum Associates, Inc.

Dervin, B. (1983). An overview of sensemaking research: Concepts, methods, and results to date. In Paper presented at the annual meeting of the International Communication Association. Dallas, TX, May. Available: http:// communication.sbs.ohio-state.edu/sense-making/art/artdervin83. html

Endsley, M. R. (2006). Situation awareness. In G. Salvendy (Ed.), Handbook of Human Factors and Ergonomics (pp. 528-542). John Wiley \& Sons, Inc., Hoboken, NJ, USA

Ferneley, E., \& Sobreperez, P. (2006). Resist, comply or workaround: An examination of different facets of user engagement with information systems. European Journal of Information Systems, 15, 345-356.

Field, J., Woltjer, R., \& Rankin, A. (2015). Experimental investigation of flight crew strategies in handling unexpected events. In Proceedings of the 18th International Symposium on Aviation Psychology. Dayton, OH.

Fischoff, B. (1975). Hindsight is not foresight: The effect of outcome knowledge on judgement under uncertainty. Journal of Experimental Psychology: Human Perception and Performance, 1(3), 288-299.

Flach, J. M. (2000). Discovering situated meaning: An ecological approach to task analysis. In J. M. Schraagen, S. F. Chipman, \& V. J. Shalin (Eds.), Cognitive task analysis (pp. 87-100). Mahwah, NJ: Lawrence Erlbaum.

Flach, J. M. (2012). Complexity: Learning to muddle through. Cognition, Technology \& Work, 14, 187-197. 
Flanagan, J. C. (1954). The critical incident technique. Psychology Bulletine, 51, 327358.

Frankfort-Nashmias, C., \& Nashmias, D. (1996). Research methods in the social sciences (fifth edit). London, UK: St Martins Press, Inc.

Furniss, D., Back, J., Blandford, A., Hildebrandt, M., \& Broberg, H. (2011). A resilience markers framework for small teams. Reliability Engineering \& System Safety, 96(1), $2-10$.

Grote, G., Weichbrodt, J. C., Günter, H., Zala-Mezö, E., \& Künzle, B. (2008). Coordination in high-risk organizations: The need for flexible routines. Cognition, Technology \& Work, 11(1), 17-27.

Grøtan, T. O., Størseth, F., Rø, M. H., \& Skjerve, A. B. (2008). Resilience, adaptation and improvisation - increasing resilience by organising for successful improvisation. In Proceedings of the 3rd Symposium on Resilience Engineering. Juan-les-Pins, France.

Hadida, A. L., \& Tarvainen, W. (2015). Organizational improvisation: A consolidating review and framework. International Journal of Management Reviews, 17(4), 437459.

Hall, A. D., \& Fagen, R. E. (1968). Definition of system. In W. F. Buckley (Ed.), Modern systems research for the behavioural scientist (pp. 81-92). Chicago, IL: Aldine Publishing Company.

Hammond, R. R. (1993). Naturalistic decision making from a brunswikian viewpoint: Past, present and future. In G. A. Klein, J. Orasanu, \& R. Calderwood (Eds.), Decision making in action: Models and Methods. Norwood, NJ: Ablex.

Harms-Ringdahl, L. (2001). Safety analysis. Boca Raton, FL: CRC Press.

Hoffman, R. R., Crandall, B., \& Shadbolt, N. (1998). Use of the critical decision method to elicit expert knowledge: A case study in the methodology of cognitive task analysis. Human Factors, 40(2), 254-276.

Hoffman, R. R., Henderson, S., Moon, B., David, T., \& Litman, J. A. (2011). Reasoning difficulty in analytical activity. Theoretical Issues in Ergonomics Science, 12(3), $225-240$.

Hoffman, R. R., \& Mcneese, M. D. (2009). A history for macrocognition. Journal of Cognitive Engineering and Decision Making, 3(2), 97-110.

Hoffman, R. R., \& Woods, D. D. (2011). Beyond simon's slice: Five fundamental tradeoffs that bound the performance of macrocognitive work systems. IEEE Intelligent Systems, 26(6), 67-71.

Holling, C. (1973). Resilience and stability of ecological systems. Annual Review of Ecological Systems, (4), 1-23. 
Hollnagel, E. (2004). Barrier and accident prevention. Aldershot, UK: Ashgate Publishing Limited.

Hollnagel, E. (2009). The four cornerstones of resilience engineering. In E. Hollnagel \& S. Dekker (Eds.), Resilience Engineering Perspectives, Vol 2 - Preparation and Restoration (pp. 117-133). Farnham, UK: Ashgate Publishing Limited.

Hollnagel, E. (2011). Epilogue: RAG- the resilience analysis grid. In E. Hollnagel, J. Paries, D. D. Woods, \& J. Wreathall (Eds.), Resilience Engineering in Practice, Vol 1. Farnham, UK: Ashgate Publishing Limited.

Hollnagel, E. (2012a). Coping with complexity: Past, present and future. Cognition, Technology \& Work, 14(3).

Hollnagel, E. (2012b). Resilience engineering and the systemic view of safety at work: Why work-as-done is not the same as work-as-imagined. In Bericht zum 58. Kongress der Gesellschaft für Arbeitswissenschaft vom 22 bis 24 Februar 2012. (pp. 19-24). Dortmund: Gfa-Press.

Hollnagel, E. (2014). Safety-I and Safety-II - the past and future of safety management. Farnham, UK: Ashgate Publishing Limited.

Hollnagel, E., Nemeth, C. P., \& Dekker, S. (2008). Resilience engineering perspectives: Remaining sensitive to the possibility of failure, Vol 1. Aldershot: Ashgate Publishing Limited.

Hollnagel, E., Pariès, J., Woods, D. D., \& Wrethall, J. (2011). Resilience engineering in practice: A guidebook, Vol 1. Farnham, Surrey, UK: Ashgate Publishing Limited.

Hollnagel, E., Pedersen, O. M., \& Rasmussen, J. (1981). Notes on human performance analysis (Risø-M-2285).Roskilde, Denmark: Risø National Laboratory, Electronics Department.

Hollnagel, E., \& Woods, D. D. (1983). Cognitive systems engineering: New wine in new bottles. International Journal of Man-Machine Studies, 18, 583-600.

Hollnagel, E., \& Woods, D. D. (2005). Joint cognitive systems: Foundations of cognitive systems engineering. Boca Ranton: CRC Press, Taylor \& Francis Group.

Hollnagel, E., Woods, D. D., \& Leveson, N. (2006). Resilience engineering: Concepts and precepts. Aldershot, UK: Ashgate Publishing Limited.

Huber, S., Van Wijgerden, I., Witt, A., \& Dekker, S. (2009). Learning from organizational incidents: Resilience engineering for high-risk process environments. Process Safety Program, 28(1), 90-95.

Human, O. (2015). Complexity: E-special introduction. Theory, Culture \& Society, (3), 1-20.

Hutchins, E. (1995). Cognition in the wild. Cambridge, MA: MIT. 
Höglund, F. (2013). The use of resilience strategies in crowd management at a music festival. (Master thesis). Linköping, Sweden: Linköping University Press. Retrieved from: http://liu.diva-portal.org/smash/get/diva2:659638/FULLTEXT01.pdf

Kamoche, K. (2003). Towards a theory of organizational improvisation. Looking Beyond the Jazz Metaphor, 40(8), 2023-2051.

Klein, G. A., Calderwood, R., \& MacGregor, D. (1989). Critical decision method for eliciting knowledge. IEEE Trans Syst Man Cybern, 19(3), 462-472.

Klein, G. A., Klein, D. E., Hoffman, R. R., \& Hollnagel, E. (2003). Macrocognition. IEEE Intelligent Systems, 18(3), 81-85.

Klein, G. A., Phillips, J. K., Rall, E. L., \& Peluso, D. a. (2007). A data-frame theory of sensemaking. In Expertise Out of Context: Proceedings of the Sixth International Conference on Naturalistic Decision Making (pp. 115-155). Boca Raton, FL: Taylor and Francis.

Klein, G. A., Pliske, R., Crandall, B., \& Woods, D. D. (2004). Problem detection. Cognition, Technology \& Work, 7(1), 14-28.

Klein, G. A., Snowden, D., \& Pin, C. (2011). Anticipatory thinking. In K. L. Mosier \& U. M. Fischer (Eds.), Informed by Knowledge: Expert Performance in Complex Situations (pp. 1-10). New York, NY. Taylor and Francis Group.

Klein, G. A., Wiggins, S., \& Dominguez, C. O. (2010). Team sensemaking. Theoretical Issues in Ergonomics Science, 11(4), 304-320.

Klein, H. K., \& Myers, M. D. (1999). A set of principles for conducting and evaluating interpretive field studies in information systems. MIS Quarterly, 23(1), 67-93.

Kontogiannis, T. (1999). User strategies in recovering from errors in man-machine systems. Safety Science, 32, 49-68.

Kontogiannis, T. (2009). A contemporary view of organizational safety: Variability and interactions of organizational processes. Cognition, Technology \& Work, 12(4), 231249.

Koopman, P., \& Hoffman, R. R. (2003). Work-arounds, make-work and kludges. IEEE Intelligent Systems, (Nov./Dec.), 70-75.

Korolija, N. (1998). Episodes in talk. Constructing coherence in multiparty conversation. (Doctoral thesis). Linköping, Sweden: Linköping University Press

Korolija, N., \& Linell, P. (1996). Episodes: coding and analyzing coherence in multiparty conversations. Linguistics, 34, 799-831.

Korolija, N., \& Lundberg, J. (2010). Speaking of human factors: Emergent meanings in interviews with professional accident investigators. Safety Science, 48(2), 157-165. 
Kulling, P., Sigurdsson, S., \& Hamberger, B. (2008). KAMEDO report no. 92: Evacuation of Swedes from Lebanon-Observational studies in connection with the war in Lebanon in summer 2006. Prehosp Disaster Med, 23, 376-480.

Larsson, P. (2008). Prepared to go anywhere. SRSA Magazine, December.

Le Coze, J. C., \& Herchin, N. (2014). Describing and prescribing for safe operations within a large technical system (LTS): First reflections. In C. P. Nemeth \& E. Hollnagel (Eds.), Resilience engineering in practice, Vol 2: Becoming resilient. (pp. 13-32). Aldershot: Ashgate Publishing Limited.

Lundberg, J., \& Rankin, A. (2014). Resilience and vulnerability of small flexible crisis response teams: implications for training and preparation. Cognition, Technology \& Work, 16(2), 143-155.

Lundberg, J., Rollenhagen, C., \& Hollnagel, E. (2009). What-you-look-for-is-what-youfind - The consequences of underlying accident models in eight accident investigation manuals. Safety Science, 47(10), 1297-1311.

Lundberg, J., Rollenhagen, C., Hollnagel, E., \& Rankin, A. (2012). Strategies for dealing with resistance to recommendations from accident investigations. Accident Analysis and Prevention, 45, 455-467.

Malakis, S., \& Kontogiannis, T. (2013). A sensemaking perspective on framing the mental picture of air traffic controllers. Applied Ergonomics, 44(2), 327-339.

Manyena, S. B. (2006). The concept of resilience revisited. Disasters, 30(4), 433-450.

Masten, A. S. (2001). Ordinary magic: Resilience processes in development. American Psychologist, 56(3), 227-238.

McDaniels, T., Chang, S., Cole, D., Mikawoz, J., \& Longstaff, H. (2008). Fostering resilience to extreme events within infrastructure systems: Characterizing decision contexts for mitigation and adaptation. Global Environmental Change, 18(2), 310318.

Mendonça, D. (2008). Measures of resilient performance. In E. Hollnagel, P. Nemeth, C. P., \& S. Dekker (Eds.), Resilience engineering perspectives, Vol 1: Remaining sensitive to the possibility of failure (pp. 29-46). Aldershot: Ashgate Publishing Limited.

Mendonça, D., Beroggi, G. E. G., \& Wallace, W. A. (2001). Decision support for improvisation during emergency response operations. International Journal of Emergency Management, 1(1), 30-38.

Mendonça, D., \& Fiedrich, F. (2006). Training for improvisation in emergency management: opportunities and limits for information technology. International Journal of Emergency Management (IJEM), 3(4), 348-363. 
Mendonça, D., \& Wallace, W. A. (2004). Studying organizationally-situated improvisation in response to extreme events. International Journal of Mass Emergencies and Disasters, 22(2), 5-30.

Mendonça, D., \& Wallace, W. A. (2015). Factors underlying organizational resilience: The case of electric power restoration in New York City after 11 September 2001. Reliability Engineering and System Safety, 141, 83-91.

Miles, M., \& Huberman, M. (1994). Qualitative data analysis: An expanded sourcebook. Thousand Oaks, CA: Sage Publications.

Miller, J. E., Patterson, E. S., \& Woods, D. D. (2006). Elicitation by critiquing as a cognitive task analysis methodology. Cognition, Technology and Work, 8, 90-102.

Moorman, C., \& Miner, A. S. (1998). Organizational improvisation and organizational Memory. The Academy of Management Review, 23(4), 698.

Morgan, D. L. (1997). Focus groups as qualitative research. Thousand Oaks, CA: Sage Publications.

Mumaw, R., Roth, E., Vicente, K., \& Burns, C. (2000). There is more to monitoring a nuclear power plant than meets the eye. Human Factors: The Journal of the Human Factors and Ergonomics Society, 42(1), 36-55.

Mumaw, R., Sarter, N. B., \& Wickens, C. (2001). Analysis of pilots monitoring and performance on an automated flight deck. In Proceedings of the 11th International Symposium on Aviation Psychology. Columbus, $\mathrm{OH}$.

Neisser, U. (1976). Cognition and reality: Principles and implications of cognitive psychology. San Francisco, CA: W. H. Freeman and Company.

Nemeth, C., Cook, R., \& Woods, D. D. (2004). The Messy Details: Insights from the Study of Technical Work in Healthcare. IEEE Transactions on Systems, Man, and Cybernetics - Part A: Systems and Humans, 34(6), 689-692.

Nemeth, C. P., \& Herrera, I. (2015). Building change: Resilience engineering after ten years. Reliability Engineering and System Safety, 141, 1-4.

Nemeth, C. P., \& Hollnagel, E. (2014). Resilience engineering in practice, Vol 2: Becoming resilient. Farnham, UK: Ashgate Publishing Limited.

Nemeth, C. P., Hollnagel, E., \& Dekker, S. (2009). Resilience engineering perspectives, Vol 2: Preparation and restoration. Farnham, UK: Ashgate Publishing Limited.

Nemeth, C. P., Nunnally, M., O’Connor, M. F., Brandwijk, M., Kowalsky, J., \& Cook, R. I. (2007). Regularly irregular: how groups reconcile cross-cutting agendas and demand in healthcare. Cognition, Technology \& Work, 9(3), 139-148.

Nilsson, L. (2012). Påverkan och störningar: En kvalitativ studie om yttre påverkan på trafikledare $i$ störda lägen på DLC Hallsberg. (Master thesis). Linköping, Sweden: Linköping University Press. Retrieved from: diva2:535297/ FULLTEXT01.pdf. 
Norman, D. (1990). The design of everyday things. New York, NY: Doubleday.

Orlikowski, W. J., \& Baroudi, J. J. (1991). Studying information technology in organisation: Research approaches and assumptions. Information Systems Research, 2(1), 1-28.

Orton, J. D., \& Weick, K. E. (1990). Coupled systems: A reconceptualization. The Academy of Management Review, 15(2), 203-223.

Patterson, E. S., Roth, E. M., Woods, D. D., Chow, R., \& Gomes, J. O. (2004). Handoff strategies in settings with high consequences for failure: Lessons for health care operations. International Journal for Quality in Health Care, 16(2), 125-132.

Patton, M. Q. (1990). Qualitative evaluation and research methods. Thousand Oaks, CA: Sage Publications.

Perrow, C. (1984). Normal accidents: Living with high-risk technologies. New York: Basic Books.

Pollock, N. (2005). When is it a work-around? Conflict and negotiation in computer systems development. Science, Technology, and Human Values, 30, 1-19.

Rankin, A. (2008). Utredningar vid ett kärnkraftverk - tre utredares syn på utredningsarbetet. Linköping University.

Rankin, A. (2009). Rollimprovisation vid responsinsatser: En studie av en ledningsövning för Svenska Stödstyrkan. (Master Thesis) Linköping, Sweden: Linköping University Press. Retrieved from: http://liu.divaportal.org/smash/get/diva2:273037/FULLTEXT01.pdf

Rankin, A., Dahlbäck, N., \& Lundberg, J. (2013). A case study of factor influencing role improvisation in crisis response teams. Cognition, Technology \& Work, 15(1), 7993.

Rankin, A., Kovordanyi, R., \& Eriksson, H. (2010). Episode analysis for evaluating response operations and identifying training needs. In Proceedings of NordiCHI conference. Reykjavik, Iceland.

Rankin, A., Lundberg, J., \& Woltjer, R. (2011). Resilience strategies for managing everyday risks. In Proceedings of the 4th Resilience Engineering Association Symposium. Sophia Antipolis, France.

Rankin, A., Lundberg, J., Woltjer, R., Rollenhagen, C., \& Hollnagel, E. (2014). Resilience in everyday operations: A framework for analyzing adaptations in high-risk work. Journal of Cognitive Engineering and Decision Making, 8(1), 7897.

Rankin, A., Woltjer, R., Field, J., \& Woods, D. D. (2013). "Staying ahead of the aircraft" and managing surprise in modern airliners. In Proceedings of 5th Resilience Engineering Association Symposium. Soesterberg, the Netherlands. 
Rasmussen, J. (1974). Mental procedures in real life tasks: A case study of electronic trouble shooting. Ergonomics, 17(3), 293-307.

Rasmussen, J. (1986). Information processing and human-machine interaction: an approach to cognitive engineering. New York: North-Holland.

Rasmussen, J. (1997). Risk management in a dynamic society: A modelling problem. Safety Science.

Rasmussen, J., \& Lind, M. (1981). Coping with complexity. In Proceedings of the First European Annual Conference on Human Decision Making and Manual Control, Delft University of Technology (Vol. 14, p. pp 69-91). Delft, The Netherlands, 2527 May.

Reason, J. T. (1990). Human error. Cambridge, U.K.: Cambridge University Press.

Reason, J. (1997). Managing the risks of organizational accidents. Burlington, VT: Ashgate Publishing Limited.

Righi, A. W., Saurin, T. A., \& Wachs, P. (2015). A systematic literature review of resilience engineering: Research areas and a research agenda proposal. Reliability Engineering \& System Safety, 141, 142-152.

Ropohl, G. (1999). Philosophy of socio-technical systems. Research in Philosophy and Technology, 4(3), 186-194.

Shannon, C., \& Weaver, W. (1969). The mathematical theory of communication. Urbana, Illinois: University of Illinois Press.

Simmie, J., \& Martin, R. (2010). The economic resilience of regions: towards an evolutionary approach. Cambridge Journal of Regions, Economy and Society, 3(1), 27-43.

Simon, H. (1969). The Sciences of the Artificial. MIT Press.

Sklet, S. (2004). Comparison of some selected methods for accident investigation. Journal of Hazardous Materials, 111(April), 29-37.

Trnka, J., \& Johansson, B. (2009). Collaborative command and control practice: Adaptation, self-regulation and supporting behaviour. Int. J. Information Systems for Crisis Response and Management, 1(2), 47-67.

Trnka, J., Lundberg, J. and Jungert, E. (2016) Design and evaluation of a role improvisation exercise for crisis and disaster response teams, Int. J. Information Technology and Management, Vol. 15, No. 3, pp.251-271.

Trnka, J., Rankin, A., Jungert, E., Lundberg, J., Granlund, R., Granlund, H., \& Johansson, B. (2009). Information support in modern crisis and disaster response operations. (Project Report). Linköping, Sweden. Retrieved from:

https://www.ida.liu.se/divisions/hcs/research/saf-sec/projects/SRV-response_sven.pdf 
Trotter, M. J., Salmon, P. M., Lenné, M. G., Trotter, M. J., Salmon, P. M., \& Lenné, M. G. (2016). Improvisation: Theory, measures and known influencing factors. Theoretical Issues in Ergonomics Science, 14(5), 475-498.

Vera, D., \& Crossan, M. (2004). Theatrical improvisation: Lessons for organizations. Organizational Studies, 16(3), 203-224.

Vera, D., \& Crossan, M. (2005). Improvisation and innovative performance in teams. Organization Science. 16(3), 203-224.

Wachtendorf, T. (2004). Improvising 9/11: Organizational improvisation following the world trade centre disaster. (Doctoral thesis). University of Delaware, US.

Walker, J., \& Cooper, M. (2011). Genealogies of resilience: From systems ecology to the political economy of crisis adaptation. Security Dialogue, 42(2), 143-160.

Wears, R. L. (2011). Exploring the dynamics of resilient performance. (Doctoral thesis), Business administration. Ecole Nationale Sup'erieure des Mines de Paris, Paris, France. Retrieved from: https://pastel.archives-ouvertes.fr/pastel-00664145

Webb, G. (2004). Role improvising during crisis situations. International Journal of Emergency Management, 2(1/2), 47.

Weick, K. E. (1995). Sensemaking in organisations. Thousand Oaks, CA: Sage.

Weick, K. E. (1998). Introductory essay: Improvisation as a mindset for organizational Analysis. Organization Science, 9(5), 543-555.

Weick, K. E., Sutcliffe, K. M., \& Obstfeld, D. (2005). Organizing and the process of sensemaking. Organization Science, 16(4), 409-421.

Wibeck, V. (2000). Fokusgrupper - om fokuserade gruppintervjuer som undersökningsmetod. Lund, Sweden: Studentlitteratur AB.

Wiener, N. (1948). Cybernetics: or control and communication in the animal and the machine. Cambridge, MA: MIT Press.

Wiener, N. (1965). Cybernetics. Cambridge, MA: MIT Press.

Woltjer, R., Field, J., \& Rankin, A. (2015). Adapting to the unexpected in the cockpit. In Proceedings of the 6th Resilience Engineering Association Symposium. Lisbon, Portugal.

Woltjer, R., Pinska-Chauvin, E., Laursen, T., \& Josefsson, B. (2015). Towards understanding work-as-done in air traffic management safety assessment and design. Reliability Engineering and System Safety, 141, 115-130.

Woods, D. D. (1993). Process tracing methods for the study of cognition outside of the experimental psychology laboratory. In Decision making in action: Models and Methods (pp. 228-251). Norwood, NJ: Ablex Publ 
Woods, D. D. (2006). Essential characteristics of resilience. In E. Hollnagel, D. D. Woods, \& N. Leveson (Eds.), Resilience Engineering: Concepts and Precepts. Farnham, UK: Ashgate Publishing Limited.

Woods, D. D. (2015). Four concepts for resilience and the implications for the future of resilience engineering. Reliability Engineering and System Safety, 141, 5-9.

Woods, D. D. (2016). On the origins of cognitive systems engineering: Personal reflections. In P. Smith \& R. R. Hoffman (Eds.), Cognitive Systems Engineering: A Future for a Changing World (pp. 1-28).

Woods, D. D., \& Branlat, M. (2011). How human adaptive systems balance fundamental trade-offs: Implications for polycentric governance architectures. In Proceedings of $4^{\text {th }}$ Resilience Engineering Association Symposium. Sophia Antipolis, France.

Woods, D. D., \& Cook, R. I. (2006). Incidents - markers of resilience or brittleness? In E. Hollnagel, D. D. Woods, \& N. Leveson (Eds.), Resilience Engineering: Concepts and Precepts. Aldershot, UK: Ashgate Publishing Limited.

Woods, D. D., \& Dekker, S. (2000). Anticipating the effects of technological change: A new era of dynamics for human factors. Theoretical Issues in Ergonomic Science, 1(3), 272-282.

Woods, D. D., Dekker, S., Cook, R. I., Johannesen, L., \& Sarter, N. B. (2010). Behind human error (2nd Ed.). Aldershot, UK: Ashgate Publishing Limited.

Woods, D. D., \& Hollnagel, E. (2006a). Joint cognitive systems engineering: Patterns in cognitive systems engineering. Boca Raton, FL, US: CRC Press, Taylor \& Francis Group.

Woods, D. D., \& Hollnagel, E. (2006b). Prologue. In E. Hollnagel, D. D. Woods, \& N. Leveson (Eds.), Resilience engineering: Concepts and precepts. Aldershot, UK: Ashgate Publishing Limited

Zolli, A., \& Healy, A. M. (2012). Resilience: Why things bounce back. London, UK: Headline Publishing Group.

Zsambok, C. E., \& Klein, G. A. (1997). Naturalistic decision making. Mahwah, New Jersey: Lawrence Erlbaum Associates, Publishers. 


\section{Appendix A}

\section{Focus group set-up (Paper II)}

The focus groups took place on two separate days. Each occasion was a full-day event, starting at 9 a.m. and ending at 5 p.m. During the morning session central themes in resilience engineering and safety culture were introduced in two separate presentations, each followed by a discussion. The central themes were:

- Respond: the ability to respond with enough strength

- Monitoring: the ability to identify unsafe situations

- Anticipating: the ability to anticipate unsafe situations and learn from previous incidents

- Values that compete with safety

- The implementation of rules/procedures as remedial actions

- Changing attitudes and values through remedial actions

In the afternoon, the participants were divided into smaller groups that formed the separate focus groups. On the first occasion, there were a total of four groups (14 participants) and on the second occasion 5 groups (18 participants). The focus groups were performed in parallel three-hour sessions, with 3-4 participants in each group and one focus group leader. Following the focus group sessions, each group summarized their discussion to one of the other groups, who could ask questions and discuss with the first group. Two or more different organisations were represented in each group.

The focus groups lasted around three and a half hours, including a 20 minute coffee break. The first 45 minutes of the focus group session included a round of introductions, and reflections on the discussions from the morning session. The participants were given a few minutes to write down their thoughts on a piece of paper and then share their reflections with the other participants in a round-robin fashion. This was followed by discussions guided by pre-prepared questions. As the questions were different for the two occasions, these will be presented separately below. The group leader's task was as moderator in the discussions, focused on ensuring that main topics were addressed, and all participants had a chance to share their view. In the last 30 minute of the focus group session, each group presented key points of their discussion to another group (15 $\mathrm{min}$ /group). The "listening" group were asked to comment and discuss the results. The day ended with a 30 minute summation for all participants of key issues that had been raised during the day.

\section{Focus groups 1-4: Topics of discussion}

The participants were asked to identify situations within their organisations that relate to themes presented during the morning presentation on resilience and safety culture (see previous list). Three main questions guided the discussions (questions have been translated from Swedish): 
- Problem definition: how familiarity are you with the issues presented?

- Vision of the future: How do you envision working with these issues?

- What is today's starting position: Could you work like that today? What consideration would have to be made? How are the different considerations valued?

To help stimulate the discussion the participants were provided with written information about the central themes. Further, examples of work situations where individuals and teams have had to identify and respond to unsafe situations were provided. The examples were all based on real events and taken from preceding interviews with accident investigators (Lundberg et al., 2009).

\section{Focus groups 5-9: Topics of discussion}

Results from the first set of focus groups provided many examples of everyday work practices requiring local adaptations and strategies to manage and respond to risks. It was noted that the examples helped fuse the discussion, allowing participants joint understanding as they compared current work standards and problems. The topic of the second set of focus groups was thus narrowed down to discussion on examples of "working near the safety margin".

In these focus groups, the participants were asked to identify situations, within each respective organisation, were minor deviations may have negative consequences, i.e. working near the margins of safety. The discussion included the four main areas:

- Presentation of situations for all organisations

- Identification of variables influencing the outcome of such situations, positive and negative.

- How are these situations managed today?

- What resources are available?

The questions had been sent out to the participants 2 weeks prior to the focus group to give them time to think about situations of working near the safety margin in their organisation. To further help the discussions real examples of "working near the safety margin" were provided. The examples were all based on real events and taken from preceding interviews with accident investigators (Lundberg et al., 2009). For the last two questions the participants were asked to discuss their examples from the perspective of the topics on resilience and safety culture presented in the morning session. 


\section{Appendix B}

\section{Interview guide (Paper IV)}

Fill in background information questionnaire and consent sheet.

Introduction: Who we are; name + short background and explain reason for several interviewers; first interviews in the project, the interviewers have different backgrounds. Allow participants to introduce themselves.

Project goals (read): The pilot's task in modern airliners has transitioned from flying the aircraft by means of manual control, to increased programming of automation and monitoring of the cockpit systems. Despite the substantial and proven safety benefits of automation systems in modern aircraft, evidence indicates that when faced with unexpected and challenging situations, pilots sometimes have difficulties in quickly responding to situations that require a rapid transition in their activity from monitors, to active and authoritative decision-makers exercising manual control of the aircraft. The focus of the project lies on the various aspects of the LOC-I problem such as; surprise, confusion, problem solving.

The project aims to investigate what leads to "surprise" situations and difficulties with automation management and manual control of modern flight decks. The results are expected to impact procedures, training and cockpit design in the aerospace industry.

Interview goals (read): Interviews will be carried out with pilots and instructors to identify situations that can be tested in an experimental setting. This information will be used for model and scenario development to perform experiments in simulators and during live flying later in the project.

Time: 45 minutes is planned. However, do you mind if the interview maybe takes 1 hour to complete?

\section{Interview questions}

\section{Surprises, confusion and problem solving (specific)}

- Have you experienced any recent situations where you have been surprised, confused, had to problem solve in operations?

- What happened?

- Why was it confusing? (time, information, situational circumstances, expectations, mental models)

- Was it clear to you what you should do? (options, information considered? Goals?)

- How where procedures/checklists used? Where they helpful?

- Did teamwork play a role in this example? Communication?

- What did this surprise do with stress levels? Was this a problem?

- Are these topics addressed in training? 
- What solution would you suggest to handle these situations?

In the next step, ask about a situation that was somewhat different, e.g., if procedures were NOT a factor in this example, can you think of an example where they did play a role? If no further (or any) examples come to mind, ask classes of situations, e.g., "hot and high", "low and slow", mode transitions, sensor failure, arrivals changes, descent, traffic, weather or atmospheric conditions...

\section{Surprises, confusion and problem solving (general)}

- Have you encountered more, similar situations?

- What do you think are most common reasons for pilots to be "surprised", confused during flight?

- How can you prepare to be "surprised"? What activities, practices, personal strategies, checklists, procedures to prepare for unexpected (or semi unexpected) situations? (include both personal techniques and SOPs)

- Describe situations where you make small adjustments early to avoid or prepare for possibly bigger trouble later.

- What are cues that someone else is getting "surprised" or confused? How do you get ready to intervene (things you look for or do before completely taking over yourself)?

- What role do coordination and teamwork play in situations of surprise?

- Stress-factor, what happens emotionally when you are surprised/confused? Does this affect the performance (is it a problem?)

- What does it mean to "problem solve" in the cockpit?

- What are your main resources to solve problems? (Procedures, check lists, manuals, knowledge by heart, colleague, sim experience, etc...)

- Are these topics addressed in training?

\section{More specific questions regarding the areas we want to cover:}

\section{Training for "surprises"}

- Is there any part of your previous training that has helped you deal with "surprises" (in example provided above or in general)?

- Have the type of situations that surprise or confuse you changed due to your experience?

\section{Automation}

- How are surprises related to knowledge of the systems?

- Do you think that pilots in modern aircraft have a sufficient understanding for the automated system? Should there be more focus on this in training?

- Are some systems more crucial than other to have good/deep understanding for?

- How about interaction between different systems? (e.g.Turkish Airlines) 
- Can you see a difference in dealing with automation and/or attitude towards using and trusting automation between experienced and novice pilots (10 years + experience vs 5 years max experience)

- How has 'staying ahead of the aircraft' changed as the automation does more of the flying and you do more supervising?

\section{Team Work/Communication}

- What/How/When needs to be communicated for a shared understanding in demanding situation? (e.g., environment, systems etc)

- Are 'surprise-event' accompanied by higher stress levels? How does it affect communication (e.g., CRM processes trained)?

- For example on the defined roles of PF and PNF?

\section{Procedure applicability}

In some situation, there may be a need to adjust/adapt/deviate from procedure:

- Are there situation when you have had to adapt procedures to cope with the situation?

- Are there situations when you are expected to deviate from procedures?

- What are reasons you might need to adapt/deviate from a procedure (e.g., time to evaluate/plan and take action) (How do you decide?)

\section{Manual Control (and mode transition)}

- Under normal circumstances, how much do you fly manually?

- Do you use any general "rule of thumb" when to use which modes/in what situations?

- How do you know when NOT to let the automation handle it, and use manual control? How long do you "sit and wait" "sit on your hands"?

- Do you feel confident to take over manually in every situation?

- Are there situations when it difficult to detect (automatic) mode changes? 


\section{Papers}

The articles associated with this thesis have been removed for copyright reasons. For more details about these see:

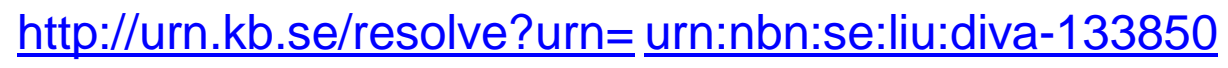




\section{Dissertations}

\section{Linköping Studies in Science and Technology Linköping Studies in Arts and Science Linköping Studies in Statistics \\ Linköping Studies in Information Science}

\section{Linköping Studies in Science and Technology}

No 14 Anders Haraldsson: A Program Manipulation System Based on Partial Evaluation, 1977, ISBN 917372-144-1.

No 17 Bengt Magnhagen: Probability Based Verification of Time Margins in Digital Designs, 1977, ISBN 91-7372157-3.

No 18 Mats Cedwall: Semantisk analys av processbeskrivningar i naturligt språk, 1977, ISBN 91- 7372168-9.

No 22 Jaak Urmi: A Machine Independent LISP Compiler and its Implications for Ideal Hardware, 1978, ISBN 91-7372-188-3.

No 33 Tore Risch: Compilation of Multiple File Queries in a Meta-Database System 1978, ISBN 91- 7372-232-4.

No 51 Erland Jungert: Synthesizing Database Structures from a User Oriented Data Model, 1980, ISBN 917372-387-8.

No 54 Sture Hägglund: Contributions to the Development of Methods and Tools for Interactive Design of Applications Software, 1980, ISBN 91-7372-404-1.

No 55 Pär Emanuelson: Performance Enhancement in a Well-Structured Pattern Matcher through Partial Evaluation, 1980, ISBN 91-7372-403-3.

No 58 Bengt Johnsson, Bertil Andersson: The HumanComputer Interface in Commercial Systems, 1981, ISBN 91-7372-414-9.

No 69 H. Jan Komorowski: A Specification of an Abstract Prolog Machine and its Application to Partial Evaluation, 1981, ISBN 91-7372-479-3.

No 71 René Reboh: Knowledge Engineering Techniques and Tools for Expert Systems, 1981, ISBN 91-7372489-0.

No 77 Östen Oskarsson: Mechanisms of Modifiability in large Softw are Systems, 1982, ISBN 91- 7372-527-7.

No 94 Hans Lunell: Code Generator Writing Systems, 1983, ISBN 91-7372-652-4.

No 97 Andrzej Lingas: Advances in Minimum Weight Triangulation, 1983, ISBN 91-7372-660-5.

No 109 Peter Fritzson: Tow ards a Distributed Programming Environment based on Incremental Compilation, 1984, ISBN 91-7372-801-2.

No 111 Erik Tengvald: The Design of Expert Planning Systems. An Experimental Operations Planning System for Turning, 1984, ISBN 91-7372- 805-5.

No 155 Christos Levcopoulos: Heuristics for Minimum Decompositions of Polygons, 1987, ISBN 91-7870133-3.

No 165 James W. Goodwin: A Theory and System for NonMonotonic Reasoning, 1987, ISBN 91-7870-183-X.

No 170 Zebo Peng: A Formal Methodology for Automated Synthesis of VLSI Systems, 1987, ISBN 91-7870-225-9.

No 174 Johan Fagerström: A Paradigm and System for Design of Distributed Systems, 1988, ISBN 91-7870301-8.

No 192 Dimiter Driankov: Tow ards a Many Valued Logic of Quantified Belief, 1988, ISBN 91-7870-374-3.
No 213 Lin Padgham: Non-Monotonic Inheritance for an Object Oriented Knowledge Base, 1989, ISBN 917870-485-5.

No 214 Tony Larsson: A Formal Hardware Description and Verification Method, 1989, ISBN 91-7870-517-7.

No 221 Michael Reinfrank: Fundamentals and Logical Foundations of Truth Maintenance, 1989, ISBN 917870-546-0.

No 239 Jonas Löwgren: Knowledge-Based Design Support and Discourse Management in User Interface Management Systems, 1991, ISBN 91-7870-720-X.

No 244 Henrik Eriksson: Meta-Tool Support for Knowledge Acquisition, 1991, ISBN 91-7870-746-3.

No 252 Peter Eklund: An Epistemic Approach to Interactive Design in Multiple Inheritance Hierarchies, 1991, ISBN 91-7870-784-6.

No 258 Patrick Doherty: NML3 - A Non-Monotonic Formalism with Explicit Defaults, 1991, ISBN 917870-816-8.

No 260 Nahid Shahmehri: Generalized Algorithmic Debugging, 1991, ISBN 91-7870-828-1.

No 264 Nils Dahlbäck: Representation of DiscourseCognitive and Computational Aspects, 1992, ISBN 91-7870-850-8.

No 265 Ulf Nilsson: Abstract Interpretations and Abstract Machines: Contributions to a Methodology for the Implementation of Logic Programs, 1992, ISBN 917870-858-3.

No 270 Ralph Rönnquist: Theory and Practice of Tensebound Object References, 1992, ISBN 91-7870-873-7.

No 273 Björn Fjellborg: Pipeline Extraction for VLSI Data Path Synthesis, 1992, ISBN 91-7870-880-X.

No 276 Staffan Bonnier: A Formal Basis for Horn Clause Logic with External Polymorphic Functions, 1992, ISBN 91-7870-896-6.

No 277 Kristian Sandahl: Developing Knowledge Management Systems with an Active Expert Methodology, 1992, ISBN 91-7870-897-4.

No 281 Christer Bäckström: Computational Complexity of Reasoning about Plans, 1992, ISBN 91-7870-979-2.

No 292 Mats Wirén: Studies in Incremental Natural Language Analysis, 1992, ISBN 91-7871-027-8.

No 297 Mariam Kamkar: Interprocedural Dynamic Slicing with Applications to Debugging and Testing, 1993, ISBN 91-7871-065-0.

No 302 Tingting Zhang: A Study in Diagnosis Using Classification and Defaults, 1993, ISBN 91-7871-078-2

No 312 Arne Jönsson: Dialogue Management for Natural Language Interfaces - An Empirical Approach, 1993, ISBN 91-7871-110-X.

No 338 Simin Nadjm-Tehrani: Reactive Systems in Physical Environments: Compositional Modelling and Framework for Verification, 1994, ISBN 91-7871-237-8.

No 371 Bengt Savén: Business Models for Decision Support and Learning. A Study of Discrete-Event Manufacturing Simulation at Asea/ ABB 1968-1993, 1995, ISBN 91-7871-494-X. 
No 375 Ulf Söderman: Conceptual Modelling of Mode Switching Physical Systems, 1995, ISBN 91-7871-5164.

No 383 Andreas Kågedal: Exploiting Groundness in Logic Programs, 1995, ISBN 91-7871-538-5.

No 396 George Fodor: Ontological Control, Description, Identification and Recovery from Problematic Control Situations, 1995, ISBN 91-7871-603-9.

No 413 Mikael Pettersson: Compiling Natural Semantics, 1995, ISBN 91-7871-641-1.

No 414 Xinli Gu: RT Level Testability Improvement by Testability Analysis and Transformations, 1996, ISBN 91-7871-654-3.

No 416 Hua Shu: Distributed Default Reasoning, 1996, ISBN 91-7871-665-9.

No 429 Jaime Villegas: Simulation Supported Industrial Training from an Organisational Learning Perspective - Development and Evaluation of the SSIT Method, 1996, ISBN 91-7871-700-0.

No 431 Peter Jonsson: Studies in Action Planning: Algorithms and Complexity, 1996, ISBN 91-7871-7043.

No 437 Johan Boye: Directional Types in Logic Programming, 1996, ISBN 91-7871-725-6.

No 439 Cecilia Sjöberg: Activities, Voices and Arenas: Participatory Design in Practice, 1996, ISBN 91-7871728-0.

No 448 Patrick Lambrix: Part-Whole Reasoning in Description Logics, 1996, ISBN 91-7871-820-1.

No 452 Kjell Orsborn: On Extensible and Object-Relational Database Technology for Finite Element Analysis Applications, 1996, ISBN 91-7871-827-9.

No 459 Olof Johansson: Development Environments for Complex Product Models, 1996, ISBN 91-7871-855-4.

No 461 Lena Strömbäck: User-Defined Constructions in Unification-Based Formalisms, 1997, ISBN 91-7871857-0.

No 462 Lars Degerstedt: Tabulation-based Logic Programming: A Multi-Level View of Query Answering, 1996, ISBN 91-7871-858-9.

No 475 Fredrik Nilsson: Strategi och ekonomisk styrning En studie av hur ekonomiska styrsystem utformas och används efter företagsförvärv, 1997, ISBN 917871-914-3.

No 480 Mikael Lindvall: An Empirical Study of Requirements-Driven Impact Analysis in Object-Oriented Softw are Evolution, 1997, ISBN 91-7871-927-5.

No 485 Göran Forslund: Opinion-Based Systems: The Cooperative Perspective on Knowledge-Based Decision Support, 1997, ISBN 91-7871-938-0.

No 494 Martin Sköld: Active Database Management Systems for Monitoring and Control, 1997, ISBN 917219-002-7.

No 495 Hans Olsén: Automatic Verification of Petri Nets in a CLP framew ork, 1997, ISBN 91-7219-011-6.

No 498 Thomas Drakengren: Algorithms and Complexity for Temporal and Spatial Formalisms, 1997, ISBN 917219-019-1.

No 502 Jakob Axelsson: Analysis and Synthesis of Heterogeneou s Real-Time Systems, 1997, ISBN 91-7219-035-3.

No 503 Johan Ringström: Compiler Generation for DataParallel Programming Languages from Two-Level Semantics Specifications, 1997, ISBN 91-7219-045-0.

No 512 Anna Moberg: Närhet och distans - Studier av kommunikationsmönster i satellitkontor och flexibla kontor, 1997, ISBN 91-7219-119-8.
No 520 Mikael Ronström: Design and Modelling of a Parallel Data Server for Telecom Applications, 1998, ISBN 91-7219-169-4.

No 522 Niclas Ohlsson: Tow ards Effective Fault Prevention - An Empirical Study in Software Engineering, 1998, ISBN 91-7219-176-7.

No 526 Joachim Karlsson: A Systematic Approach for Prioritizing Software Requirements, 1998, ISBN 917219-184-8.

No 530 Henrik Nilsson: Declarative Debugging for Lazy Functional Languages, 1998, ISBN 91-7219-197-x.

No 555 Jonas Hallberg: Timing Issues in High-Level Synthesis, 1998, ISBN 91-7219-369-7.

No 561 Ling Lin: Management of 1-D Sequence Data - From Discrete to Continu ous, 1999, ISBN 91-7219-402-2.

No 563 Eva L Ragnemalm: Student Modelling based on Collaborative Dialogue with a Learning Companion, 1999, ISBN 91-7219-412-X.

No 567 Jörgen Lindström: Does Distance matter? On geographical dispersion in organisations, 1999, ISBN 917219-439-1.

No 582 Vanja Josifovski: Design, Implementation and Evaluation of a Distributed Mediator System for Data Integration, 1999, ISBN 91-7219-482-0.

No 589 Rita Kovordányi: Modeling and Simulating Inhibitory Mechanisms in Mental Image Reinterpretation - Towards Cooperative HumanComputer Creativity, 1999, ISBN 91-7219-506-1.

No 592 Mikael Ericsson: Supporting the Use of Design Knowledge - An Assessment of Commenting Agents, 1999, ISBN 91-7219-532-0.

No 593 Lars Karlsson: Actions, Interactions and Narratives, 1999, ISBN 91-7219-534-7.

No 594 C. G. Mikael Johansson: Social and Organizational Aspects of Requirements Engineering Methods - A practice-oriented approach, 1999, ISBN 91-7219-541$\mathrm{X}$.

No 595 Jörgen Hansson: Value-Driven Multi-Class Overload Management in Real-Time Database Systems, 1999, ISBN 91-7219-542-8.

No 596 Niklas Hallberg: Incorporating User Values in the Design of Information Systems and Services in the Public Sector: A Methods Approach, 1999, ISBN 917219-543-6.

No 597 Vivian Vimarlund: An Economic Perspective on the Analysis of Impacts of Information Technology: From Case Studies in Health-Care tow ards General Models and Theories, 1999, ISBN 91-7219-544-4.

No 598 Johan Jenvald: Methods and Tools in ComputerSupported Taskforce Training, 1999, ISBN 91-7219547-9.

No 607 Magnus Merkel: Understanding and enhancing translation by parallel text processing, 1999, ISBN 917219-614-9.

No 611 Silvia Coradeschi: Anchoring symbols to sensory data, 1999, ISBN 91-7219-623-8.

No 613 Man Lin: Analysis and Synthesis of Reactive Systems: A Generic Layered Architecture Perspective, 1999, ISBN 91-7219-630-0.

No 618 Jimmy Tjäder: Systemimplementering i praktiken En studie av logiker i fyra projekt, 1999, ISBN 917219-657-2.

No 627 Vadim Engelson: Tools for Design, Interactive Simulation, and Visualization of Object-Oriented Models in Scientific Computing, 2000, ISBN 91-7219709-9. 
No 637 Esa Falkenroth: Database Technology for Control and Simulation, 2000, ISBN 91-7219-766-8.

No 639 Per-Arne Persson: Bringing Power and Knowledge Together: Information Systems Design for Autonomy and Control in Command Work, 2000, ISBN 91-7219796-X.

No 660 Erik Larsson: An Integrated System-Level Design for Testability Methodology, 2000, ISBN 91-7219-890-7.

No 688 Marcus Bjäreland: Model-based Execution Monitoring, 2001, ISBN 91-7373-016-5.

No 689 Joakim Gustafsson: Extending Temporal Action Logic, 2001, ISBN 91-7373-017-3.

No 720 Carl-Johan Petri: Organizational Information Provision - Managing Mandatory and Discretionary Use of Information Technology, 2001, ISBN-91-7373-1269.

No 724 Paul Scerri: Designing Agents for Systems with Adjustable Autonomy, 2001, ISBN 9173732079.

No 725 Tim Heyer: Semantic Inspection of Software Artifacts: From Theory to Practice, 2001, ISBN 91 73732087.

No 726 Pär Carlshamre: A Usability Perspective on Requirements Engineering - From Methodology to Product Development, 2001, ISBN 9173732125.

No 732 Juha Takkinen: From Information Management to Task Management in Electronic Mail, 2002, ISBN 91 73732583.

No 745 Johan Åberg: Live Help Systems: An Approach to Intelligent Help for Web Information Systems, 2002, ISBN 91-7373-311-3.

No 746 Rego Granlund: Monitoring Distributed Teamwork Training, 2002, ISBN 91-7373-312-1.

No 757 Henrik André-Jönsson: Indexing Strategies for Time Series Data, 2002, ISBN 917373-346-6.

No 747 Anneli Hagdahl: Development of IT-supported Interorganisational Collaboration - A Case Study in the Swedish Public Sector, 2002, ISBN 91-7373-314-8.

No 749 Sofie Pilemalm: Information Technology for NonProfit Organisations - Extended Participatory Design of an Information System for Trade Union Shop Stew ard s, 2002, ISBN 91-7373-318-0.

No 765 Stefan Holmlid: Adapting users: Towards a theory of use quality, 2002, ISBN 91-7373-397-0.

No 771 Magnus Morin: Multimedia Representations of Distributed Tactical Operations, 2002, ISBN 91-7373-4217.

No 772 Pawel Pietrzak: A Type-Based Framew ork for Locating Errors in Constraint Logic Programs, 2002, ISBN 91-7373-422-5.

No 758 Erik Berglund: Library Communication Among Programmers Worldwide, 2002, ISBN 91-7373-349-0.

No 774 Choong-ho Yi: Modelling Object-Oriented Dynamic Systems Using a Logic-Based Framew ork, 2002, ISBN 91-7373-424-1.

No 779 Mathias Broxvall: A Study in the Computational Complexity of Temporal Reasoning, 2002, ISBN 917373-440-3.

No 793 Asmus Pandikow: A Generic Principle for Enabling Interoperability of Structured and Object-Oriented Analysis and Design Tools, 2002, ISBN 91-7373-479-9.

No 785 Lars Hult: Publika Informationstjänster. En studie av den Internetbaserade encyklopedins bruksegenskaper, 2003, ISBN 91-7373-461-6.

No 800 Lars Taxén: A Framework for the Coordination of Complex Systems' Development, 2003, ISBN 917373-604-X
No 808 Klas Gäre: Tre perspektiv på förväntningar och förändringar i samband med införande av informationssystem, 2003, ISBN 91-7373-618-X.

No 821 Mikael Kindborg: Concurrent Comics programming of social agents by children, 2003, ISBN 91-7373-651-1.

No 823 Christina Ölvingson: On Development of Information Systems with GIS Functionality in Public Health Informatics: A Requirements Engineering Approach, 2003, ISBN 91-7373-656-2.

No 828 Tobias Ritzau: Memory Efficient Hard Real-Time Garbage Collection, 2003, ISBN 91-7373-666-X.

No 833 Paul Pop: Analysis and Synthesis of Communication-Intensive Heterogeneous Real-Time Systems, 2003, ISBN 91-7373-683-X.

No 852 Johan Moe: Observing the Dynamic Behaviour of Large Distributed Systems to Improve Development and Testing - An Empirical Study in Software Engineering, 2003, ISBN 91-7373-779-8.

No 867 Erik Herzog: An Approach to Systems Engineering Tool Data Representation and Exchange, 2004, ISBN 91-7373-929-4.

No 872 Aseel Berglund: Augmenting the Remote Control: Studies in Complex Information Navigation for Digital TV, 2004, ISBN 91-7373-940-5.

No 869 Jo Skåmedal: Telecommuting's Implications on Travel and Travel Patterns, 2004, ISBN 91-7373-935-9.

No 870 Linda Askenäs: The Roles of IT - Studies of Organising when Implementing and Using Enterprise Systems, 2004, ISBN 91-7373-936-7.

No 874 Annika Flycht-Eriksson: Design and Use of Ontologies in Information-Providing Dialogue Systems, 2004, ISBN 91-7373-947-2.

No 873 Peter Bunus: Debugging Techniques for EquationBased Languages, 2004, ISBN 91-7373-941-3.

No 876 Jonas Mellin: Resource-Predictable and Efficient Monitoring of Events, 2004, ISBN 91-7373-956-1.

No 883 Magnus Bång: Computing at the Speed of Paper: Ubiquitous Computing Environments for Healthcare Professionals, 2004, ISBN 91-7373-971-5

No 882 Robert Eklund: Disfluency in Swedish humanhuman and human-machine travel booking dialogues, 2004, ISBN 91-7373-966-9.

No 887 Anders Lindström: English and other Foreign Linguistic Elements in Spoken Swedish. Studies of Productive Processes and their Modelling using Finite-State Tools, 2004, ISBN 91-7373-981-2.

No 889 Zhiping Wang: Capacity-Constrained Production-inventory systems - Modelling and Analysis in both a traditional and an e-business context, 2004, ISBN 9185295-08-6.

No 893 Pernilla Qvarfordt: Eyes on Multimodal Interaction, 2004, ISBN 91-85295-30-2.

No 910 Magnus Kald: In the Borderland between Strategy and Management Control - Theoretical Framework and Empirical Evidence, 2004, ISBN 91-85295-82-5.

No 918 Jonas Lundberg: Shaping Electronic News: Genre Perspectives on Interaction Design, 2004, ISBN 9185297-14-3.

No 900 Mattias Arvola: Shades of use: The dynamics of interaction design for sociable use, 2004, ISBN 9185295-42-6.

No 920 Luis Alejandro Cortés: Verification and Scheduling Techniques for Real-Time Embedded Systems, 2004, ISBN 91-85297-21-6.

No 929 Diana Szentivanyi: Performance Studies of FaultTolerant Middlew are, 2005, ISBN 91-85297-58-5. 
No 933 Mikael Cäker: Management Accounting as Constructing and Opposing Customer Focus: Three Case Studies on Management Accounting and Customer Relations, 2005, ISBN 91-85297-64-X.

No 937 Jonas Kvarnström: TALplanner and Other Extensions to Temporal Action Logic, 2005, ISBN 9185297-75-5.

No 938 Bourhane Kadmiry: Fuzzy Gain-Scheduled Visual Servoing for Unmanned Helicopter, 2005, ISBN 9185297-76-3.

No 945 Gert Jervan: Hybrid Built-In Self-Test and Test Generation Techniques for Digital Systems, 2005, ISBN : 91-85297-97-6.

No 946 Anders Arpteg: Intelligent Semi-Structured Information Extraction, 2005, ISBN 91-85297-98-4.

No 947 Ola Angelsmark: Constructing Algorithms for Constraint Satisfaction and Related Problems - Methods and Applications, 2005, ISBN 91-85297-99-2.

No 963 Calin Curescu: Utility-based Optimisation of Resource Allocation for Wireless Networks, 2005, ISBN 91-85457-07-8.

No 972 Björn Johansson: Joint Control in Dynamic Situations, 2005, ISBN 91-85457-31-0.

No 974 Dan Lawesson: An Approach to Diagnosability Analysis for Interacting Finite State Systems, 2005, ISBN 91-85457-39-6.

No 979 Claudiu Duma: Security and Trust Mechanisms for Groups in Distributed Services, 2005, ISBN 91-8545754-X.

No 983 Sorin Manolache: Analysis and Optimisation of Real-Time Systems with Stochastic Behaviour, 2005, ISBN 91-85457-60-4.

No 986 Yuxiao Zhao: Standards-Based Application Integration for Business-to-Business Communications, 2005, ISBN 91-85457-66-3.

No 1004 Patrik Haslum: Admissible Heuristics for Automated Planning, 2006, ISBN 91-85497-28-2.

No 1005 Aleksandra Tešanovic: Developing Reusable and Reconfigurable Real-Time Software using Aspects and Components, 2006, ISBN 91-85497-29-0.

No 1008 David Dinka: Role, Identity and Work: Extending the design and development agenda, 2006, ISBN 9185497-42-8.

No 1009 Iakov Nakhimovski: Contributions to the Modeling and Simulation of Mechanical Systems with Detailed Contact Analysis, 2006, ISBN 91-85497-43-X.

No 1013 Wilhelm Dahllöf: Exact Algorithms for Exact Satisfiability Problems, 2006, ISBN 91-85523-97-6.

No 1016 Levon Saldamli: PDEModelica - A High-Level Language for Modeling with Partial Differential Equations, 2006, ISBN 91-85523-84-4.

No 1017 Daniel Karlsson: Verification of Component-based Embedded System Designs, 2006, ISBN 91-85523-79-8

No 1018 Ioan Chisalita: Communication and Networking Techniques for Traffic Safety Systems, 2006, ISBN 9185523-77-1.

No 1019 Tarja Susi: The Puzzle of Social Activity - The Significance of Tools in Cognition and Cooperation, 2006, ISBN 91-85523-71-2

No 1021 Andrzej Bednarski: Integrated Optimal Code Generation for Digital Signal Processors, 2006, ISBN 9185523-69-0.

No 1022 Peter Aronsson: Automatic Parallelization of Equation-Based Simulation Programs, 2006, ISBN 9185523-68-2.
No 1030 Robert Nilsson: A Mutation-based Framework for Automated Testing of Timeliness, 2006, ISBN 9185523-35-6.

No 1034 Jon Edvardsson: Techniques for Automatic Generation of Tests from Programs and Specifications, 2006, ISBN 91-85523-31-3.

No 1035 Vaida Jakoniene: Integration of Biological Data, 2006, ISBN 91-85523-28-3.

No 1045 Genevieve Gorrell: Generalized Hebbian Algorithms for Dimensionality Reduction in Natural Language Processing, 2006, ISBN 91-85643-88-2.

No 1051 Yu-Hsing Huang: Having a New Pair of Glasses Applying Systemic Accident Models on Road Safety, 2006, ISBN 91-85643-64-5.

No 1054 Åsa Hedenskog: Perceive those things which cannot be seen - A Cognitive Systems Engineering perspective on requirements management, 2006, ISBN 91-85643-57-2.

No 1061 Cécile Åberg: An Evaluation Platform for Semantic Web Technology, 2007, ISBN 91-85643-31-9.

No 1073 Mats Grindal: Handling Combinatorial Explosion in Softw are Testing, 2007, ISBN 978-91-85715-74-9.

No 1075 Almut Herzog: Usable Security Policies for Runtime Environments, 2007, ISBN 978-91-85715-65-7.

No 1079 Magnus Wahlström: Algorithms, measures, and upper bounds for Satisfiability and related problems, 2007, ISBN 978-91-85715-55-8.

No 1083 Jesper Andersson: Dynamic Software Architectures, 2007, ISBN 978-91-85715-46-6.

No 1086 Ulf Johansson: Obtaining Accurate and Comprehensible Data Mining Models - An Evolutionary Approach, 2007, ISBN 978-91-85715-34-3.

No 1089 Traian Pop: Analysis and Optimisation of Distributed Embedded Systems with Heterogeneous Scheduling Policies, 2007, ISBN 978-91-85715-27-5.

No 1091 Gustav Nordh: Complexity Dichotomies for CSPrelated Problems, 2007, ISBN 978-91-85715-20-6.

No 1106 Per Ola Kristensson: Discrete and Continuous Shape Writing for Text Entry and Control, 2007, ISBN 97891-85831-77-7.

No 1110 He Tan: Aligning Biomedical Ontologies, 2007, ISBN 978-91-85831-56-2.

No 1112 Jessica Lindblom: Minding the body - Interacting socially through embodied action, 2007, ISBN 978-9185831-48-7.

No 1113 Pontus Wärnestål: Dialogue Behavior Management in Conversational Recommender Systems, 2007, ISBN 978-91-85831-47-0.

No 1120 Thomas Gustafsson: Management of Real-Time Data Consistency and Transient Overloads in Embedded Systems, 2007, ISBN 978-91-85831-33-3.

No 1127 Alexandru Andrei: Energy Efficient and Predictable Design of Real-time Embedded Systems, 2007, ISBN 978-91-85831-06-7.

No 1139 Per Wikberg: Eliciting Knowledge from Experts in Modeling of Complex Systems: Managing Variation and Interactions, 2007, ISBN 978-91-85895-66-3.

No 1143 Mehdi Amirijoo: QoS Control of Real-Time Data Services under Uncertain Workload, 2007, ISBN 97891-85895-49-6.

No 1150 Sanny Syberfeldt: Optimistic Replication with Forward Conflict Resolution in Distributed Real-Time Databases, 2007, ISBN 978-91-85895-27-4.

No 1155 Beatrice Alenljung: Envisioning a Future Decision Support System for Requirements Engineering - A Holistic and Human-centred Perspective, 2008, ISBN 978-91-85895-11-3. 
No 1156 Artur Wilk: Types for XML with Application to Xcerpt, 2008, ISBN 978-91-85895-08-3.

No 1183 Adrian Pop: Integrated Model-Driven Development Environments for Equation-Based Object-Oriented Languages, 2008, ISBN 978-91-7393-895-2.

No 1185 Jörgen Skågeby: Gifting Technologies Ethnographic Studies of End-users and Social Media Sharing, 2008, ISBN 978-91-7393-892-1.

No 1187 Imad-Eldin Ali Abugessaisa: Analytical tools and information-sharing methods supporting road safety organizations, 2008, ISBN 978-91-7393-887-7.

No 1204 H. Joe Steinhauer: A Representation Scheme for Description and Reconstruction of Object Configurations Based on Qualitative Relations, 2008, ISBN 978-91-7393-823-5.

No 1222 Anders Larsson: Test Optimization for Core-based System-on-Chip, 2008, ISBN 978-91-7393-768-9.

No 1238 Andreas Borg: Processes and Models for Capacity Requirements in Telecommunication Systems, 2009, ISBN 978-91-7393-700-9.

No 1240 Fredrik Heintz: DyKnow: A Stream-Based Knowledge Processing Middleware Framework, 2009, ISBN 978-91-7393-696-5.

No 1241 Birgitta Lindström: Testability of Dynamic RealTime System s, 2009, ISBN 978-91-7393-695-8.

No 1244 Eva Blomqvist: Semi-automatic Ontology Construction based on Patterns, 2009, ISBN 978-91-7393-683-5.

No 1249 Rogier Woltjer: Functional Modeling of Constraint Management in Aviation Safety and Command and Control, 2009, ISBN 978-91-7393-659-0.

No 1260 Gianpaolo Conte: Vision-Based Localization and Guidance for Unmanned Aerial Vehicles, 2009, ISBN 978-91-7393-603-3.

No 1262 AnnMarie Ericsson: Enabling Tool Support for Formal Analysis of ECA Rules, 2009, ISBN 978-91-7393598-2.

No 1266 Jiri Trnka: Exploring Tactical Command and Control: A Role-Playing Simulation Approach, 2009, ISBN 978-91-7393-571-5.

No 1268 Bahlol Rahimi: Supporting Collaborative Work through ICT - How End-users Think of and Adopt Integrated Health Information Systems, 2009, ISBN 978-91-7393-550-0

No 1274 Fredrik Kuivinen: Algorithms and Hardness Results for Some Valued CSPs, 2009, ISBN 978-91-7393-525-8.

No 1281 Gunnar Mathiason: Virtual Full Replication for Scalable Distributed Real-Time Databases, 2009, ISBN 978-91-7393-503-6.

No 1290 Viacheslav Izosimov: Scheduling and Optimization of Fault-Tolerant Distributed Embedded Systems, 2009, ISBN 978-91-7393-482-4.

No 1294 Johan Thapper: Aspects of a Constraint Optimisation Problem, 2010, ISBN 978-91-7393-464-0.

No 1306 Susanna Nilsson: Augmentation in the Wild: User Centered Development and Evaluation of Augmented Reality Applications, 2010, ISBN 978-917393-416-9.

No 1313 Christer Thörn: On the Quality of Feature Models, 2010, ISBN 978-91-7393-394-0.

No 1321 Zhiyuan He: Temperature Aware and DefectProbability Driven Test Scheduling for System-onChip, 2010, ISBN 978-91-7393-378-0.

No 1333 David Broman: Meta-Languages and Semantics for Equation-Based Modeling and Simulation, 2010, ISBN 978-91-7393-335-3.

No 1337 Alexander Siemers: Contributions to Modelling and Visualisation of Multibody Systems Simulations with
Detailed Contact Analysis, 2010, ISBN 978-91-7393317-9.

No 1354 Mikael Asplund: Disconnected Discoveries: Availability Studies in Partitioned Networks, 2010, ISBN 978-91-7393-278-3.

No 1359 Jana Rambusch: Mind Games Extended: Understanding Gameplay as Situated Activity, 2010, ISBN 978-91-7393-252-3.

No 1373 Sonia Sangari: Head Movement Correlates to Focus Assignment in Swedish,2011,ISBN 978-91-7393-154-0.

No 1374 Jan-Erik Källhammer: Using False Alarms when Developing Automotive Active Safety Systems, 2011, ISBN 978-91-7393-153-3.

No 1375 Mattias Eriksson: Integrated Code Generation, 2011, ISBN 978-91-7393-147-2.

No 1381 Ola Leifler: Affordances and Constraints of Intelligent Decision Support for Military Command and Control - Three Case Studies of Support Systems, 2011, ISBN 978-91-7393-133-5.

No 1386 Soheil Samii: Quality-Driven Synthesis and Optimization of Embedded Control Systems, 2011, ISBN 978-91-7393-102-1.

No 1419 Erik Kuiper: Geographic Routing in Intermittentlyconnected Mobile Ad Hoc Networks: Algorithms and Performance Models, 2012, ISBN 978-91-7519981-8.

No 1451 Sara Stymne: Text Harmonization Strategies for Phrase-Based Statistical Machine Translation, 2012, ISBN 978-91-7519-887-3.

No 1455 Alberto Montebelli: Modeling the Role of Energy Management in Embodied Cognition, 2012, ISBN 978-91-7519-882-8.

No 1465 Mohammad Saifullah: Biologically-Based Interactive Neural Network Models for Visual Attention and Object Recognition, 2012, ISBN 978-91-7519-838-5.

No 1490 Tomas Bengtsson: Testing and Logic Optimization Techniques for Systems on Chip, 2012, ISBN 978-917519-742-5.

No 1481 David Byers: Improving Software Security by Preventing Known Vulnerabilities, 2012, ISBN 97891-7519-784-5.

No 1496 Tommy Färnqvist: Exploiting Structure in CSPrelated Problems, 2013, ISBN 978-91-7519-711-1.

No 1503 John Wilander: Contributions to Specification, Implementation, and Execution of Secure Software, 2013, ISBN 978-91-7519-681-7.

No 1506 Magnus Ingmarsson: Creating and Enabling the Useful Service Discovery Experience, 2013, ISBN 97891-7519-662-6.

No 1547 Wladimir Schamai: Model-Based Verification of Dynamic System Behavior against Requirements: Method, Language, and Tool, 2013, ISBN 978-917519-505-6

No 1551 Henrik Svensson: Simulations, 2013, ISBN 978-917519-491-2.

No 1559 Sergiu Rafiliu: Stability of Adaptive Distributed Real-Time Systems with Dynamic Resource Management, 2013, ISBN 978-91-7519-471-4.

No 1581 Usman Dastgeer: Performance-aware Component Composition for GPU-based Systems, 2014, ISBN 978-91-7519-383-0.

No 1602 Cai Li: Reinforcement Learning of Locomotion based on Central Pattern Generators, 2014, ISBN 978-917519-313-7.

No 1652 Roland Samlaus: An Integrated Development Environment with Enhanced Domain-Specific 
Interactive Model Validation, 2015, ISBN 978-917519-090-7.

No 1663 Hannes Uppman: On Some Combinatorial Optimization Problems: Algorithms and Complexity, 2015, ISBN 978-91-7519-072-3.

No 1664 Martin Sjölund: Tools and Methods for Analysis, Debugging, and Performance Improvement of Equation-Based Models, 2015, ISBN 978-91-7519-071-6.

No 1666 Kristian Stavåker: Contributions to Simulation of Modelica Models on Data-Parallel Multi-Core Architectures, 2015, ISBN 978-91-7519-068-6.

No 1680 Adrian Lifa: Hardware/ Software Codesign of Embedded Systems with Reconfigurable and Heterogeneous Platforms, 2015, ISBN 978-91-7519-0402.

No 1685 Bogdan Tanasa: Timing Analysis of Distributed Embedded Systems with Stochastic Workload and Reliability Constraints, 2015, ISBN 978-91-7519-022-8.

No 1691 Håkan Warnquist: Troubleshooting Trucks Automated Planning and Diagnosis, 2015, ISBN 97891-7685-993-3.

No 1702 Nima Aghaee: Thermal Issues in Testing of Advanced Systems on Chip, 2015, ISBN 978-91-7685949-0.

No 1715 Maria Vasilevskaya: Security in Embed ded Systems: A Model-Based Approach with Risk Metrics, 2015, ISBN 978-91-7685-917-9.

No 1729 Ke Jiang: Security-Driven Design of Real-Time Embedded System, 2016, ISBN 978-91-7685-884-4.

No 1733 Victor Lagerkvist: Strong Partial Clones and the Complexity of Constraint Satisfaction Problems: Limitations and Applications, 2016, ISBN 978-91-7685856-1.

No 1734 Chandan Roy: An Informed System Development Approach to Tropical Cyclone Track and Intensity Forecasting, 2016, ISBN 978-91-7685-854-7.

No 1746 Amir Aminifar: Analysis, Design, and Optimization of Embedded Control Systems, 2016, ISBN 978-917685-826-4.

No 1747 Ekhiotz Vergara: Energy Modelling and Fairness for Efficient Mobile Communication, 2016, ISBN 978-91-7685-822-6.

No 1748 Dag Sonntag: Chain Graphs - Interpretations, Expressiveness and Learning Algorithms, 2016, ISBN 978-91-7685-818-9.

No 1768 Anna Vapen: Web Authentication using Third Parties in Untrusted Environments, 2016, ISBN 978-91-7685-753-3.

No 1778 Magnus Jandinger: On a Need to Know Basis: A Conceptual and Methodological Framew ork for Modelling and Analysis of Information Demand in an Enterprise Context, 2016, ISBN 978-91-7685-713-7.

No 1798 Rahul Hiran: Collaborative Network Security: Targeting Wide-area Routing and Edgenetw ork Attacks, 2016, ISBN 978-91-7685-662-8.

No 1813 Nicolas Melot: Algorithms and Framework for Energy Efficient Parallel Stream Computing on Many-Core Architectures, 2016, ISBN 978-91-7685623-9.

No 1823 Amy Rankin: Making Sense of Adaptations: Resilience in High-Risk Work, 2017, ISBN 978-917685-596-6.

\section{Linköping Studies in Arts and Science}

No 504 Ing-Marie Jonsson: Social and Emotional Characteristics of Speech-based In-Vehicle Information Systems: Impact on Attitude and Driving Behaviour, 2009, ISBN 978-91-7393-478-7.

No 586 Fabian Segelström: Stakeholder Engagement for Service Design: How service designers identify and communicate insights, 2013, ISBN 978-91-7519-554-4.

No 618 Johan Blomkvist: Representing Future Situations of Service: Prototyping in Service Design, 2014, ISBN 978-91-7519-343-4

No 620 Marcus Mast: Human-Robot Interaction for SemiAutonomous Assistive Robots, 2014, ISBN 978-917519-319-9.

No 677 Peter Berggren: Assessing Shared Strategic Understanding, 2016, ISBN 978-91-7685-786-1.

No 695 Mattias Forsblad: Distributed cognition in home environments: The prospective memory and cognitive practices of older adults, 2016, ISBN 97891-7685-686-4.

\section{Linköping Studies in Statistics}

No 9 Davood Shahsavani: Computer Experiments Designed to Explore and Approximate Complex Deterministic Models, 2008, ISBN 978-91-7393-976-8.

No 10 Karl Wahlin: Roadmap for Trend Detection and Assessment of Data Quality, 2008, ISBN 978-91-7393792-4.

No 11 Oleg Sysoev: Monotonic regression for large multivariate datasets, 2010, ISBN 978-91-7393-412-1.

No 13 Agné Burauskaite-Harju: Characterizing Temporal Change and Inter-Site Correlations in Daily and Subdaily Precipitation Extremes, 2011, ISBN 978-91-7393110-6.

\section{Linköping Studies in Information Science}

No 1 Karin Axelsson: Metodisk systemstrukturering- att skapa samstämmighet mellan informationssystemarkitektur och verksamhet, 1998. ISBN-9172-19-296-8.

No 2 Stefan Cronholm: Metodverktyg och användbarhet en studie av datorstödd metodbaserad systemutveckling, 1998, ISBN-9172-19-299-2.

No 3 Anders Avdic: Användare och utvecklare - om anveckling med kalkylprogram, 1999. ISBN-91-7219606-8.

No 4 Owen Eriksson: Kommunikationskvalitet hos informationssystem och affärsprocesser, 2000, ISBN 917219-811-7.

No 5 Mikael Lind: Från system till process - kriterier för processbestämning vid verksamhetsanalys, 2001, ISBN 91-7373-067-X.

No 6 Ulf Melin: Koordination och informationssystem i företag och nätverk, 2002, ISBN 91-7373-278-8.

No 7 Pär J. Ågerfalk: Information Systems Actability - Understanding Information Technology as a Tool for Business Action and Communication, 2003, ISBN 917373-628-7.

No 8 Ulf Seigerroth: Att förstå och förändra systemutvecklingsverksamheter - en taxonomi för metautveckling, 2003, ISBN91-7373-736-4.

No 9 Karin Hedström: Spår av datoriseringens värden Effekter av IT i äldreomsorg, 2004, ISBN 91-7373-9634. 
No 10 Ewa Braf: Knowledge Demanded for Action Studies on Knowledge Mediation in Organisations, 2004, ISBN 91-85295-47-7.

No 11 Fredrik Karlsson: Method Configuration method and computerized tool support, 2005, ISBN 91-8529748-8.

No 12 Malin Nordström: Styrbar systemförvaltning - Att organisera systemförvaltningsverksamhet med hjälp av effektiva förvaltningsobjekt, 2005, ISBN 91-8529760-7.

No 13 Stefan Holgersson: Yrke: POLIS - Yrkeskunskap, motivation, IT-system och andra förutsättningar för polisarbete, 2005, ISBN 91-85299-43-X.

No 14 Benneth Christiansson, Marie-Therese Christiansson: Mötet mellan process och komponent - mot ett ramverk för en verksamhetsnära kravspecifikation vid anskaffning av komponentbaserade informationssystem, 2006, ISBN 91-8564322-X. 